\title{
Functional ecology of iceplant taxa and their role in eco-restoration of New Zealand sand dunes.
}

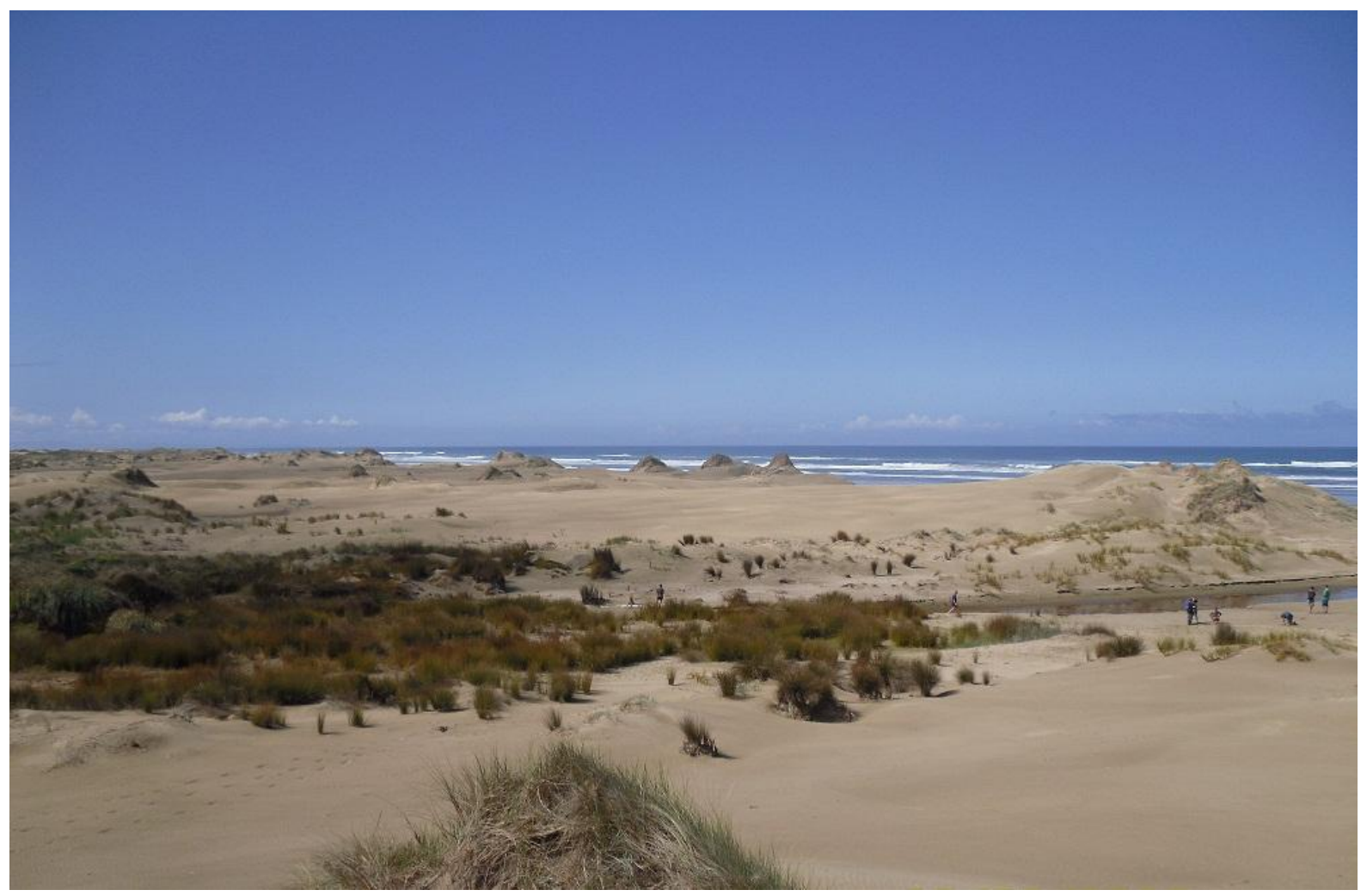

Guyo Duba Gufu

A thesis submitted for the partial fulfilment for the degree of

Master of Science in Ecology and Biodiversity

Victoria University of Wellington

School of Biological Sciences 


\section{ABSTRACT}

Biological invasion by non-native plant species has often been cited as a cause of native biodiversity loss. While the outcome of species invasions depends on interactions between exotic and resident native species, most studies of biological invasions have focused solely on the direct negative impacts of non-indigenous species on native biota. Although investigations of the role of competition in shaping natural plant communities were dominant in the previous generations and are still popular, more recent experimental research has uncovered the striking influence of facilitation on community dynamics. This thesis aims to investigate competitive and facilitative influence of the invasive South African iceplant (Carpobrotus edulis) on Spinifex sericeus, a native foredune grass species, with particular reference to implications of these interactions for dune restoration in New Zealand. It further explores the growth rates, substrate preferences and mating systems of the exotic and native iceplant taxa found in New Zealand.

I begin by briefly outlining the influence of competition and facilitation on natural plant communities with reference to the role of facilitation in eco-restoration. I also give a few examples where exotic species have been found to facilitate native ones. Secondly, a neighbour removal experiment was conducted on coastal sand dunes with the main aim of studying the effects of Carpobrotus edulis on establishment of Spinifex sericeus at the foredune region. Finally, I compared the growth rates of the most widely distributed iceplant taxa in New Zealand in different substrates and the breeding systems of the exotic Carpobrotus.

Examples abound in literature of exotic plant species facilitating native ones especially in forestry. In the neighbour removal study, Carpobrotus edulis protected Spinifex seedlings against storm erosion, sandblasting and salt sprays while at the same time suppressing its leaf production. Suppression of Spinifex leaf production was more pronounced at top of the dune where stress elements is presumably more benign. There was no evidence of allelopathic suppression of Spinifex by C. edulis. Only Carpobrotus chilensis displayed some level of substrate preference by putting on relatively lower biomass in gravel. The exotic Carpobrotus spp. put on greater dry matter content than the native 
Disphyma australe and the Carpobrotus-x-Disphyma hybrid. The hybrid displayed a faster vegetative growth rate whereas $D$. australe allocated relatively more biomass to the roots than the shoot. Both Carpobrotus spp. are self compatible and highly capable of intrageneric and intergeneric hybridisation.

Mass removal of the existing exotic iceplant stands from foredunes along high energy coasts is not advisable as they serve as useful stabilisers. The intergeneric hybrid is sexually sterile with sparsely spread stolons that could allow co-occurrence with other species and therefore is more suitable for foredune stabilisation. However, more research needs to be conducted on the ecology of the intergeneric hybrid. 


\section{ACKNOWLEDGEMENTS}

I want to register my sincere gratitude and appreciation to several individuals and organisations without whose support this project could not have been realized.

I am profoundly grateful to my supervisor Dr. Stephen Hartley for his wise guidance, commitment and patience throughout this project. His critical comments, insistence on quality and exceptional data manipulation skills have not only helped me accomplish this research but have also made me develop a keen interest in the discipline. I would like to thank my other supervisor Prof. Kevin Gould for his support, guidance and willingness to share knowledge. I also want to sincerely thank Dr. Hannah Buckley, Bradley, and Sam Case for their hospitality and help with sampling plants during my visit to Christchurch. Special thanks to Mark Ross the ranger at Queen Elizabeth Park and Hamish Carson for all the support in setting up my field study.

My gratitude also goes to Dr. Lesley Milicich for her resourcefulness and assistance with field and laboratory work. Thanks a lot Susanne Krejcek and Bridget Johnson for always being there for me and helping with fieldwork, and to the other members of my lab group for their invaluable critique of my work.

My studies at Victoria University would not have been possible without NZAID, who gave me a scholarship. I am greatly indebted to Julia Harrison, the current NZAID contract manager at Victoria International for all her support and understanding throughout my study period; Inge De Leeuw the former contract manager for among other things ensuring that I got timely treatment for my fractured knee. Thank you Mr. Gregg, my orthopaedic surgeon at Wellington Hospital for fixing my knee and giving me back my life.

My deep appreciation also goes to Wellington Botanical Society for a research grant; members of the Dune Restoration Trust of New Zealand for sharing their knowledge and firsthand experience in restoration during their various conferences. 
Finally, I wish to sincerely thank my dear wife for bearing the agony of separation during my first year of study, for convincing me to come over to New Zealand at a time when I felt I didn't have the energy to study, and for her constant support. 


\section{Table of contents}

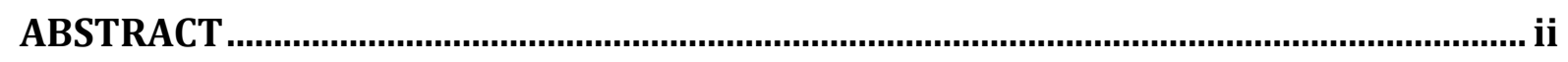

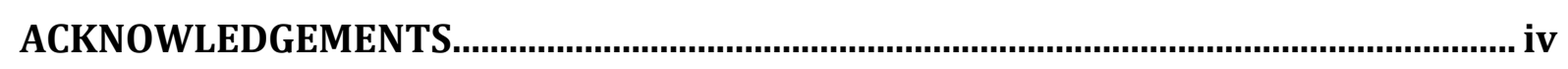

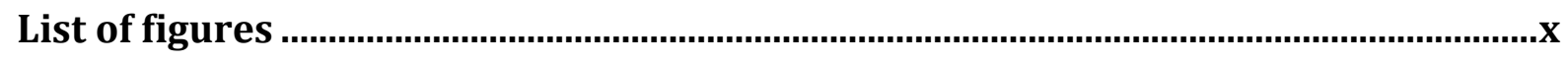

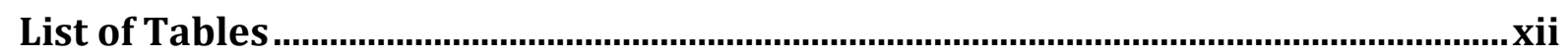

1. Chapter one: Plant interactions and the role of exotic species in eco-restoration

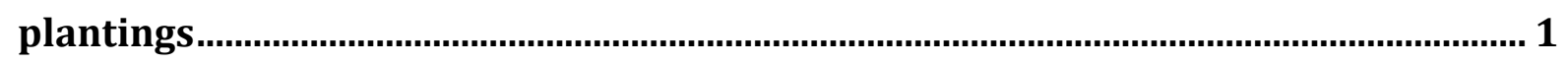

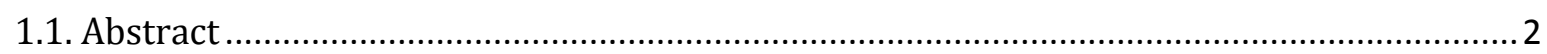

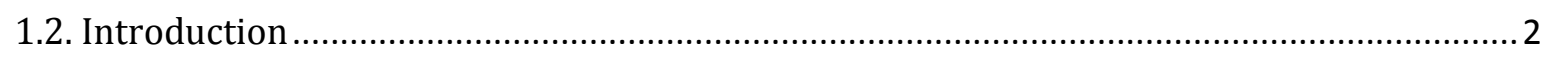

1.3. Role of competition in shaping plant community structure .............................................

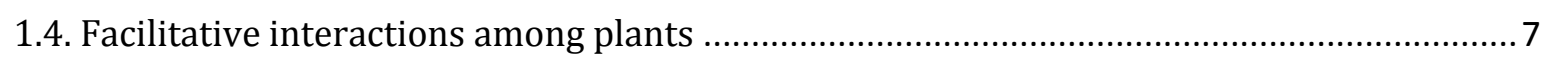

1.5. Competition-facilitation interplay and its influence on plant community structure..........10

1.6. Role of facilitation by exotic plant species in eco-restoration ..........................................13

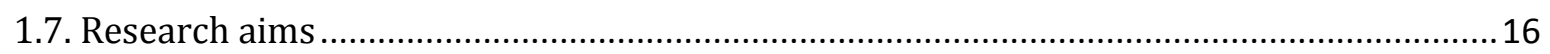

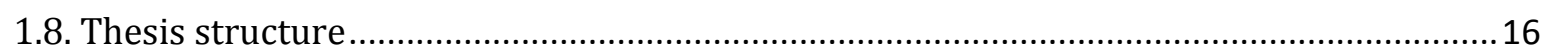

2. Chapter two: Mixed effects of invasive Carpobrotus edulis (Aizoaceae) on Spinifex sericeus and its implications for sand dune restoration................................24

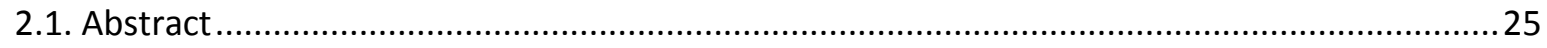

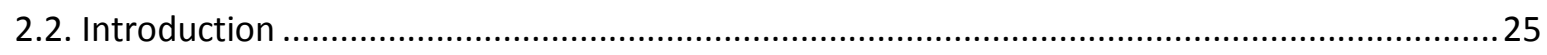

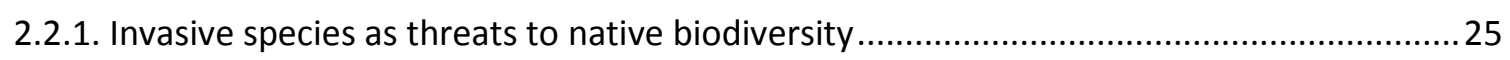

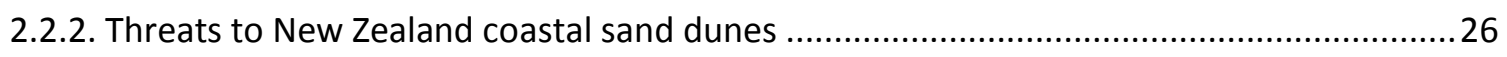

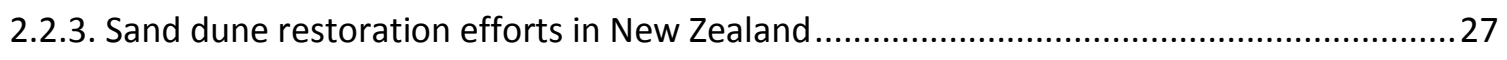

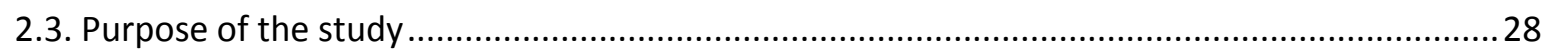

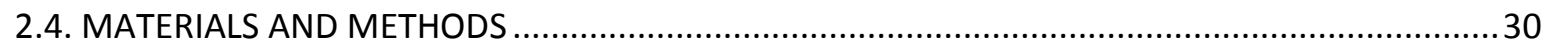

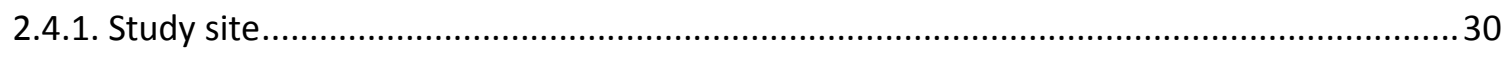

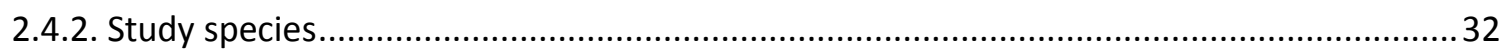




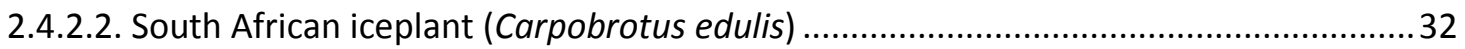

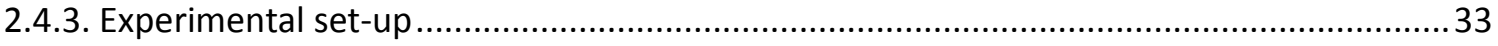

2.4.3.1. Experiment 1 (manual removal) ................................................................................. 33

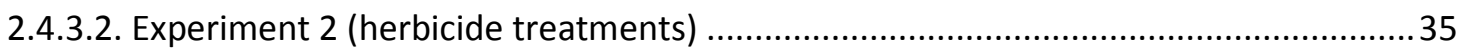

2.4.4. Physical properties of dunes with and without iceplant ................................................ 35

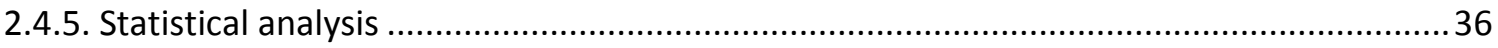

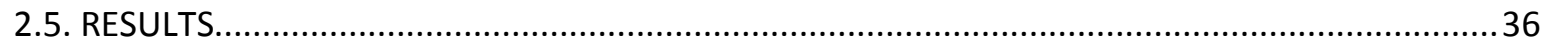

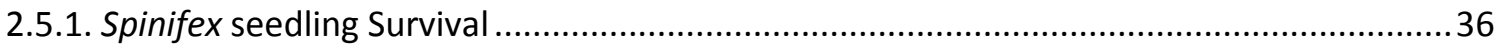

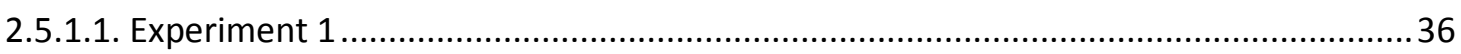

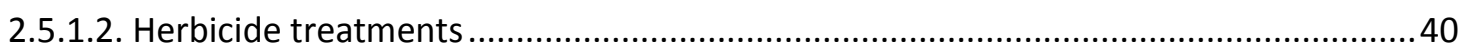

2.5.2. Number of leaves produced by Spinifex seedlings ......................................................... 42

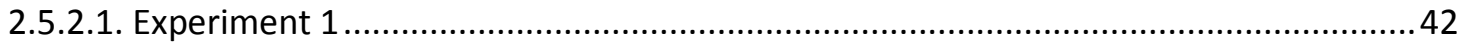

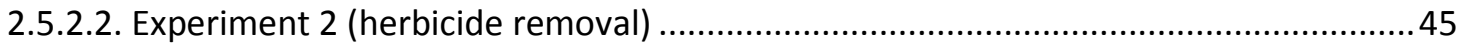

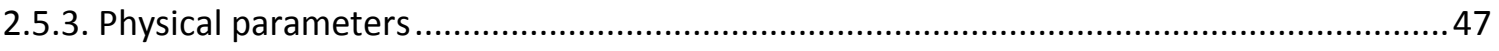

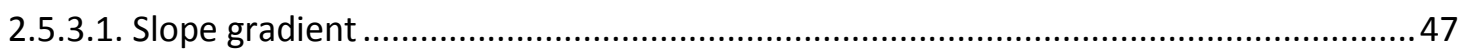

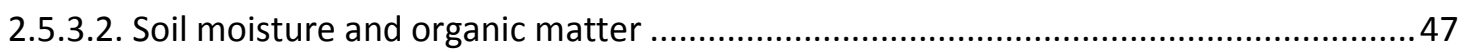

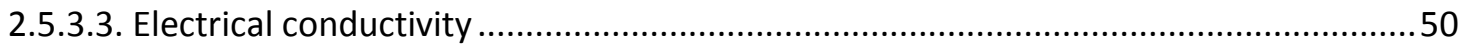

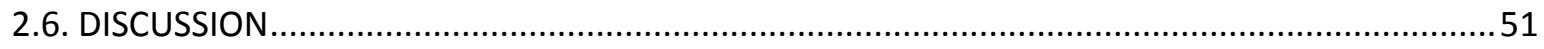

2.6.1. Confounding factors to Spinifex seedling survival and growth........................................51

2.6.2. Positive effects of $C$. edulis on Spinifex seedlings ..........................................................53

2.6.3. Negative effects of $C$. edulis on Spinifex seedlings ........................................................ 54

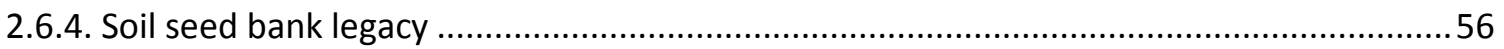

2.7. Conclusion and management recommendations .................................................................. 56

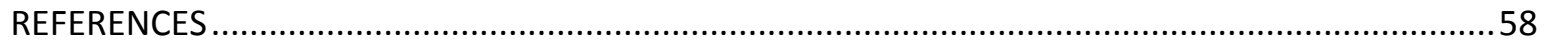




\section{Chapter three: Substrate preference and breeding systems in introduced}

Carpobrotus spp., native Disphyma australe and their hybrid....................................64

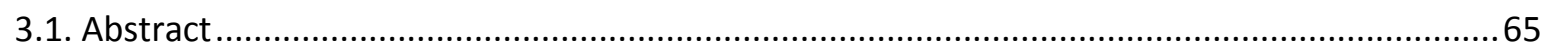

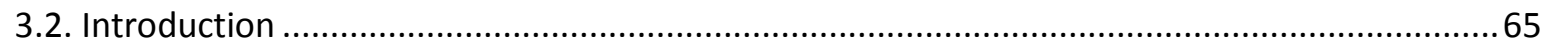

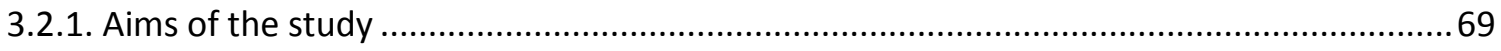

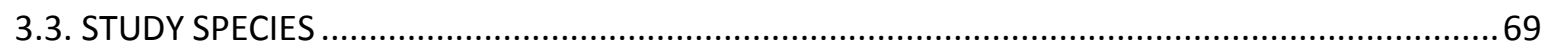

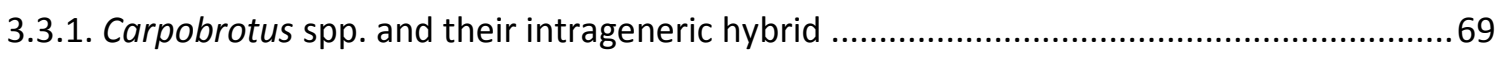

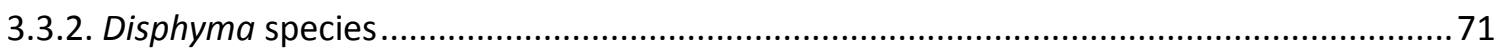

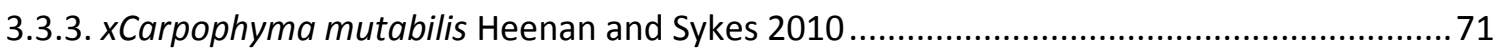

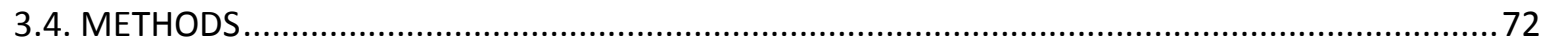

3.4.1. Experiment 1 (Common garden experiment - growth characteristics in different

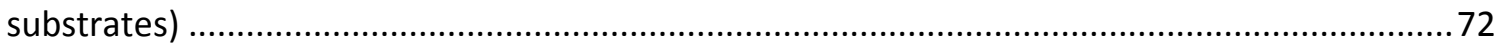

3.4.2. Experiment 2 (Field Growth monitoring) ......................................................................... 75

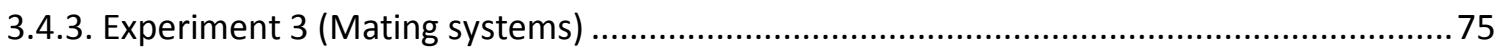

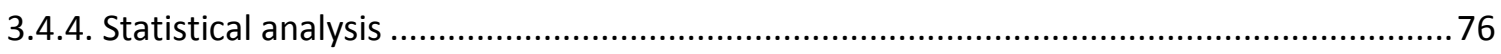

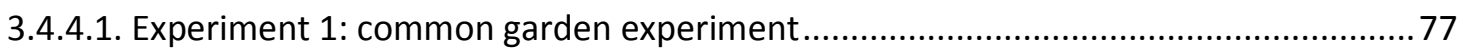

3.4.4.2. Experiment 2: field growth monitoring …......................................................... 77

3.4.4.3. Experiment 3: breeding and cross-pollination........................................................ 78

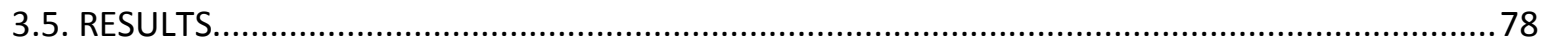

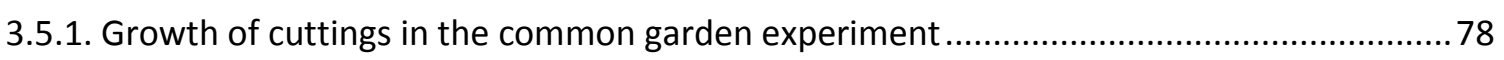

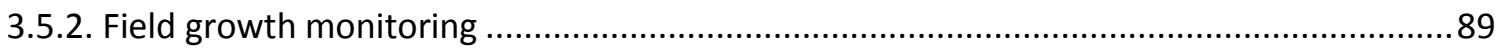

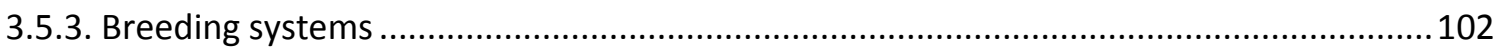

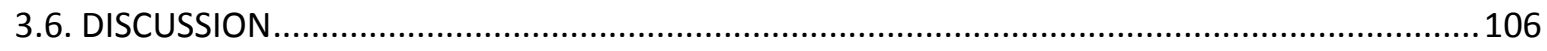

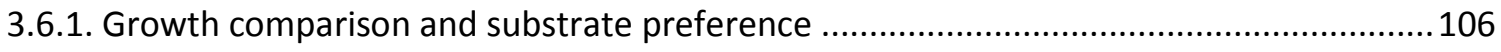

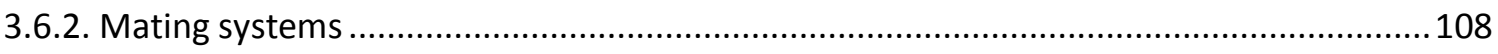

3.6.3. Implications of the Hybrid (xCarpophyma mutabilis Heenan and Sykes 2010) for $D$. australe 
4. Chapter four: Overall conclusions and recommendations

4.1. Interactive effects of $C$. edulis on Spinifex sericeus and its role in sand dune restoration...... 118

4.2. Growth, substrate preference and mating systems of the various iceplant taxa ..................120

4.3. Recommendations for restoration of Carpobrotus dominated sand dunes ..........................122

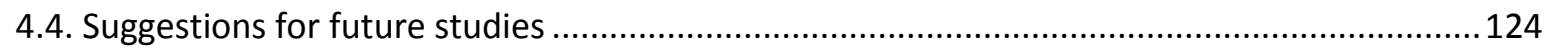

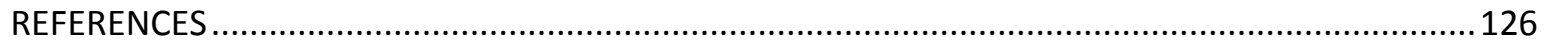

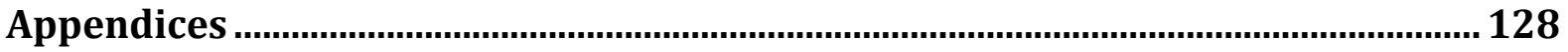

Appendix 1: Geographical coordinates of the various sites .....................................................128

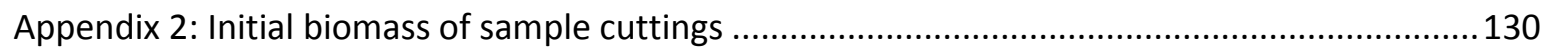

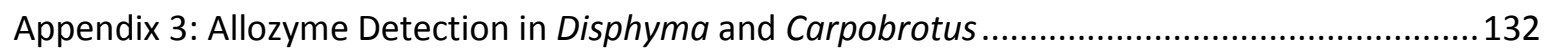

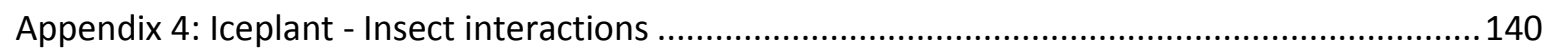




\section{List of figures}

Figure 1.1: Carpobrotus edulis dominated foredune with some Spinifex sericeus ..................1

Figure 2:1: Seedlings of Spinifex sericeus ready to be transplanted .....................................24

Fig. 2.2: Map showing the location of Queen Elizabeth Park ............................................... 31

Fig. 2.3: Error plot showing the effect of plant location on Spinifex seedling survival in December 2010.

Fig. 2.4: A graph showing effect of treatment on Spinifex seedling survival. ........................38

Fig. 2.5: A graph showing effect of plant location on Spinifex survival .................................40

Fig. 2.6: Effect of treatment on Spinifex survival in the herbicide treated plots

Fig. 2.7: Mean cumulative number of leaves produced by Spinifex plants in experiment 1 in relation to treatment over time.

Fig. 2.8: Mean cumulative number of leaves per plant in Experiment 1 in relation to plant location over time.

Fig. 2.9: Average number of leaves produced by each Spinifex plant in the Iceplant treatment of Experiment 1 in relation to plant location. .45

Fig. 2.10: Graph showing leaf production of Spinifex in the herbicide-treated plots. .46

Fig. 2.11: Slope gradients of the plots of the different treatments in experiment 1 .47

Fig. 2.12: Percentage soil organic matter at the bottom and top of the dunes. .48

Fig. 2.13: Percentage soil moisture content of soil . .49

Fig. 2.14: Electrical conductivity of soil samples obtained from the top and bottom of the dunes .50

Fig. 3.1. Photos showing flower colours of the different iceplant taxa found in New Zealand 64

Fig. 3.2: Map showing sites from where the iceplant cuttings were obtained. .73

Fig. 3.3: Photo of a hybrid stolon showing morphological features referred to frequently ... 74

Fig.3.4: Boxplots showing final biomass of the cuttings of the various taxa growing in different substrate types.

Fig. 3.5: Boxplots showing variability in final biomass of $C$. chilensis cuttings growing in different substrates 
Fig. 3.6: The final root mass ratio (RMR) of cuttings of each taxon growing in the various substrates

Fig. 3.7: Boxplots showing leaf production by the cuttings over the four month field growth period

Fig. 3.8: Average internode length of cuttings of each taxon in the various substrates grown over a period of six months.

Fig. 3.9: Increase in stolon lengths of the various taxa over the four-month field exposure period

Fig. 3.10: Bivariate correlation between shoot dry weight and number of leaves, and stolon lengths .88

Fig. 3.11: Final biomass of the hybrid cuttings from the various populations. .89

Fig. 3.12: Number of leaves produced by stolons of sample plants of the various taxa over each of the growth periods in the field growth experiment.

Fig. 3.13: Mean lengths of stolons of each taxon over the various growth periods in the field growth experiment.

Fig. 3.14: Net number of nodes produced along the main axes of stolons of plants of each taxon during the various growth periods in the field growth experiment

Fig. 3.15: Number of lateral branches produced by a stolon of plants of each taxon over the various growth periods in the field growth experiment

Fig. 3.16: Estimated shoot dry weight put on by the sample plants of each taxon over the various growth periods in the field growth experiment 100

Fig. 3.17: The dry weight to fresh weight ratios of the sample shoots harvested from the field. 102

Fig. 3.18: Mean flower density of sample plants of the various taxa during the main flowering season of the year 2011.

Fig. 3.19: Number of seeds per fruit produced by each of the two Carpobrotus species subjected to the different breeding treatments.... 105

Fig. 4.1: XCarpohyma mutabilis on the beach at Day's Bay, Wellington 117 


\section{List of Tables}

Table 2.1: ANOVA table showing effect of treatment and location on Spinifex seedling survival for the month of December

Table 2.2: A summary ANOVA table showing effect of treatment and location on Spinifex survival for the months of July 2011 through October 2011.

Table 2.3: ANOVA table showing effect of treatment and location on Spinifex seedling survival in the herbicide removal experiment 1

Table 2.4: ANOVA table showing effect of treatment and location on the cumulative number of leaves produced by plants in experiment.

Table 2.5: ANOVA table showing effect of treatment and location on survival of Spinifex

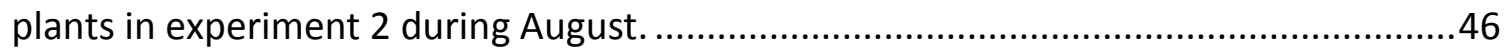

Table 2.6: Soil organic matter difference between bare and iceplant sites..........................48

Table 3.1: Two-way ANOVA table showing that total dry weights of the cuttings................79

Table 3.2: Tukey HSD table comparing biomass of $C$. chilensis cuttings growing in gravel and sand

Table 3.3: Two-way ANOVA table showing effect of substrate on root mass ratio of the cuttings.

Table 3.4: ANOVA table showing effect of substrate and its interaction with taxon on increase in the number of leaves of the cuttings over the four-month field exposure period

Table 3.5: Summary of separate ANOVAs showing that over the four month field exposure period substrate had an effect on leaf increase of $C$. chilensis only. .85

Table 3.6: ANOVA table comparing the lengths of stolon internodes of the various taxa growing in different substrate types.

Table 3.7: Bivariate correlation (Pearson's R-squared) between shoot dry weight and measured parameters of the cuttings and the stolons harvested from the sample field plants.

Table 3.8: Nested ANOVA summary table comparing the number of leaves produced by the field sample plants of each taxon over the various growth periods. .90 
Table 3.9: Tukey HSD table comparing variability in the average number of leaves produced by plants of each taxon over the different growth periods

Table 3.10: Nested ANOVA table of lengths of the main axes stolons

Table 3.11: A summary Tukey HSD test table comparing mean stolon lengths

the different growth periods

Table 3.12: Nested ANOVA table showing variability among taxa and among plants of the same taxon in the total number of their nodes over each growth period.

Table 3.13: A summary Tukey HSD test table comparing the aggregate number of nodes produced along the main stolons and lateral branches by plants of the various taxa over the different growth periods.

Table 3.14: Nested ANOVA table showing variability in the number of lateral branches produced by the plants in the field growth experiment. .96

Table 3.15: A Tukey HSD table comparing the mean number of lateral branches produced by the plants of various taxa in the different growth periods

Table 3.16: Summary of multiple linear regressions used to estimate shoot dry weights of plants in the field growth experiment

Table 3.17: Nested ANOVA table showing variability in estimated shoot dry weights among the various taxa and plants of each taxon in the field growth experiment. .99

Table 3.18: A Tukey HSD table comparing the means of the aggregate estimated dry weights put on by the shoots of the various taxa over the different growth periods 101

Table 3.19: Descriptive statistics of number of seeds produced per fruit by the two Carpobrotus species subjected to different breeding treatments. 104 


\section{Chapter one}

\section{Plant interactions and the role of exotic species in eco-restoration plantings}

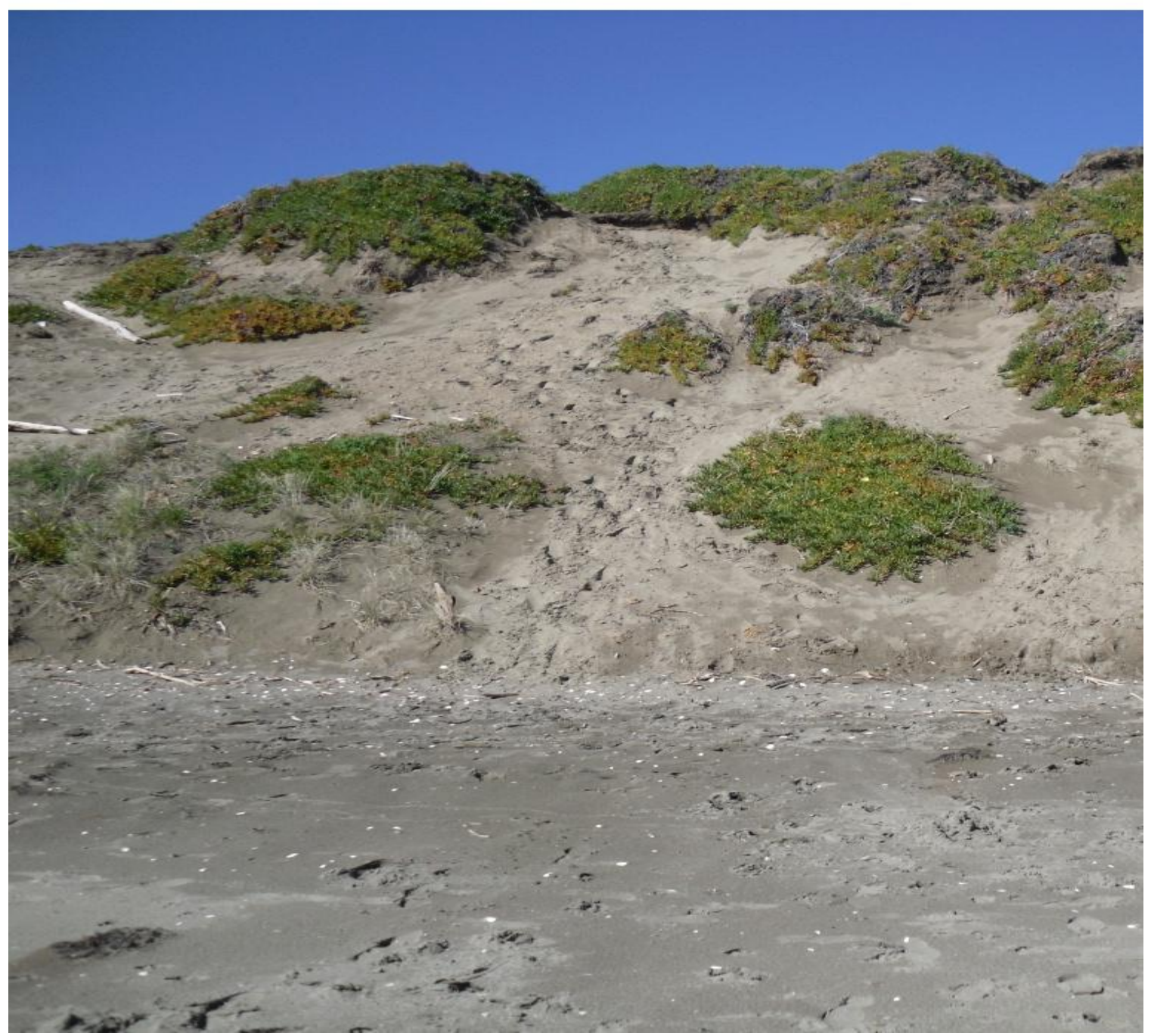

Figure 1.1: Carpobrotus edulis plants dominating the foredune with some Spinifex sericeus (foreground) surviving among them. Photo taken by author at Queen Elizabeth Park in November 2010. 


\subsection{Abstract}

Plant community structure is determined by both biotic and abiotic environmental conditions. Investigations of the role of competition in shaping natural plant communities were prevalent in previous generations and are still popular. However, more recent experimental research has uncovered the striking influence of facilitation on community dynamics. There is general consensus on the importance of facilitation and competition in natural communities, but the importance of competition in highly stressful environments is widely contested by plant ecologists. With the current climatic change, land-use change and widespread biotic exchange, natural ecosystems are threatened and ecological functions are being lost. In response to loss of biodiversity, ecological restoration enables us to regain at least some of the ecological services. Ecological restoration will normally aim at managing negative plant interactions while enhancing the positive ones. Here, I outline the influence of competition and facilitation on natural plant communities with reference to the role of facilitation in eco-restoration. I also highlight a few examples where exotic species have been found to facilitate native ones.

\subsection{Introduction}

Plant interactions play a key role in regulation of communities and ecosystems (Padilla and Pugnaire 2006), and may mediate the impacts of environmental change (Brooker 2006). Interactions among plants may have positive, negative or neutral effects. A negative interaction occurs when the presence of a neighbour has detrimental effects on the relative success of a plant. Ecologists are said to have been preoccupied with competitive processes for a long time (Bertness and Callaway 1994) with nearly all influential ecologists since Darwin having held the view that the natural world is shaped by conflict (Bruno, Stachowicz et al. 2003). Notable examples given by Bruno et al. (2003 pp 119) include "the mathematical models of interspecific competition developed by Lotka and Volterra, Gause's principle of competitive exclusion, and both Hutchinson's and MacArthur's work on niche and species packing". Examples of negative plant interactions include 
exploitative competition and interference. Exploitative competition involves a struggle to pre-empt space and limiting resources such as light, water and nutrients (Callaway and Walker 1997) that determine growth, survival, and fecundity of individual plants (Lamb and Cahill 2008). On the other hand, interference includes strategies that improve competitive position of a species against competitors by killing, poisoning or intimidation (Levine 1976). Chemical-mediated growth inhibition (e.g. allelopathy) is therefore a form of interference.

Facilitation loosely refers to a relationship between two organisms in which at least one participant benefits and neither suffers (Bruno, Stachowicz et al. 2003). Though it was a central theme during the initial periods of the development of Ecology as a science, the topic of facilitation has suffered some neglect along the way (Brooker and Callaghan 1998). However, more recent research clearly indicates that the influence of facilitation on population- and community-level variables is at least as important as other factors (Bruno, Stachowicz et al. 2003; Padilla and Pugnaire 2006). Neighbouring plants may provide benefits for each other, such as nutrients, shade, more available moisture and protection from herbivores (Callaway 1998; Padilla and Pugnaire 2006), but the general importance of positive interactions to community diversity, structure and productivity is not always acknowledged (Bertness and Callaway 1994). Recently, there has been an increasing interest in facilitation, and its importance for plant community dynamics (Maestre, Bautista et al. 2003), in spite of which, little has been done to incorporate it into the conceptual framework of ecology (Bertness and Leonard 1997; Bruno, Stachowicz et al. 2003).

The study of plant interactions is as old as the discipline of Ecology itself. In this chapter, I attempt to explore the importance of competition and facilitation in determining plant community structure, drawing attention to the role of facilitation, particularly of exotic species in ecological restoration. This exercise is by no means exhaustive. Here, interference is treated as a mechanism of competition, and facilitation encompasses both commensalism and mutualism. I begin by briefly examining the importance of competition and facilitation to community structure before highlighting the impacts of the interplay between the two processes. Finally, I sum up with examples where facilitation by exotic species has been used in ecological restoration. This chapter does not treat ecological restoration in its strict 
sense (return to a pre-existing state) and so includes rehabilitation and reclamation as well (for terminologies see Aronson, Floret et al. 1993). While there is a lot of literature on facilitation and competition, there seems to be significantly less research documenting how exotic species influence ecological restoration (D'Antonio and Meyerson 2002).

\subsection{Role of competition in shaping plant community structure}

Competition has been a central component of many of the basic ecological theories that guided plant ecologists (Brooker 2006). It is frequent among plants, and may be absent only in the early stages of the initial colonization (Bazzaz 1979) when density is low. Competition has also been found to influence both fitness components of individuals (Bengtsson, Fagerström et al. 1994) and the local plant species abundance (Bengtsson, Fagerström et al. 1994; Howard and Goldberg 2001). It is generally believed that the structure and function of plant communities are strongly influenced by resource competition (Boyden, Binkley et al. 2005) since traits associated with competitive dominance also have effects on ecosystem nutrient cycling (Aerts 1999). For instance, according to Aerts (1999), plants in nutrient-poor environments typically exhibit slow growth rates as well as low tissue turn-over and thus more nutrient retention ("stress tolerant" sensu Grime 1977). The flipside of this is that those plants of nutrient-rich environments typically have greater resource capture and higher tissue turn-over, hence faster nutrient recycling. Therefore, by regulating nutrient recycling and in effect its availability to other species, competition influences the structure of plant communities. It has been suggested that for plant species to coexist they have to be differentiated in their abilities to compete for the various limiting resources (Tilman 1980). The principle of competitive exclusion posits that closely related taxa cannot coexist because they have similar requirements for which they compete more intensely than with their distantly related counterparts (Mayfield and Levine 2010). This implies that competition results in local diversity because resource partitioning would allow unrelated taxa to coexist but not closely related ones with similar resource requirements. On the other hand, Bengtsson et al. (1994) noted in a review that species richness generally increases when dominants are 
removed, supporting the assumption that dominant species often have negative effects on diversity. This seems to be in agreement with Grime (1977) that a superior competitor for one resource is also a superior competitor for all the other resources, in effect suppressing diversity. Although many plant scientists agree that interspecific competition is an important determinant of structure and dynamics of plant communities, there is much less concurrence on the mechanisms involved and its significance to community dynamics in different environments (Aerts 1999).

Environmental productivity is said to influence the intensity with which plants compete for resources as well as the specific resources for which they compete. According to Tilman (1988), the intensity of competition remains the same but the resources for which plants compete may change depending on habitat productivity. In fertile environments with dense canopies, competition is mainly for light and the successful competitor will have traits that lead to overtopping of its neighbours (Aerts 1999). In nutrient-poor environments competition is mainly for nutrients (Aerts 1999) but the importance, or even existence, of competition in such an environment has been strongly debated and persistently questioned throughout the history of ecological science (Fowler 1986; Grace 1993). This debate on the significance of competition to plant community structure has recently been dominated by the Grime and Tilman schools of thought, especially as relates to its importance in low productivity habitats (Grace 1991). Grime (1977) noted that the observed mortality of neighbours could not be exclusively a result of competition but could just as well be attributed to the capacity of a plant to exploit the features of the environment. Grime (1977) argues that in a nutrient-poor environment plant success is a result of nutrient capture and retention (also Aerts 1999) and not superior competitive ability, concluding that competition is rather unimportant in such habitats. Tilman (1989) on the other hand, demonstrated in an experiment involving bunchgrass (Schizachyrium scoparium) that competition may be strong regardless of habitat productivity, and that plant success is a result of its ability to deplete resources to levels too low for other species but to which it is tolerant (Tilman 1989). The Grime-Tilman debate (Thompson 1987; Tilman 1987; Thompson and Grime 1988) has been synthesised by Grace (1991) who concluded that their 
disagreements are mostly about different aspects of competition; while Tilman discusses intensity of competition, Grime refers to its importance (see also Brooker, Kikvidze et al. 2005; Brooker and Kikvidze 2008; Kikvidze and Brooker 2010). Competition intensity refers to the reduction in the level of performance of a plant as a consequence of presence of a neighbour while competition importance refers to the impact of a neighbour as a proportion of the combined effects of all biotic and abiotic environmental factors (Welden and Slauson 1986). The persistent debate on competition is said to stem mainly from failure of researchers to distinguish between competition intensity and its importance (Brooker and Kikvidze 2008).

Another negative plant interaction is allelopathy, a non-resource interaction where one plant has negative effects on another through release of chemical compounds into the environment (Inderjit, Wardle et al. 2011). This phenomenon has been suggested as a mechanism for the remarkable success of invasive plants that frequently establish virtual monocultures where diverse communities once thrived (Hierro and Callaway 2003). For example, the diffuse knapweed (Centaurea diffusa) invades and dominates native bunchgrass communities of North America through allelopathic effects of its root exudates (Brooker 2006) to which native communities lack co-evolved tolerance (Callaway and Aschehoug 2000). Bazzaz (1979) noted that several members of pioneer plants produce toxins, mostly phenolic compounds that are inhibitory to several other species. Unlike resource competition that may produce diversity, allelopathy generally promotes the establishment of monocultures.

Competition plays an important role in biological invasions. Colonization, along with modification of many ecosystems throughout the world by exotic plants, and a resultant reduction in biodiversity, has become a commonly observed phenomenon (Vitousek 1990). A review of competitive interactions between native and exotic plants suggested that the spread and establishment of the exotic species is related to their ability to competitively suppress resident species (Levine, Vilà et al. 2003). The extent to which the success of an invader is explained by its competitive superiority, or the disturbances and dispersal that allow them to become established, is central to the debate on the importance of 
competition and plant invasion and is valuable to the design of strategies to control invaders (Cuesta, Villar-Salvador et al. 2004). While there are many other explanations for plant invasions, such as enemy release (Keane and Crawley 2002), evolution of increased competitive ability (Blossey and Notzold 1995), and novel weapons hypothesis (Callaway and Ridenour 2004), competition still remains a central driver of biological invasions in addition to regulation of community composition.

\subsection{Facilitative interactions among plants}

Facilitative interactions have been demonstrated in a broad range of ecosystems, with most evidence coming from severely stressful environments such as semi-arid areas (Gomez-Aparicio, Zamora et al. 2004), salt marshes (Bertness and Shumway 1993; Didham, Tylianakis et al. 2007), and intertidal zones (Bertness and Leonard 1997). Direct positive interactions occur when neighbours modify environmental conditions, leading to positive effects (Bertness and Callaway 1994) for others. Presence of stress-tolerant plants can ameliorate potentially limiting physical stress in their immediate vicinity, thereby providing favorable sites where less tolerant species can then succeed (Bertness and Callaway 1994; King 2008).

The positive effect of an adult plant on seedlings of another species is called the "nurse-plant" effect (Bertness and Callaway 1994; Padilla and Pugnaire 2006) and has been found in harsh habitats, suggesting that habitat amelioration by neighbours is important for positive recruitment events (Bertness and Callaway 1994). Nurse plants concentrate nutrient cycling directly under their canopies (Callaway 1995; King 2008). For example, Kahi and colleagues (2009) observed that soil nitrogen content under canopy of mesquite (Prosopis juliflora) was $45 \%$ higher than in open areas. Other plants respond positively to such nutrient islands, leading to the formation and maintenance of vegetation patches around shrubs (King 2008). It has been experimentally determined that many shrubs acted as nurse-plants, resulting in increased survival of planted seedlings (Castro, Zamora et al. 2004; Gomez-Aparicio, Zamora et al. 2004). Generally, nurse-plant effects contribute to 
recruitment and survivorship of regenerating beneficiary species and have been used widely in forestry (e.g. Castro, Zamora et al. 2004; Cuesta, Villar-Salvador et al. 2004; GómezAparicio, Gómez et al. 2005; Sullivan, Williams et al. 2007; Smit, den Ouden et al. 2008). For instance, Aerts et al. (2007) found that seedlings of African wild olive (Olea europaea), survived better under shrub canopy of Euclea racemosa than in open fields.

There is improvement in soil moisture under the canopies of benefactor plants. This may be due to hydraulic lift (Richards and Caldwell 1987; Prieto, Martínez-Tillería et al. 2010) by the deeper roots of the larger plant. At night when transpiration is low, water absorbed by the roots of benefactor plants from the deeper soil layers tends to seep into the superficial layer (Caldwell and Richards 1989) where the beneficiary herbaceous species have their roots concentrated and consequently get access to this water. For example, Caldwell and Richards (1989) conducted a field experiment where they dipped roots of Artemisia tridentata (a deep rooted shrub) in water that has been highly enriched with hydrogen isotope, deuterium and observed that the stable isotopes appeared in the neighbouring tussock grass, Agropyron desertorum (shallow-rooted) confirming the phenomenon of hydraulic lift. Prieto and colleagues (2010) demonstrated that there was increased soil water potential in superficial layers after covering shrubs of five different species with opaque plastic bags for $48-72$ hours. The shading effect of the nurse plant species also produces a microhabitat with lower temperature and wind speeds, as well as higher humidity, resulting in reduced transpiration demands and thermal stress (Holmgren, Scheffer et al. 1997; Aerts, Negussie et al. 2007) that further contributes to positive recruitment of the under-story beneficiary species.

Plants growing in oxygen limited soils are known to passively conduct oxygen from leaves to their roots that may then diffuse into the surrounding medium where it could oxidize harmful dissolved chemicals and ameliorate anoxia for other species (Callaway 1995). In a field and greenhouse experiment, Callaway and King (1996) found that narrow-leaved willow (Salix exigua) seedlings survived only in the presence of earenchymatous Typha latifolia at environmental temperatures of $11-12^{\circ} \mathrm{C}$. Black rush (Juncus gerardi), has also been observed to oxygenate the surrounding soil through its aerenchyma tissues that serve 
as conduits for oxygen delivery to the rhizosphere (Hacker and Bertness 1999). This shows that under certain environmental conditions highly aerenchymatous species can aerate soil near its roots, improving growth of the less aerenchymatous neighbours that would otherwise not perform well in anoxic habitats like marshes (Callaway and King 1996).

Benefactor plants modify the substrate, making it more suitable for supporting other species. Sand-binding species stabilize the substrate for eventual colonization by successive sand dune plants (Lichter 2000). Leaf litter of such pioneer plants has been observed to improve soil structure and increase its cation exchange capacity, and water holding capacity (Hunter and Aarssen 1988). Later arriving species can then respond positively to the improved soil micro-conditions.

Protection from herbivores is an indirect form of facilitation where highly palatable species gain protection by growing among thorny (Callaway 1995) or less palatable neighbours (Callaway, Kikvidze et al. 2000; Brooker, Maestre et al. 2008). This phenomenon is widespread in rangelands where grasses find refuge among undesirable neighbours.

Co-flowering species have been shown to facilitate each other when the pollinator attraction of one species is greater than that of its neighbour (Callaway 1995; Padilla and Pugnaire 2006). In a field experiment, Hegland et al. (2009) found that positive interactions for pollinator attraction were more numerous than negative ones. In an experiment to test whether pollination of Raphanus raphanistrum was enhanced by other co-flowering species, Ghazoul (2006) found that pollination visits increased when it occurred with at least one of Cirsium arvense, Hypericum perforatum and Solidago canadensis compared to when it occurred alone.

There is widespread resource sharing among neighbouring plants through root grafts (Graham and Bormann 1966) and mycorrhizal networks (Hunter and Aarssen 1988; Selosse, Richard et al. 2006). An example is nitrogen transfer between Casuarina cunninghamiana and Eucalyptus maculata (He, Critchley et al. 2005). Woods and Brock (1964) found that radioisotopes of phosphorous and calcium introduced into the stumps of red maple (Acer 
rubrum) appeared in 19 other neighbouring species. Although they did not come up with a definitive mechanism of the transfer, Woods' and Brock's (1964) experiment shows that transfer of materials among neighbouring plants is widespread. The breadth of literature on plant facilitation is extensive and the bottom line is that facilitation is a ubiquitous process in harsh environments where the presence of a neighbour enhances recruitment, survivorship, and performance of a beneficiary plant.

\subsection{Competition-facilitation interplay and its influence on plant community structure}

The composition and structure of a community are shaped by both abiotic factors and interactions among organisms, though the specific types of interactions partly responsible are usually less evident in plant communities (Holzapfel and Mahall 1999). In current models of plant community structure, it is widely accepted that positive and negative interactions operate simultaneously (Bertness and Callaway 1994; Callaway and Walker 1997; Holmgren, Scheffer et al. 1997; Brooker and Callaghan 1998). A growing number of studies indicate that the net outcome of most interactions between neighbouring plants is determined by the relative strength of facilitation and competition (Aguiar, Soriano et al. 1992; Callaway and Walker 1997; Holmgren, Scheffer et al. 1997; Holzapfel and Mahall 1999; Michalet, Brooker et al. 2006; Villarreal-Barajas and Martorell 2009). In highly stressful conditions, initial colonizers tend to ameliorate stress and facilitate further plant colonization (Bertness and Shumway 1993). However, the search for general patterns in the relationship between resource availability and the intensity or importance of competition has been controversial in population and community ecology (Boyden, Binkley et al. 2005). Reviews on these patterns (Callaway 1995; Bruno, Stachowicz et al. 2003; Brooker, Maestre et al. 2008) generally suggest that plant interactions shift from competition to facilitation along stress gradients (Bertness and Callaway 1994). Positive interactions are suggested to be more important in plant communities as abiotic stress or consumer pressure increases, while competition dominates when physical stress and consumer pressure are both relatively subtle (Bertness and Callaway 1994). The reasoning is that harsh environments may restrict plants from acquiring resources, and any amelioration 
of these conditions will favour growth to the extent that it outweighs the competitive impacts of growing in close associations, whereas in benign environments amelioration of environmental conditions has a minimal impact and the balance is tipped towards negative effects (Olofsson, Jon et al. 1999). Grime (1977) reasons that while the prevalent plant coping strategy in productive, less disturbed environments is competition, stress tolerance is more important in persistently unproductive habitats. Brooker and Callaghan (1998) also claim that competition is rather unimportant in nutrient-poor environments and its intensity increases only with increasing productivity. Pugnaire and Luque (2001) compared biomass of understory species of the shrub Retama sphaerocarpa at a highly fertile valley bottom site and steeper rocky outcrops with their counterparts growing outside the shrub canopy and concluded that facilitation weakened with increase in soil fertility. Small-flowered forget-me-not (Myosotis laxa) was observed to have benefited significantly from soil oxygenation when grown with Typha latifolia at low soil temperatures, but the positive effects disappeared at higher soil temperatures and the interaction became competitive (Callaway and King 1996). Holmgren and Scheffer (2010) however, propose that facilitation is more important in mild, not severe environments, arguing that although the relative role of facilitation increases along stress gradient, its absolute effect is largest at moderately stressful conditions. They argue that under highly stressful conditions facilitation by a neighbour may not be sufficient enough to allow any growth as competition by the "benefactor" for the same resource may cancel out the effect of facilitation (Holmgren and Scheffer 2010).

The magnitude of competition experienced by species is said to vary among lifehistory stages and size asymmetry (Howard and Goldberg 2001), and may affect the outcome of interactions between plant species (Callaway and Walker 1997). In many cases, seedlings of beneficiary species are found spatially associated with nurse plants, whereas adults are not, suggesting that the importance of competition and facilitation shifts among the various life-history stages (Callaway and Walker 1997; Miriti 2006). Whereas naturally established seedlings of African wild olive (Olea europaea ssp. Cuspidata) were found restricted to sites under the canopy of pioneer shrub Bush guarri (Euclea racemosa ssp. Schimperi), the adults were not (Aerts, Negussie et al. 2007). Similarly, the sahuaro (saguaro) 
cactus (Carnegiea gigantean) of the Sonoran Desert is commonly limited to areas beneath the canopy of its nurse-plant, the foothill paloverde (Cercidium microphyllum), but the close proximity was observed to lead to increased stem die-back and greater mortality of the nurse tree, C. microphyllum (McAuliffe 1984). Archer et al. (1988) found that once Prosopis glandulosa created habitat suitable for colonization by other woody perennials, the colonizers were able either to outcompete the original Prosopis nurse plant or to prevent it from reproducing in the clusters. Such patterns of nurse plant mortality indicate that some native species that begin their lives as the beneficiaries become significant competitors with their former exotic benefactors as they mature (Callaway and Walker 1997). These observations suggest that the positive effects of benefactors are strong when beneficiaries are young but competitive interactions dominate as the beneficiaries get older and larger (Callaway and Walker 1997; Schwinning and Weiner 1998; Miriti 2006). It is suggested that acquisition of resources usually depends more on plant size than on species identity (Bengtsson, Fagerström et al. 1994) and therefore asymmetry in competition is mainly a result of differences in plant size rather than species differences. Some benefactor species seem to play an altruistic role by contributing to survivorship of other species at their own expense. In summary, relationships between plant species can change from positive to negative with changes in size of the interacting species.

Other than degrees of environmental stress, ontogeny, and size asymmetry, shifts in dominance between facilitative and competitive outcomes also depend on density and successional stage. Thickets of early successional species often inhibit colonization by later successional species (Berkowitz, Canham et al. 1995) by using up resources and starving later arrivals (Bazzaz 1979). 


\subsection{Role of facilitation by exotic plant species in eco-restoration}

Control of the introduction and spread of invasive exotic species is a highly costly and time-consuming undertaking. For instance, invasive species are reported to have cost New Zealand about $\$ 3.4$ billion (just under $2 \%$ of GDP) in control expenditure and production losses in the year 2008 (Biosecurity 2009). In the United States, the annual costs of invasive species are estimated at between US\$120-138 billion (Pimentel, Lach et al. 2000; Pimentel, Zuniga et al. 2005). In addition to economic costs, exotic plant invasions pose serious threats to native biodiversity and ecosystem functioning (Spence, Ross et al. 2010). It has been suggested that there is need for development of novel, low-cost and effective restoration techniques for maintaining these ecosystem functions and services (Hobbs, Arico et al. 2006). Facilitation, having been recognized as an important structuring force, is increasingly being considered as an ecological mechanism for developing vegetation restoration tools, particularly for severe and highly disturbed environments (Brooker and Callaghan 1998; Brooker, Maestre et al. 2008). Most restoration projects are typically preceded by mechanical or chemical removal of weed species (Berger 1993). For example, in reforestation, shrub cover is cleared before planting tree seedlings (Aerts, Negussie et al. 2007) as they are thought to compete with the seedlings (Gomez-Aparicio, Zamora et al. 2004). This may not be advisable given that shrubs may sometimes have positive impacts on the seedlings (Castro, Zamora et al. 2004) as demonstrated by studies referred to in the sections above. Removal of plants, even exotic ones, is said to have negative impacts on the ecosystem (Zavaleta, Hobbs et al. 2001; D'Antonio and Meyerson 2002). Moreover, clearing shrub cover is a disturbance that would create empty niches which may favour establishment of undesirable invasive species (Hierro and Callaway 2003). It is prudent to find ways of using the extant exotics positively as it may sometimes be necessary to use fast-growing exotic species in restoration of highly degraded sites (D'Antonio and Meyerson 2002).

Most studies of biological invasions have focused solely on the direct negative impacts of non-indigenous species on native biota (Rodriguez 2006). Incorporating facilitative interactions of invasive species into future ecological research will be important 
to determine their relative strength in comparison to competition and changes in ecosystem processes and biodiversity (Rodriguez 2006). Some ecological traits of invasive exotic species, including nitrogen fixation, fast growth, and resistance to stress contribute to their ability for colonizing new areas (Noble 1989). On the other hand, these traits can be of relevance to fostering ecological restoration as an alteration of ecological conditions, and resource flow may promote the establishment of late successional species (Ehrenfeld 2003; Levine, Vilà et al. 2003; Ewel and Putz 2004). There are however, very few examples of research where facilitation by exotic species have been exploited for restoration. In a study at a degraded coastal pasture site in Puerto Rico it was observed that seedlings of several secondary forest species were abundant in the understory of exotic Albizia lebbek plantation but absent from grass control plots (Parrotta 1992), suggesting an important role played by such exotic plantations in forest regeneration. Similar observations were made by Chapman and Chapman (1996) in Pinus spp. and Cupressus lusitanica plantations, and under the canopies of the exotic Acacia mangium by Kuusipalo et al. (1995). While undisturbed forest habitats are important for conservation at a landscape scale, it has been suggested that exotic plantations may complement them by providing additional habitats for forest plant species (Hylander and Nemomissa 2009).

Invasive nitrogen-fixing plants can facilitate neighbouring plants. For example, in the lowland pampas of Argentina, the vegetative growth and aboveground biomass of native perennial grass Paspalum dilatatum increased in the presence of non-indigenous nitrogenfixer, Lotus tenuis (Quinos, Insausti et al. 1998). Gorse (Ulex europaeus) is an invasive pioneer nitrogen-fixer introduced to New Zealand that has been observed to enrich the soil, making way for native forest regeneration (McQueen, Tozer et al. 2006; Sullivan, Williams et al. 2007). Gorse is also said to shade out invasive grasses in old fields, creating suitable microsites for regeneration of native woody species such as Pittosporum eugenioides that eventually replace it (Norton 2009). An invasive aquatic species (Hydrilla verticillata) that was originally thought to have an extremely high potential of eliminating submerged aquatic species in the United States has recently been reported to have beneficial effects on habitat quality, allowing native species to re-establish and maintain themselves (Hershner and Havens 2008). 
According to Van Aarde et al. (1996), Richards Bay Mining Company in South Africa removed all the vegetation from sand dunes before mining. After mining, the dunes were stabilized by sowing seeds of a mixture of exotic species such as babala grass (Pennisetum americanum), sun hemp (Crotalaria juncea), and a mixture of native grass seeds, forming a dense cover within a month. After 6-8 months the introduced grass species died off, leaving the local weeping love grass (Eragrostis curvula) after ameliorating surface microclimate for germination and subsequent establishment of the indigenous species (Van Aarde, Ferreira et al. 1996). Berens et al. (2008) quantified seed rain and seedling establishment of heterospecific woody species under fruiting exotic guava (Psidium guajava) trees in farms around Kakamega, Kenya and found that $93 \%$ of the seedlings were animal dispersed native species from the nearby Kakamega forest. Guava tree, though invasive in some regions, can serve as focal points for restoration in degraded areas by attracting seed dispersers (Berens, Farwig et al. 2008). Similarly, reclamation of derelict old quarries at Bamburi, Kenya using the exotic whistling pine (Casuarina equisetifolia) succeeded in ameliorating the salinity and nutrient deficiency, allowing regeneration of native bird-dispersed plants (Siachoono 2010). The abandoned gaping quarries at Bamburi are now a nature park where native plants are increasing in abundance and diversity (pers. observation). Fischer et al. (2009) tested whether the invasive Cinchona species had facilitative effects in simplified tropical Hawaiian systems and found that there were significantly more endemic herbs and shrubs under canopy of the invader than in uninvaded plots. Similar observations were made under invasive shrub Pyracantha angustifolia by Tecco and colleagues (2006).

Another area that may not have received sufficient attention is the mediation by exotic ecosystem engineers in creating micro-conditions suitable for native species colonization or substituting extinct native species by providing the same ecological services (Griffiths and Harris 2010). For example, Aldabra giant tortoises (Aldabrachelys gigantea) introduced to several small islands surrounding Mauritius, appear to have successfully substituted the herbivory and seed dispersal functions of native tortoises that recently became extinct (Griffiths, Jones et al. 2010). Taxon substitutions have been proposed as a new approach for ecological restoration (Donlan, Berger et al. 2006) and Hansen (2010 pp 
124-125) has outlined proposals where extinct plant species could be substituted by related extant ones.

\subsection{Research aims}

Various studies (e.g. Castro, Zamora et al. 2004; Gomez-Aparicio, Zamora et al. 2004; Aerts, Negussie et al. 2007) have shown that restoration via nurse-plant facilitation is viable. However, there are only a few examples of restoration using facilitation by exotic species. There is need for more research into facilitative effects of exotic plants on native species and their possible role in ecological restoration.

This thesis aims to investigate competitive and facilitative influence of the invasive South African iceplant (Carpobrotus edulis) on native plants, specifically Spinifex sericeus, with particular reference to implications of these interactions for dune restoration in New Zealand. It further explores the growth rates, substrate preferences and mating systems of the exotic and native iceplant taxa found in New Zealand. The information gathered will add to the existing knowledge base on the ecology of iceplant taxa found in New Zealand and in advising coastal sand dune restoration practitioners.

\subsection{Thesis structure}

The remaining sections of the thesis are divided into three chapters. Chapter two investigates the competitive and facilitative effects of $C$. edulis on Spinifex. Chapter three examines the ecology of iceplant taxa found in New Zealand in terms of their in-situ growth, substrate preference and mating systems. Chapter four is a summary of the findings of the research and recommendations for future work. Chapters two and three have been prepared as manuscripts for journal submission and may differ in style, and contain some repetition. 


\section{REFERENCES}

Aerts, R. (1999). "Interspecific competition in natural plant communities: mechanisms, trade-offs and plant-soil feedbacks." Journal of Experimental Botany 50(330): 29-37.

Aerts, R., A. Negussie, et al. (2007). "Restoration of dry afromontane forest using pioneer shrubs as nurse-plants for Olea europaea ssp. cuspidata." Restoration Ecology 15(1): 129-138.

Aguiar, M. R., A. Soriano, et al. (1992). "Competition and Facilitation in the recruitment of seedlings in Patagonian Steppe." Functional Ecology 6(1): 66-70.

Archer, S., C. Scifres, et al. (1988). "Autogenic Succession in a Subtropical Savanna: Conversion of Grassland to Thorn Woodland." Ecological Monographs 58(2): 111-127.

Aronson, J., C. Floret, et al. (1993). "Restoration and Rehabilitation of Degraded Ecosystems in Arid and Semi-Arid Lands. I. A View from the South." Restoration Ecology 1(1): 8-17.

Bazzaz, F. A. (1979). "The Physiological Ecology of Plant Succession." Annual Review of Ecology and Systematics 10(1): 351-371.

Bengtsson, J., T. Fagerström, et al. (1994). "Competition and coexistence in plant communities." Trends in Ecology \& Evolution 9(7): 246-250.

Berens, D. G., N. Farwig, et al. (2008). "Exotic guavas are foci of forest regeneration in Kenyan farmland." Biotropica 40(1): 104-112.

Berger, J. J. (1993). "Ecological Restoration and Non-Indigenous Plant Species: A Review." Restoration Ecology 1(2): 74-82.

Berkowitz, A. R., C. D. Canham, et al. (1995). "Competition Vs. facilitation of tree seedling growth and survival in early successional communities." Ecology 76(4): 1156-1168.

Bertness, M. D. and R. Callaway (1994). "Positive interactions in communities." Trends in Ecology \& Evolution 9(5): 191-193.

Bertness, M. D. and G. H. Leonard (1997). "The role of positive interactions in communities: Lessons from intertidal habitats." Ecology 78(7): 1976-1989.

Bertness, M. D. and S. W. Shumway (1993). "Competition and facilitation in marsh plants." American Naturalist 142(4): 718-724.

Biosecurity, N. Z. (2009). Economic costs of pests to New Zealand, MAF Biosecurity New Zealand Technical Paper No: 2009/31 (http://www.biosecurity.govt.nz/files/pests/surv-mgmt/economiccosts-of-pests-to-new-zealand.pdf).

Blossey, B. and R. Notzold (1995). "Evolution of Increased Competitive Ability in Invasive Nonindigenous Plants - A Hypothesis." Journal of Ecology 83(5): 887-889. 
Boyden, S., D. Binkley, et al. (2005). "Competition and Facilitation between Eucalyptus and NitrogenFixing Falcataria in Relation to Soil Fertility." Ecology 86(4): 992-1001.

Brooker, R., Z. Kikvidze, et al. (2005). "The importance of importance." Oikos 109(1): 63-70.

Brooker, R. W. (2006). "Plant-plant interactions and environmental change." New Phytologist 171(2): 271-284.

Brooker, R. W. and T. V. Callaghan (1998). "The balance between positive and negative plant interactions and its relationship to environmental gradients: a model." Oikos 81(1): 196-207.

Brooker, R. W. and Z. Kikvidze (2008). "Importance: an overlooked concept in plant interaction research." Journal of Ecology 96(4): 703-708.

Brooker, R. W., F. T. Maestre, et al. (2008). "Facilitation in plant communities: the past, the present, and the future." Journal of Ecology 96(1): 18-34.

Bruno, J. F., J. J. Stachowicz, et al. (2003). "Inclusion of facilitation into ecological theory." Trends in Ecology \& Evolution 18(3): 119-125.

Caldwell, M. M. and J. H. Richards (1989). "Hydraulic Lift - Water efflux from upper roots improves effectiveness of water-uptake by deep roots." Oecologia 79(1): 1-5.

Callaway, R. M. (1995). "Positive interactions among plants." Botanical Review 61(4): 306-349.

Callaway, R. M. (1998). "Are positive interactions species-specific?" Oikos 82(1): 202-207.

Callaway, R. M. and E. T. Aschehoug (2000). "Invasive plants versus their new and old neighbors: a mechanism for exotic invasion (vol 290, pg 521, 2000)." Science 290(5499): 2075-2075.

Callaway, R. M., Z. Kikvidze, et al. (2000). "Facilitation by unpalatable weeds may conserve plant diversity in overgrazed meadows in the Caucasus Mountains." Oikos 89(2): 275-282.

Callaway, R. M. and L. King (1996). "Temperature-Driven Variation in Substrate Oxygenation and the Balance of Competition and Facilitation." Ecology 77(4): 1189-1195.

Callaway, R. M. and W. M. Ridenour (2004). "Novel Weapons: Invasive Success and the Evolution of Increased Competitive Ability." Frontiers in Ecology and the Environment 2(8): 436-443.

Callaway, R. M. and L. R. Walker (1997). "Competition and facilitation: A synthetic approach to interactions in plant communities." Ecology 78(7): 1958-1965.

Castro, J., R. Zamora, et al. (2004). "Benefits of using shrubs as nurse plants for reforestation in Mediterranean mountains: A 4-year study." Restoration Ecology 12(3): 352-358.

Chapman, C. A. and L. J. Chapman (1996). "Exotic tree plantations and the regeneration of natural forests in Kibale National Park, Uganda." Biological Conservation 76(3): 253-257. 
Cuesta, B., P. Villar-Salvador, et al. (2004). "Facilitation of Quercus ilex in Mediterranean shrubland is explained by both direct and indirect interactions mediated by herbs." Journal of Ecology 98(3): 687696.

D'Antonio, C. and L. A. Meyerson (2002). "Exotic Plant Species as Problems and Solutions in Ecological Restoration: A Synthesis." Restoration Ecology 10(4): 703-713.

Didham, R. K., J. M. Tylianakis, et al. (2007). "Interactive effects of habitat modification and species invasion on native species decline." Trends in Ecology \& Evolution 22(9): 489-496.

Donlan, C. J., J. Berger, et al. (2006). "Pleistocene Rewilding: An Optimistic Agenda for Twenty-First Century Conservation." The American Naturalist 168(5): 660-681.

Ehrenfeld, J. G. (2003). "Effects of Exotic Plant Invasions on Soil Nutrient Cycling Processes." Ecosystems 6(6): 503-523.

Ewel, J. J. and F. E. Putz (2004). "A place for alien species in ecosystem restoration." Frontiers in Ecology and the Environment 2(7): 354-360.

Fischer, L. K., M. Von Der Lippe, et al. (2009). "Tree invasion in managed tropical forests facilitates endemic species." Journal of Biogeography 36(12): 2251-2263.

Fowler, N. (1986). "The Role of Competition in Plant Communities in Arid and Semiarid Regions." Annual Review of Ecology and Systematics 17: 89-110.

Ghazoul, J. (2006). "Floral diversity and the facilitation of pollination." Journal of Ecology 94(2): 295304.

Gómez-Aparicio, L., J. M. Gómez, et al. (2005). "Canopy vs. soil effects of shrubs facilitating tree seedlings in Mediterranean montane ecosystems." Journal of Vegetation Science 16(2): 191-198.

Gomez-Aparicio, L., R. Zamora, et al. (2004). "Applying plant facilitation to forest restoration: A meta-analysis of the use of shrubs as nurse plants." Ecological Applications 14(4): 1128-1138.

Grace, J. B. (1991). "A Clarification of the Debate Between Grime and Tilman." Functional Ecology 5(5): 583-587.

Grace, J. B. (1993). "The effects of habitat productivity on competition intensity." Trends in Ecology \& Evolution 8(7): 229-230.

Graham, B. F. and F. H. Bormann (1966). "Natural Root Grafts." Botanical Review 32(3): 255-292.

Griffiths, C. J. and S. Harris (2010). "Prevention of Secondary Extinctions through Taxon Substitution." Conservation Biology 24(3): 645-646.

Griffiths, C. J., C. G. Jones, et al. (2010). "The Use of Extant Non-Indigenous Tortoises as a Restoration Tool to Replace Extinct Ecosystem Engineers." Restoration Ecology 18(1): 1-7.

Grime, J. P. (1977). "Evidence for the Existence of Three Primary Strategies in Plants and Its Relevance to Ecological and Evolutionary Theory." The American Naturalist 111(982): 1169-1194. 
Hacker, S. D. and M. D. Bertness (1999). "Experimental evidence for factors maintaining plant species diversity in a New England salt marsh." Ecology 80(6): 2064-2073.

Hansen, D. M. (2010). "On the use of taxon substitutes in rewilding projects in islands." Islands and Evolution 19: 111-146.

He, X. H., C. Critchley, et al. (2005). "Nodulated N-2-fixing Casuarina cunninghamiana is the sink for net $\mathrm{N}$ transfer from non- $\mathrm{N}_{2}$ fixing Eucalyptus maculata via an ectomycorrhizal fungus Pisolithus $\mathrm{sp}$ using (NH4+)-N-15 or (NO3-)-N-15 supplied as ammonium nitrate." New Phytologist 167(3): 897-912.

Hegland, S. J., J. A. Grytnes, et al. (2009). "The relative importance of positive and negative interactions for pollinator attraction in a plant community." Ecological Research 24(4): 929-936.

Hershner, C. and K. J. Havens (2008). "Managing invasive aquatic plants in a changing system: Strategic consideration of ecosystem services." Conservation Biology 22(3): 544-550.

Hierro, J. L. and R. M. Callaway (2003). "Allelopathy and exotic plant invasion." Plant and Soil 256(1): 29-39.

Hobbs, R. J., S. Arico, et al. (2006). "Novel ecosystems: theoretical and management aspects of the new ecological world order." Global Ecology and Biogeography 15(1): 1-7.

Holmgren, M. and M. Scheffer (2010). "Strong facilitation in mild environments: the stress gradient hypothesis revisited." Journal of Ecology 98(6): 1269-1275.

Holmgren, M., M. Scheffer, et al. (1997). "The interplay of facilitation and competition in plant communities." Ecology 78(7): 1966-1975.

Holzapfel, C. and B. E. Mahall (1999). "Bidirectional facilitation and interference between shrubs and annuals in the Mojave Desert." Ecology 80(5): 1747-1761.

Howard, T. G. and D. E. Goldberg (2001). "Competitive Response Hierarchies for Germination, Growth, and Survival and Their Influence on Abundance." Ecology 82(4): 979-990.

Hunter, A. F. and L. W. Aarssen (1988). "Plants helping plants." Bioscience 38(1): 34-40.

Hylander, K. and S. Nemomissa (2009). "Complementary Roles of Home Gardens and Exotic Tree Plantations as Alternative Habitats for Plants of the Ethiopian Montane Rainforest." Conservation Biology 23(2): 400-409.

Inderjit, D. A. Wardle, et al. (2011). "The ecosystem and evolutionary contexts of allelopathy." Trends in Ecology \& Evolution 26(12): 655-62.

Kahi, C. G., R. K. Ngugi, et al. (2009). "The canopy effects of Prosopis juliflora (DC) and Acacia tortilis (HAYNE) trees on herbaceous plant species and soil physico-chemical properties in Njemps flats, Kenya." Tropical and Subtropical Agroecosystems 10(3): 441-449.

Keane, R. M. and M. J. Crawley (2002). "Exotic plant invasions and the enemy release hypothesis." Trends in Ecology \& Evolution 17(4): 164-170. 
Kikvidze, Z. and R. Brooker (2010). "Towards a more exact definition of the importance of competition - a reply to Freckleton et al. (2009)." Journal of Ecology 98: 719-724.

King, E. G. (2008). "Facilitative effects of Aloe secundiflora shrubs in degraded semi-arid rangelands in Kenya." Journal of Arid Environments 72(4): 358-369.

Kuusipalo, J., G. Ådjers, et al. (1995). "Restoration of natural vegetation in degraded Imperata cylindrica grassland: understorey development in forest plantations." Journal of Vegetation Science 6(2): 205-210.

Lamb, E. G. and J. F. Cahill, Jr. (2008). "When competition does not matter: Grassland diversity and community composition." American Naturalist 171(6): 777-787.

Levine, J. M., M. Vilà , et al. (2003). "Mechanisms underlying the impacts of exotic plant invasions." Proceedings of the Royal Society of London. Series B: Biological Sciences 270(1517): 775-781.

Levine, S. H. (1976). "Competitive Interactions in Ecosystems." The American Naturalist 110(976): 903-910.

Lichter, J. (2000). "Colonization constraints during primary succession on coastal Lake Michigan sand dunes." Journal of Ecology 88(5): 825-839.

Maestre, F. T., S. Bautista, et al. (2003). "Positive, negative, and net effects in grass-shrub interactions in mediterranean semiarid grasslands." Ecology 84(12): 3186-3197.

Mayfield, M. M. and J. M. Levine (2010). "Opposing effects of competitive exclusion on the phylogenetic structure of communities." Ecology Letters 13(9): 1085-1093.

McAuliffe, J. R. (1984). "Sahuaro-nurse tree associations in the Sonoran Desert: competitive effects of sahuaros." Oecologia 64(3): 319-321.

McQueen, J., W. Tozer, et al. (2006). Consequences of Alien $\mathrm{N}_{2}$-Fixers on Vegetation Succession in New Zealand. Biological Invasions in New Zealand. R. B. Allen and W. G. Lee, Springer Berlin Heidelberg. 186: 295-306.

Michalet, R., R. W. Brooker, et al. (2006). "Do biotic interactions shape both sides of the humpedback model of species richness in plant communities?" Ecology Letters 9(7): 767-773.

Miriti, M. N. (2006). "Ontogenetic shift from facilitation to competition in a desert shrub." Journal of Ecology 94(5): 973-979.

Noble, I. R., Ed. (1989). Attributes of invaders and the invading process: terrestrial and vascular plants. Biological invasions a global perspective, John Wiley \& Sons, Ltd (Retrieved in October 2011 from http://www.icsu-scope.org/downloadpubs/scope37/scope37-ch12.pdf).

Norton, D. A. (2009). "Species Invasions and the Limits to Restoration: Learning from the New Zealand Experience." Science 325(5940): 569-571. 
Olofsson, J., M. Jon, et al. (1999). "On the Balance between Positive and Negative Plant Interactions in Harsh Environments." Oikos 86(3): 539-543.

Padilla, F. M. and F. I. Pugnaire (2006). "The role of nurse plants in the restoration of degraded environments." Frontiers in Ecology and the Environment 4(4): 196-202.

Parrotta, J. A. (1992). "The role of plantation forests in rehabilitating degraded tropical ecosystems." Agriculture, Ecosystems \& Environment 41(2): 115-133.

Pimentel, D., L. Lach, et al. (2000). "Environmental and Economic Costs of Nonindigenous Species in the United States." Bioscience 50(1): 53-65.

Pimentel, D., R. Zuniga, et al. (2005). "Update on the environmental and economic costs associated with alien-invasive species in the United States." Ecological Economics 52(3): 273-288.

Prieto, I., K. Martínez-Tillería, et al. (2010). "Hydraulic lift through transpiration suppression in shrubs from two arid ecosystems: patterns and control mechanisms." Oecologia 163(4): 855-865.

Pugnaire, F. I. and M. T. Luque (2001). "Changes in plant interactions along a gradient of environmental stress." Oikos 93(1): 42-49.

Quinos, P. M., P. Insausti, et al. (1998). "Facilitative effect of Lotus tenuis on Paspalum dilatatum in a lowland grassland of Argentina." Oecologia 114(3): 427-431.

Richards, J. H. and M. M. Caldwell (1987). "Hydraulic lift - substantial nocturnal water transport between soil layers by Artemisia tridentata roots." Oecologia 73(4): 486-489.

Rodriguez, L. F. (2006). "Can invasive species facilitate native species? Evidence of how, when, and why these impacts occur." Biological Invasions 8(4): 927-939.

Schwinning, S. and J. Weiner (1998). "Mechanisms determining the degree of size asymmetry in competition among plants." Oecologia 113(4): 447-455.

Selosse, M. A., F. Richard, et al. (2006). "Mycorrhizal networks: des liaisons dangereuses?" Trends in Ecology \& Evolution 21(11): 621-628.

Siachoono, S. M. (2010). "Land reclamation efforts in Haller Park, Mombasa." International Journal of Biodiversity and Conservation 2(2): 19-25.

Smit, C., J. den Ouden, et al. (2008). "Facilitation of Quercus ilex recruitment by shrubs in Mediterranean open woodlands." Journal of Vegetation Science 19(2): 193-200.

Spence, L. A., J. V. Ross, et al. (2010). "Disturbance affects short-term facilitation, but not long-term saturation, of exotic plant invasion in New Zealand forest." Proceedings of the Royal Society B: Biological Sciences.

Sullivan, J. J., P. A. Williams, et al. (2007). "Secondary forest succession differs through naturalised gorse and native kanuka near Wellington and Nelson." New Zealand Journal of Ecology 31(1): 22-38. 
Tecco, P. A., D. E. Gurvich, et al. (2006). "Positive interaction between invasive plants: The influence of Pyracantha angustifolia on the recruitment of native and exotic woody species." Austral Ecology 31(3): 293-300.

Thompson, K. (1987). "The Resource Ratio Hypothesis and the Meaning of Competition." Functional Ecology 1(4): 297-303.

Thompson, K. and J. P. Grime (1988). "Competition Reconsidered-A Reply to Tilman." Functional Ecology 2(1): 114-116.

Tilman, D. (1980). "Resources: A Graphical-Mechanistic Approach to Competition and Predation." The American Naturalist 116(3): 362-393.

Tilman, D. (1987). "On the Meaning of Competition and the Mechanisms of Competitive Superiority." Functional Ecology 1(4): 304-315.

Tilman, D. (1988). Plant strategies and the dynamics and structure of plant communities. Princeton, N.J., Princeton University Press.

Tilman, D. (1989). "Competition, Nutrient Reduction and the Competitive Neighbourhood of a Bunchgrass." Functional Ecology 3(2): 215-219.

Van Aarde, R. J., S. M. Ferreira, et al. (1996). "An evaluation of habitat rehabilitation on coastal dune forests in northern KwaZulu-Natal, South Africa." Restoration Ecology 4(4): 334-345.

Villarreal-Barajas, T. and C. Martorell (2009). "Species-specific disturbance tolerance, competition and positive interactions along an anthropogenic disturbance gradient." Journal of Vegetation Science 20(6): 1027-1040.

Vitousek, P. M. (1990). "Biological Invasions and Ecosystem Processes: Towards an Integration of Population Biology and Ecosystem Studies." Oikos 57(1): 7-13.

Welden, C. W. and W. L. Slauson (1986). "The Intensity of Competition Versus its Importance - An Overlooked Distinction and Some Implications." Quarterly Review of Biology 61(1): 23-44.

Woods, F. W. and K. Brock (1964). "Interspecific transfer of CA-45 + P-32 by root systems." Ecology 45(4): 886-889.

Zavaleta, E. S., R. J. Hobbs, et al. (2001). "Viewing invasive species removal in a whole-ecosystem context." Trends in Ecology \& Evolution 16(8): 454-459. 


\section{Chapter two}

\section{Mixed effects of invasive Carpobrotus edulis (Aizoaceae) on Spinifex sericeus and its implications for sand dune restoration}

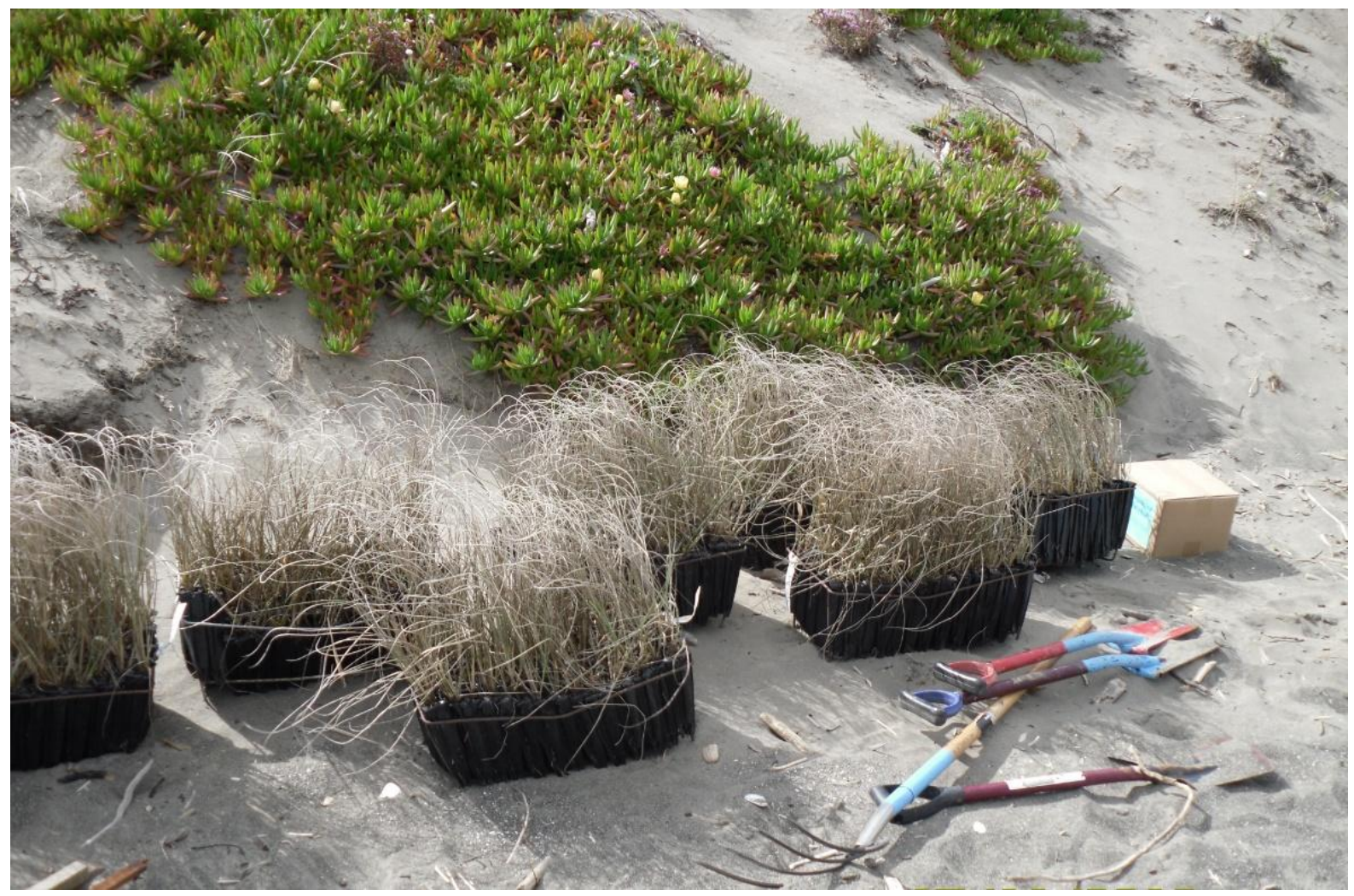

Figure 2:1: Seedlings of Spinifex sericeus (foreground) ready to be transplanted into plots where iceplant (C. edulis) was intact, removed or never existed. Photo taken by author on $15^{\text {th }}$ November 2010 at Queen Elizabeth Park. 


\subsection{Abstract}

New Zealand has experienced catastrophic losses to its native biodiversity as a consequence of the impacts of exotic species. While the outcome of species invasions depends on interactions between exotic and resident native species, it has been noted that most studies of biological invasions have focused solely on the direct negative impacts of non-indigenous species on native biota. Yet negative and positive interactions between neighbouring plants operate simultaneously. A research project involving neighbour removal was initiated on coastal sand dunes with the main aim of studying the effects of Carpobrotus edulis on establishment of Spinifex sericeus at the foredune region. Carpobrotus edulis protected Spinifex against storm erosion, sand-blasting and salt sprays while simultaneously suppressing its leaf production. Suppression of Spinifex leaf production was more pronounced at top of the dune where stress elements are presumably more benign. There was no evidence of allelopathic suppression of Sinifex by C. edulis.

\subsection{Introduction}

\subsubsection{Invasive species as threats to native biodiversity}

Invasion of natural communities by exotic species is often cited as the greatest threat to biodiversity, second only to habitat destruction (Vitousek, D'Antonio et al. 1997; Kolar and Lodge 2001; Shaw 2003). Increased international human travel and trade have led to widespread dispersal of plant and animal species (Mack, Simberloff et al. 2000) such that exotic plants have now colonized and changed many ecosystem properties throughout the world (Vitousek 1990). Invasive species result in global biotic homogenisation and loss of biodiversity through replacement of native, locally distributed species with widespread, non-native species (Olden, Poff et al. 2004). Globally, about $10 \%$ of introduced species are reported to have become naturalised, while those that have become invasive constitute around 1\% (Williams and West 2000; Richardson and Pyšek 2006). Although the proportion of exotic naturalised plant species that successfully become invasive seems negligible, they 
can cause substantial modifications to indigenous biodiversity and ecosystem functions (Williams and West 2000). Invasive species simplify communities, causing them to suffer a loss of functional diversity, potentially reducing community stability and resistance to environmental change (Olden, Poff et al. 2004). As many as $42 \%$ of endangered species are said to be on the brink of extinction, primarily due to invasive species (Pimentel, Zuniga et al. 2005) often stemming from strong competition (Wilcove, Rothstein et al. 1998). Such competition may further be underlain by a high propagule pressure (Lockwood, Cassey et al. 2005), contributing to the success of the invasive species to the detriment of native ones.

New Zealand has experienced catastrophic losses to its native biodiversity as a consequence of the impacts of exotic species (Jay, Morad et al. 2003) that have contributed to a decline of $59 \%$ of New Zealand's threatened native plant species (Dopson, de Lange et al. 1999). Over 25,000 species of plants have been introduced deliberately for agriculture, horticulture, forestry and as garden ornamentals, as well as accidentally (Taylor and Smith 1997). Many of these introduced species have gone on to establish populations in the wild so pervasively that naturalised exotic vascular plants now outnumber native New Zealand species (Taylor and Smith 1997; Williams and West 2000).

\subsubsection{Threats to New Zealand coastal sand dunes}

One distinctive feature of New Zealand's natural landscape that is now classified as a highly threatened ecosystem, partly by exotic species, is its coastal sand dunes (Sawyer 2004; Hilton 2006). The natural character of the coastal dunes has been lost from over $70 \%$ of their extent between the 1950s and 1990s (Hilton 2006) due to a combination of factors such as coastal development, farming, and forestry in addition to invasion by introduced plant and animal species (Hilton, Macauley et al. 2000). Comprehensive reviews of these threats have been carried out in recent years by researchers (e.g. Gadgil and Ede 1998; Hilton 2006). Frequent disturbance regimes by wave and wind erosion that create open niches make coastal sand dunes highly susceptible to invasions by exotic plants. The fact that a large population of New Zealanders live within $10 \mathrm{~km}$ of the coastline (Spence, Bergin 
et al. 2007) may increase propagule pressure of exotic plants, some of which have been successful garden escapees. Sand dune erosion has been further exacerbated by inappropriate use of four-wheel drive vehicles and trampling by humans (Milne and Sawyer 2002). Yet, they are important ecosystems that are a popular place for recreation (Spence, Bergin et al. 2007). The fluid form of the sand dunes and their ability to regenerate provides excellent natural buffering of the coastline against storm actions (Carter 1991; Dahm, Jenks et al. 2005) - a function which will become increasingly important in the face of the expected rise in sea levels and greater frequency of storm events (NIWA 2008). Native sand dune plant species like pingao (Ficinia spiralis) are of cultural significance to the Māori where they were used for weaving. Together with other foredune species such as Spinifex sericeus (Kowhangatara), they provide habitat for many rare and specialised plant and animal species like the endemic katipō (Latrodectus katipō) (Patrick 2002). Despite their conservation value, coastal dunes are constantly under threat from human constructions and leisure activities, and from biological invasions by exotic plants (Maltez-Mouro, Maestre et al. 2010).

\subsubsection{Sand dune restoration efforts in New Zealand}

In some early restoration projects in New Zealand, marram grass (Ammophila arenaria), the South African iceplant Carpobrotus edulis, and Carpobrotus chilensis were used to stabilise bare sand, because of their rapid growth, and tolerance to exposed conditions and sand burial. These exotic species have displaced native sand binding plants in the majority of sand dune areas (Partridge 1995 ), significantly altering the natural form and function of the dunes (Hilton, Macauley et al. 2000). Carpobrotus edulis, which is the focus of the present study, has been reported to be a problem species in areas outside its native range, including in California (Albert, D'Antonio et al. 1997; Vilà, Weber et al. 1998) and the Mediterranean Basin (Suehs, Affre et al. 2004; Vilà, Siamantziouras et al. 2008), displaying properties typical of an invader. Carpobrotus edulis often forms dense impenetrable mats which seem barely affected by herbivory or competition from native plants (Maltez-Mouro, Maestre et al. 2010). It causes smothering, thus suppressing growth 
and regeneration of native flora (Bartomeus and Vilà 2009; Maltez-Mouro, Maestre et al. 2010). It is said to compete aggressively with native plant species for space and resources (D'Antonio and Mahall 1991; D'Antonio 1993). Because of its invasiveness and presumed threats to native flora, Carpobrotus edulis is considered an unwanted organism in New Zealand (Biosecurity New Zealand 2008).

Many New Zealand coastal community groups are taking action to restore their local patches of sand dunes; typically by removing the exotic species and planting foredune sandbinding grasses and sedges (e.g. the native Spinifex and pingaō, Ficinia spiralis). Yet these exotic plants may have some facilitative effect on the native species. Although Carpobrotus edulis is said to displace native foredune flora, few, if any studies, have documented how native pioneer plants that are well adapted to frequent disturbance events have been displaced by this adventive species. The displacement notion may have been inferred from the fact that $C$. edulis stands are simple, nearly homogenous communities with very few cooccurring native plants, which may not necessarily be a product of displacement but a colonization of an empty niche by the adventive species in the absence of propagules of native pioneer species. Carpobrotus edulis may as well have a role as a useful stabiliser, creating appropriate micro-conditions suitable for establishment of native species. However, there is little quantitative information on how it interacts with other fore-dune species.

\subsection{Purpose of the study}

The outcome of species invasions depends on interactions between exotic and resident native species (Diez, Sullivan et al. 2008). It has been noted that most studies of biological invasions have focused solely on the direct negative impacts of non-indigenous species on native biota (Traveset, Brundu et al. 2008). However, negative and positive plant interactions between neighbouring plants operate simultaneously (Bertness and Callaway 1994; Brooker and Callaghan 1998) and the net outcome is determined by the relative strength of each process (Michalet, Brooker et al. 2006; Villarreal-Barajas and Martorell 
2009). Therefore, incorporating facilitative interactions of invasive species into ecological research is important to help determine the relative contribution of competition and facilitation to changes in ecosystem processes and biodiversity (Traveset, Brundu et al. 2008). On one hand, some ecological traits of invasive exotic species such as nitrogen fixation, fast growth, and resistance to stress, contribute to their ability to colonize new areas (Noble 1989). On the other, these traits can be exploited to foster ecological restoration, since alteration of ecological conditions and resource flow may promote the establishment of other species (Ehrenfeld 2003; Levine, Vilà et al. 2003; Ewel and Putz 2004).

I initiated a research project at Queen Elizabeth Park along Kapiti Coast, New Zealand where erosion of the dunes by the high seas during occasional storms has been of increasing concern to the management. Natural dune repair after storm events depends on presence of appropriate sand-trapping vegetation on the dune face (Bergin, Miller et al. 2007). While exotic species such as $C$. edulis have been used to stabilise dunes, it is deemed ineffective in repairing storm-damaged dunes between storm episodes (Bergin, Miller et al. 2007), probably because its prostrate growth form may not help trap as much sand as upright plants. To enhance self repair by the dunes, the management of Queen Elizabeth Park have initiated some restoration projects in gentler sections by removing $C$. edulis and planting Spinifex sericeus, a native stoloniferous sand-binding grass, in addition to pingaō (formerly Desmoschoenus spiralis) - now renamed Ficinia spiralis (Muasya and de Lange 2010). In line with the restoration goals of the management, the research project was initiated with the main aim of studying the effects of Carpobrotus edulis on establishment of Spinifex sericeus at the foredune region. The aims of this experiment were to determine (i) whether $C$. edulis has positive facilitative effects or negative competitive effects on Spinifex; (ii) whether the effects differ along the gradient of the dune face, (iii) if $C$. edulis has any allelopathic legacy that hampers establishment of Spinifex. 


\subsection{MATERIALS AND METHODS}

\subsubsection{Study site}

Queen Elizabeth Park is located 40km North of Wellington, New Zealand between Paekakariki and Raumati South $\left(40^{\circ} 56^{\prime} \mathrm{S}, 174^{\circ} 57^{\prime} \mathrm{E}\right.$ and $\left.40^{\circ} 58^{\prime} \mathrm{S}, 174^{\circ} 59^{\prime} \mathrm{E}\right)$. The terrain consists of undulating dunes characterised by steep seaward slopes exposed to prevailing westerly winds. There are two small streams that run into the sea at this section supplying some sand (Fig. 2.2) but the main sand supply seems to be from blowouts at the dune face that is blown inland at intervals by the westerly winds. The highest points of the dunes are elevated roughly between $4-10 \mathrm{~m}$ above sea level with slope of the eroding foredune face ranging from $32-52^{\circ}$. The dunes of the park were recognised as "Recommended Area for Protection" in the 1992 Protected Natural Areas Programme Survey of Foxton Ecological District (Ravine 1992). The dune face is dominated by South African iceplant, Carpobrotus edulis interspersed with bare spaces. Other plants present include marram (Ammophila arenaria), spinifex (Spinifex sericeus), shore bindweed (Calystegia soldanella), and purple groundsel (Senecio elegans). 


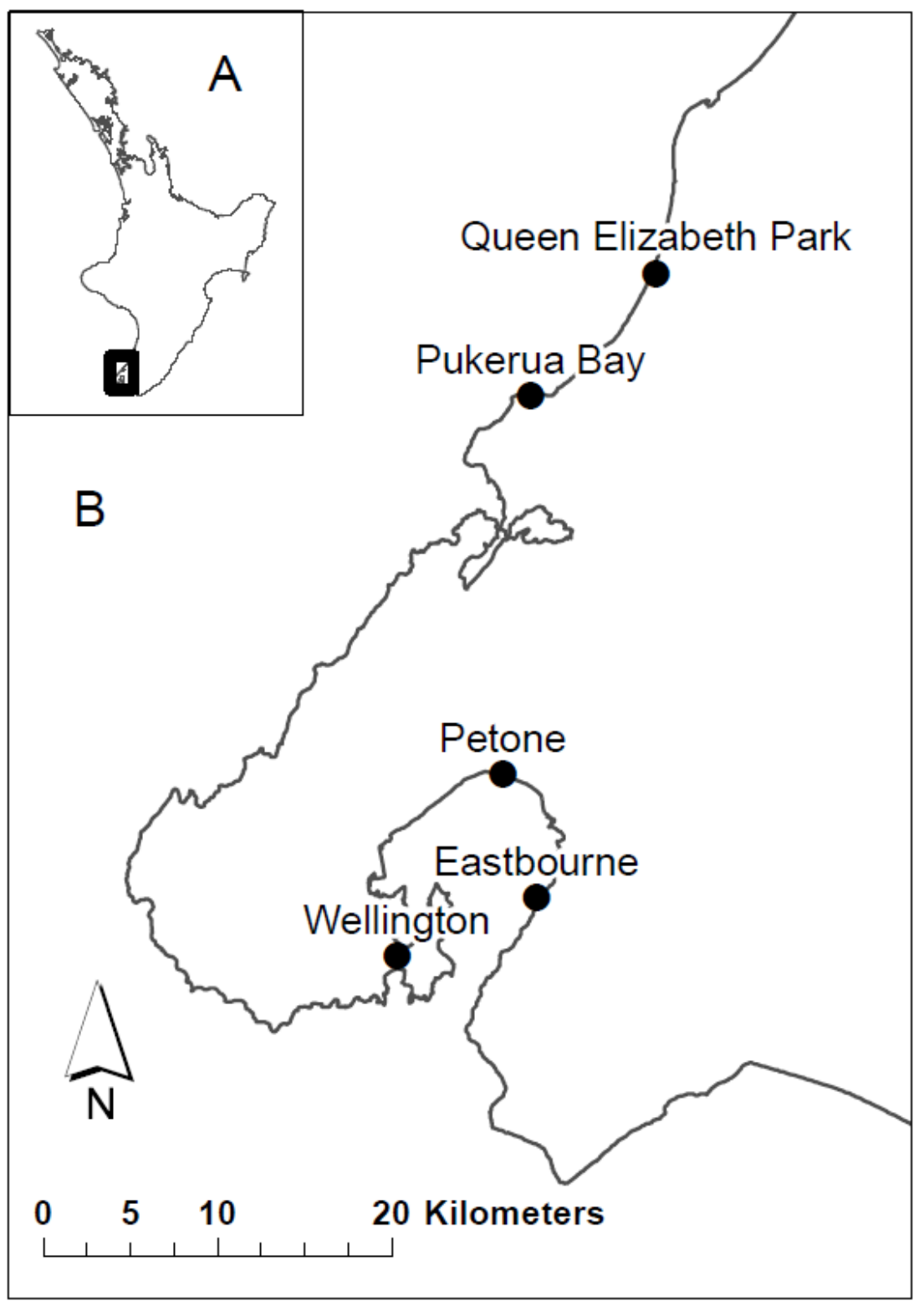

Fig. 2.2: Map of North Island, New Zealand (A) and Wellington region (B) showing the location of Queen Elizabeth Park. 


\subsubsection{Study species}

\subsubsection{Spinifex (Spinifex sericeus)}

Spinifex is a short stoloniferous, dioecioes, perennial grass that is commonly found on the sand dunes along the coasts of Australia, New Zealand and New Caledonia. It is up to $40 \mathrm{~cm}$ tall (Bergin, Miller et al. 2007) with strong creeping runners that produce roots and numerous upright leafy tillers at the nodes. The leaf blades are in-rolled, measuring 30-40 $\mathrm{cm}$ long and 7-8 $\mathrm{mm}$ wide when flattened (DERM 2011). The leaves are silvery on the upper surface, with a dense covering of short silky hairs on the underside. It is regarded as the most important pioneer sand-stabilising native plant in New Zealand (Connor 1984). It is tolerant of sand burial and salt spray (Maze and Whalley 1992). The upright leafy shoots reduce wind velocity, resulting in sand accretion. It grows well on all parts of the frontal dune and predominates particularly on the dynamic incipient foredunes, though it often appears to be less vigorous in the more stabilized semi-established and established dunes (Maze and Whalley 1992). The growth habit and ability of S. sericeus to grow vigorously in the most species-poor part of the foredune make it an ideal foredune stabilizer. For this reason, it is the main species used in planting programs for revegetation of foredunes around New Zealand.

\subsubsection{South African ice plant (Carpobrotus edulis)}

The South African iceplant is a succulent stoloniferous prostrate perennial that roots extensively at its nodes. It has its origin in the Karoo of South Africa but has now spread to the Mediterranean region, Australia, New Zealand and California (D'Antonio and Mahall 1991; Draper, Rossello-Graell et al. 2003; Suehs, Charpentier et al. 2006). It is a mat-forming species and seems to exclude other species by smothering them. Studies in the Mediterranean Basin and California have suggested that it alters soil chemistry to the detriment of native flora (Vilà, Tessier et al. 2006; Traveset, Brundu et al. 2008; Conser and Connor 2009). Carpobrotus edulis is a clonal species where growth is characterized by 
vegetative production of numerous physically interconnected ramets that could quickly expand horizontally to efficiently colonize the surrounding area (Roiloa, RodriguezEcheverria et al. 2010). The ramets are physiologically integrated such that essential resources are translocated from established to developing ones (Noble and Marshall 1983; Price and Marshall 1999) and from those growing in favourable microhabitats to the ones growing under more adverse conditions (Hartnett and Bazzaz 1983; Shumway 1995; Stuefer, DeKroon et al. 1996; Roiloa and Retuerto 2006). Clones can therefore act as cooperative systems (Stuefer, DeKroon et al. 1996), buffering the negative effects of microhabitats, colonizing patches that otherwise would be unexploitable by independent plants (Salzman and Parker 1985; Yu, Dong et al. 2004; Roiloa and Retuerto 2006).

Carpobrotus edulis employs flexible sexual and asexual reproductive strategies (Suehs, Affre et al. 2004) to increase its invasion success (Baker 1974). It is tolerant to salt sprays, sand burial and water stress, making it an ideal foredune pioneer species. The species also seems to form a simplistic community that tends towards monoculture. Its status in New Zealand is that of an unwanted organism, probably because of its weed status in the aforementioned regions (Sheppard, Shaw et al. 2006; Andreu, Vilà et al. 2009) and the fact that it hybridises with the native iceplant, Disphyma australe, genetically modifying native flora (Chinnock 1971). Carpobrotus edulis was introduced as an ornamental plant which escaped from cultivation and was later used for sand dune stabilisation. The species is said to have naturalised in New Zealand around 1883 (Webb, Sykes et al. 1988; D'Antonio and Mahall 1991).

\subsubsection{Experimental set-up}

\subsubsection{Experiment 1 (manual removal)}

To investigate the effects of Carpobrotus edulis on restoration plantings of Spinifex sericeus, a manipulative field experiment was conducted. Study plots were assigned to three treatments, each replicated seven times ( 21 plots in total). The treatments involved planting Spinifex: (i) into stands of $C$. edulis (=Iceplant plots), (ii) into areas where $C$. edulis has been 
removed manually (=Removal plots), and (iii) in open spaces where there was no preexisting vegetation (=Bare plots). Twelve seedlings of Spinifex sericeus (obtained from Taupo Native Nursery in root trainer sleeves measuring $5 \mathrm{~cm} \times 5 \mathrm{~cm}$ and $20 \mathrm{~cm}$ in depth) were planted per plot. Six seedlings were planted at the bottom of the dune face and six near the top (= two subplots measuring $2 \mathrm{~m} \times 1.5 \mathrm{~m}$ each). The distance between the subplots at the foot of the foredune and the ones towards the back varied between $2-4 \mathrm{~m}$ according to the size of dune face. The seedlings were planted between $15^{\text {th }}$ and $17^{\text {th }}$ November 2010 , spaced $40-50 \mathrm{~cm}$ apart within a plot, since wider spacing is thought to increase vulnerability to wind erosion (Bergin, Miller et al. 2007). Seedlings were planted at a depth of at least 20 $\mathrm{cm}$ - equivalent to the depth at which the seedlings were in the root trainer sleeves. Two pellets of a slow release compound fertilizer $\left(\right.$ Agpro $\left.^{\text {TM }} ; 20: 4: 2 ; \mathrm{N}: \mathrm{P}: \mathrm{K}\right)$ were applied in each planting hole before transplanting the seedlings. Since the dunes varied in shape and elevation above the sea level, the seedlings were not all planted at the same heights. Due to warm weather the plots were sprayed with $500 \mathrm{I}$ of water from an industrial sprayer on one occasion at the end of November.

During the uprooting of the iceplant to create the plots for removal treatment, other plants such as clovers (Trifolium spp and Medicago spp), shore bindweed (Calystegia soldanella) and grasses (Holcus lanatus and Lagurus ovatus) that were within the iceplant crop were not targeted for removal but some still got removed due to soil disturbance. No specific effort was made to clear all the underground structures of $C$. edulis and as a result, some below ground tissues of the iceplant still remained. This would help in determining whether underground structures can regenerate to contribute to recolonization of the plots by the iceplant.

Survival of the Spinifex seedlings was assessed periodically at an interval of about four weeks. The location of each plant was mapped, and once survival rate seemed to have stabilised, a cumulative number of fully formed leaves per plant was recorded beginning $21^{\text {st }}$ March 2011 at monthly intervals, as a proxy for plant performance. Young leaves that were still rolled and not fully open, and dry ones, were excluded. Survival and leaf production data were not collected in the month of September 2011. 


\subsubsection{Experiment 2 (herbicide treatments)}

Two additional types of removal plots were created on $10^{\text {th }}$ May 2011 by spraying out iceplant using glyphosate (Agpro Glyphosate 360 at 10ml/Litre of water). During manual removal of live plants in November 2010 for experiment 1, transportation of the plant material to a dump site about $2 \mathrm{~km}$ away proved labour intensive. This time the plants were chemically killed before manual removal to save on the effort required for disposal of the vegetative material and to minimize chances of exacerbating invasion. Dead debris of iceplant was left intact in three plots as mulching material, creating a treatment referred to as "dead debris intact". It was hoped that the plant debris left intact would moderate sand blasting and soil moisture loss, increasing survivorship and plant performance. On $25^{\text {th }}$ of May 2011, dead debris of iceplant was removed manually from three of the plots to create the alternative treatment called "dead debris removed". 16 Spinifex seedlings were planted per plot, eight at the top and eight at the bottom section of each plot (two subplots) on $1^{\text {st }}$ of June 2011, giving a total of 96 seedlings. However, the distance between the top and bottom band of the seedlings was $1-2 m$, due to size of the dune face. Planting techniques were the same as used in Experiment 1 except that planting depth was approximately $30 \mathrm{~cm}$ (i.e. about $10 \mathrm{~cm}$ above the level of root trainer sleeves). Seedlings were chosen and assigned to treatments at random. The initial number of leaves per seedling was counted and it was subsequently determined that they were not significant different by treatment or location (all $P>0.2$ ). Plant survival and cumulative number of leaves per plant were recorded periodically at 4-5 week intervals. Plant survival and leaf production data were not collected during the month of September, 2011.

\subsubsection{Physical properties of dunes with and without iceplant}

The slopes of the experimental plots were determined using a spirit level with a dial on a wooden plank $3 \mathrm{~m}$ long to even out small depressions along the slope.

Soil samples were collected in October 2011 from under the canopy of iceplant and from bare sites both at the foot and the top of the dunes. Ten samples were collected per 
site, five from the bottom of the dune and five from the top. Sample cores $4 \mathrm{~cm}$ in diameter were obtained to a depth of $5 \mathrm{~cm}$ and analysed gravimetrically for moisture, by combustion at $360{ }^{\circ} \mathrm{C}$ for organic matter content (Salehi, Beni et al. 2011), and by electrical conductivity for salinity .

\subsubsection{Statistical analysis}

Proportional survival of seedlings for each subplot in both experiments was calculated and transformed by applying square-root followed by arcsine to meet assumptions of ANOVA. The transformed survival data were analysed in SPSS (SPSS Inc. 2008). The arcsine transformed survival values were used as the dependent variable in a two-way ANOVA with "treatment" and "location" on the dune as the independent variables. A two-way ANOVA was also calculated for cumulative plant leaves, with log-transformed number of leaves as the dependent variable, and "treatment" and "location" as independent variables. Similarly, the differences in soil moisture, organic matter, electrical conductivity, and gradients of the plots were compared using General Linear Model in SPSS.

\subsection{RESULTS}

\subsubsection{Spinifex seedling Survival}

\subsubsection{Experiment 1}

Survival data for the first experiment was first collected on $15^{\text {th }}$ December 2010 (four weeks after planting), at which point a total of 185 seedlings out of an initial 252 survived (73\% survival). During the first month (December 2010), survival of seedlings was significantly higher for plants at the bottom of the dune face regardless of treatment $\left(F_{1,36}\right.$ $=5.423 ; P=0.026$; Table 2.1; Fig. 2.3), but this did not persist in the subsequent months. An iceplant plot (A4) had lost all the seedlings at its base by January. By February, one plot (C3) from the bare treatment had lost all the seedlings. A bare treatment plot (C4) also had no surviving seedlings at its base by March. Around the same time, B1, a removal plot lost all 
its seedlings at the top of the dune. Survival rate declined gradually to $47 \%$ by March and remained stable through June. However, survival was consistently higher in the removal plots until July (Fig. 2.4).

Table 2.1: ANOVA table showing effect of treatment and location on Spinifex seedling survival for the month of December (one month after planting). Neither treatment nor location (or the interaction of the two factors) had any effect for the months of January through June.

\begin{tabular}{lcccc}
\hline Source & Df & Mean Square & F & Sig. \\
\hline Treatment & 2 & .220 & 1.764 & .186 \\
Location & 1 & .676 & 5.423 & .026 \\
Treatment * Location & 2 & .010 & .078 & .925 \\
Error & 36 & .125 & & \\
& & & &
\end{tabular}

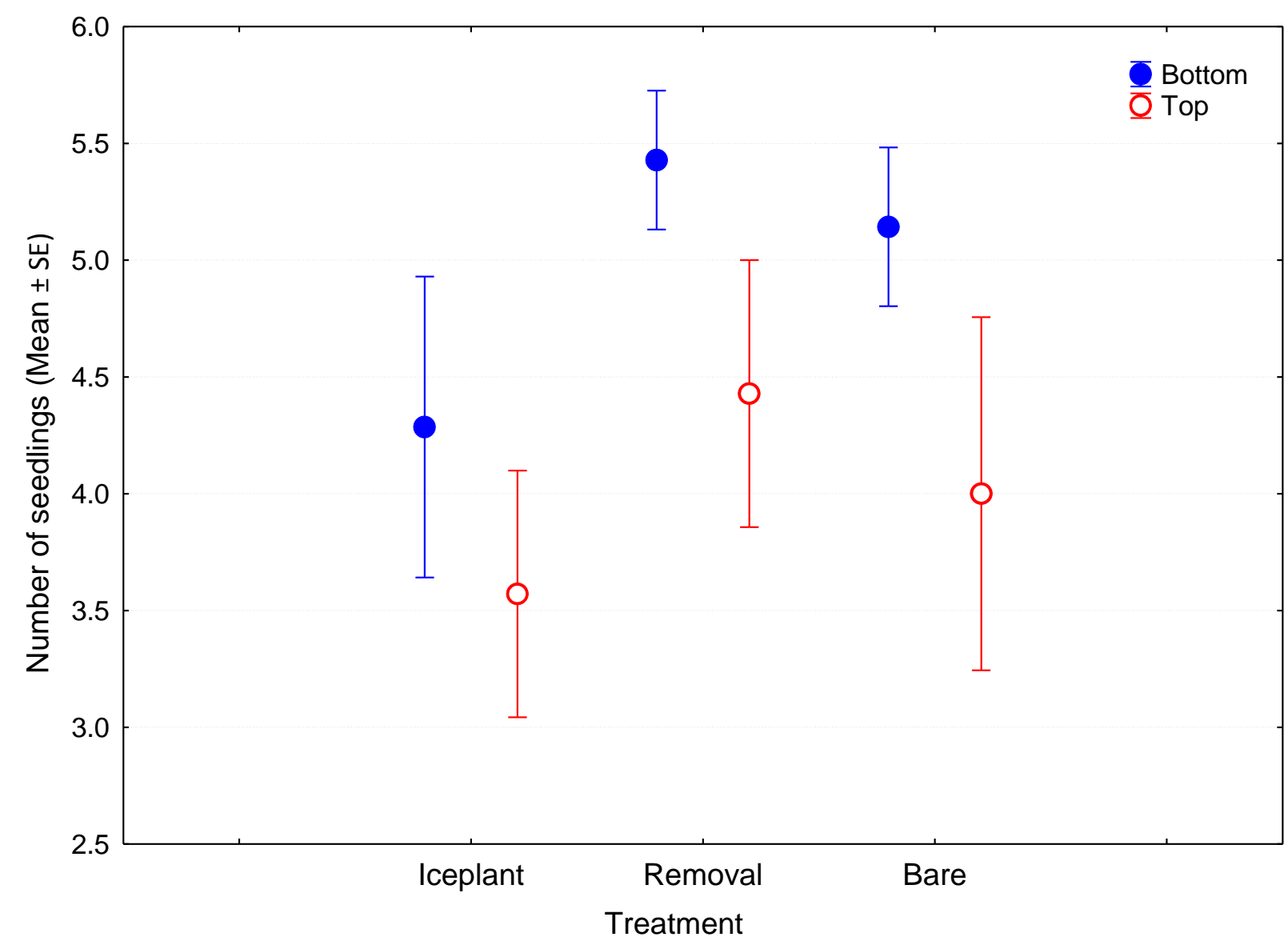

Fig. 2.3: Error plot showing that more Spinifex seedlings survived at the bottom of the dune than at the top in Experiment 1 during the month of December 2010. 


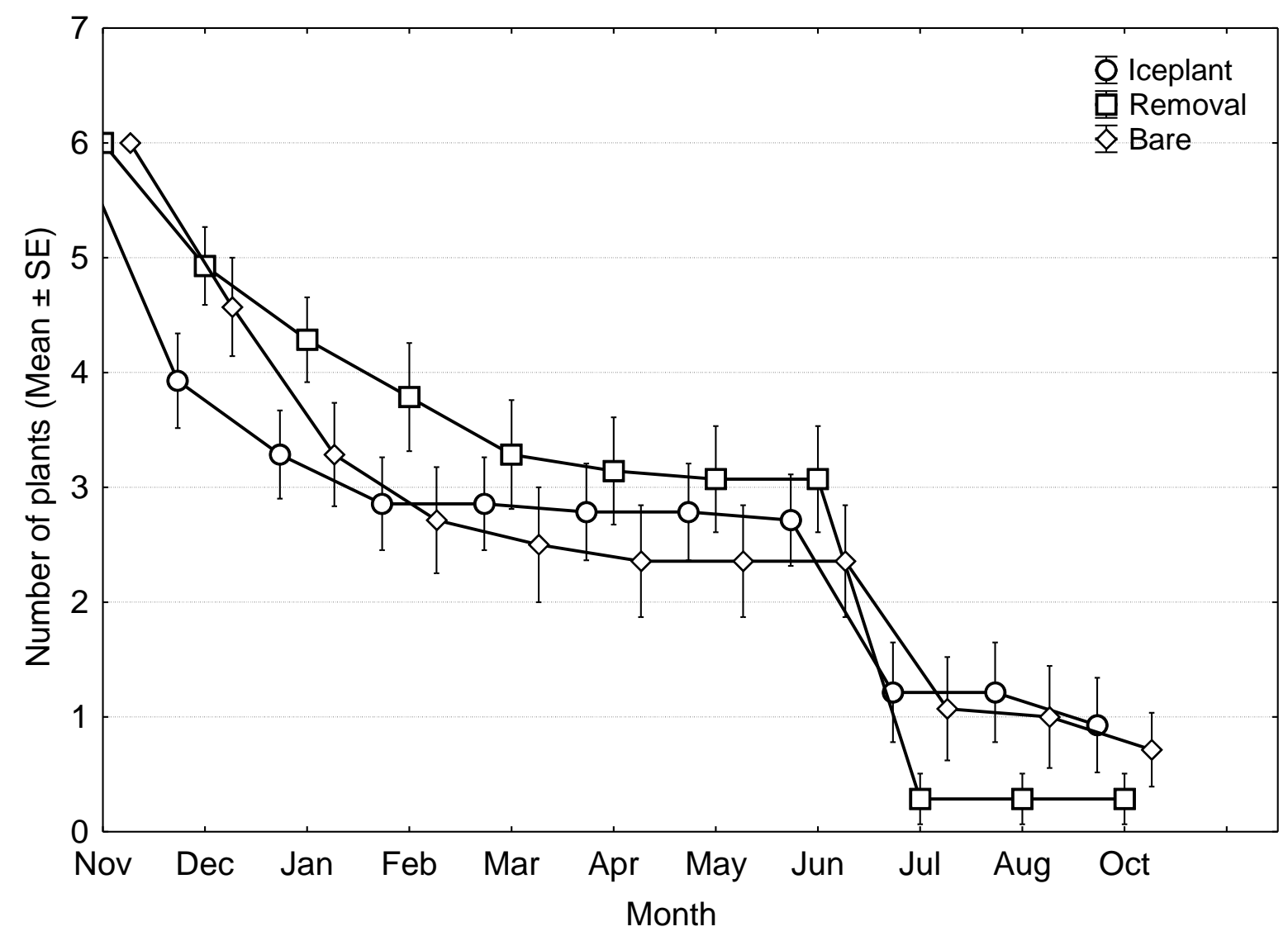

Fig. 2.4: A graph showing that treatment had no significant effect on Spinifex seedling survival except after July (the points are staggered).

There was a storm in July and in total only 36 Spinifex plants of the 114 from the previous month survived (17 in iceplant, 15 in bare treatment and 4 in the removal treatment) representing a mortality of $68.5 \%$ in just a single storm event. Plants worst affected by the storm were those in the removal treatment (Fig. 2.4) and those at the base of the dune (Fig. 2.5). Spinifex plants that survived were moved from the upper parts of the dune to just above the high tide mark.

Treatment did not have any effect on plant survival except in July where plants in the removal plots were worst affected by the storm, though statistically not significant $\left(F_{2}\right.$, $36=3.07 ; P=0.06$; Fig. 2.4). On the other hand, plant location had a highly significant effect on 
survival during the same month $\left(F_{1,36}=22.323 ; P<0.001 ;\right.$ Table 2.2$)$, which is a consequence of storm disturbance rather than the continuous dynamics of environmental conditions at these parts of the dunes. The highly significant effect of plant location persisted in subsequent months (Table 2.2; Fig. 2.5).

Table 2.2: A summary ANOVA table showing effect of treatment and location on Spinifex survival for the months of July 2011 through October 2011. Location had a highly significant effect but treatment and interaction of the two factors did not.

\begin{tabular}{|c|c|c|c|c|c|c|}
\hline & Treatment & & & Location & & \\
\hline Month & $\mathrm{F}$ & $d f$ & Sig. & $F$ & $\mathrm{df}$ & Sig \\
\hline July & 3.070 & 2,36 & .059 & 22.323 & 1,36 & $<.001$ \\
\hline August & 2.955 & 2,36 & .065 & 21.237 & 1,36 & $<.001$ \\
\hline October & 1.286 & 2,36 & .289 & 13.569 & 1,36 & .001 \\
\hline
\end{tabular}




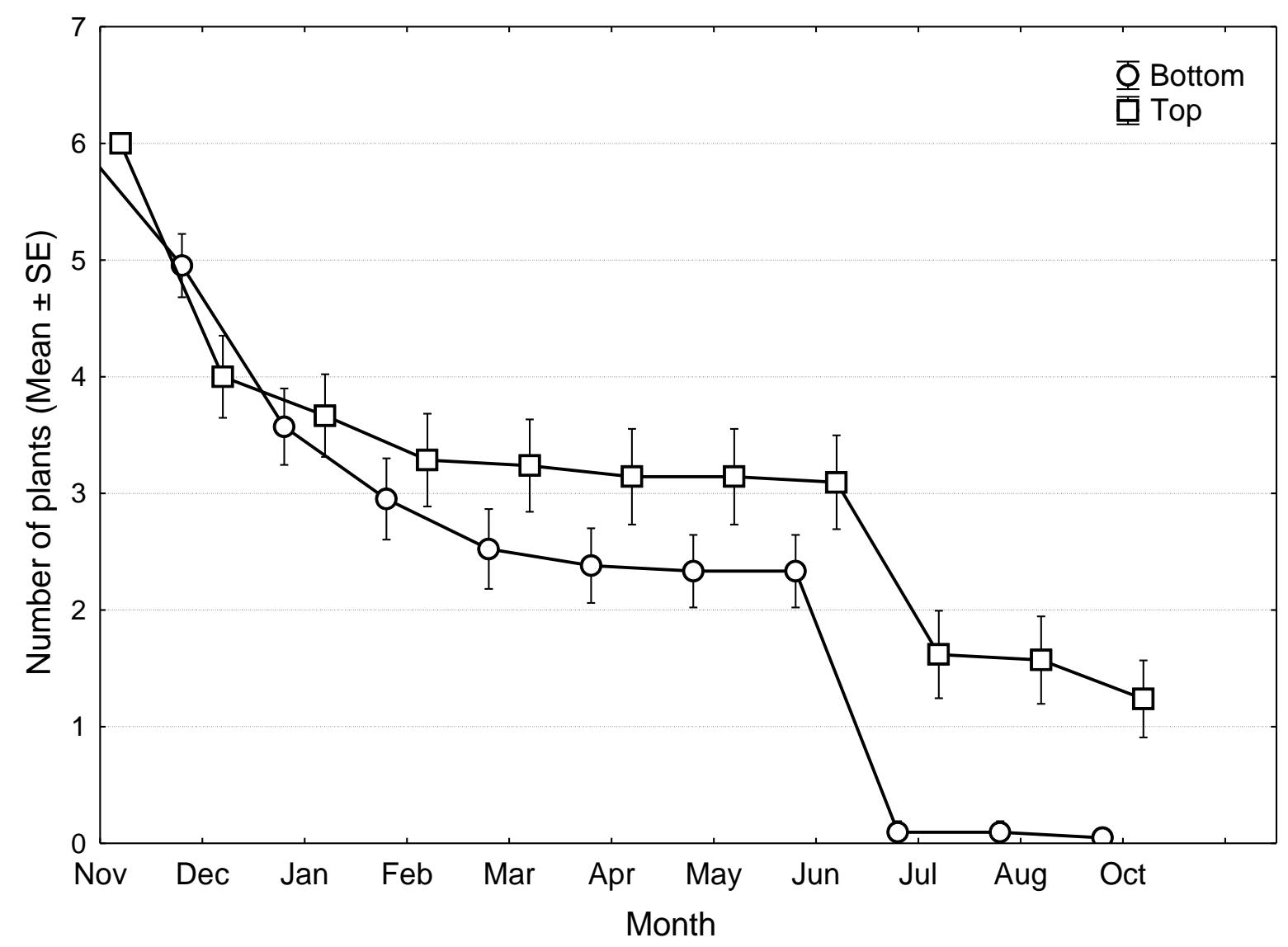

Fig. 2.5: Spinifex survival graph (points are staggered) showing that plant location had significant effect from July 2011 through to October $2011\left(F_{1,36}=22.323 ; P<0.001\right)$

Spread of Carpobrotus edulis into neighbouring removal plots was minimal and no sprouts from buried structures were noted at the removal plots.

\subsubsection{Herbicide treatments}

Survival of seedlings in the modified removal treatment was poor since only $52 \%$ of the seedlings survived to July, just a fifth of which were at the bottom of the dunes. By October, total survivorship for this batch of plants had declined further to $34 \%$. Using dead iceplant debris as mulching material did not have any effect on survival of Spinifex (Fig. 2.6; Table 2.3). However, location of the Spinifex seedlings mattered significantly, with those at the top of the dune surviving much better than those at the bottom (Fig. 2.6; Table 2.3). 


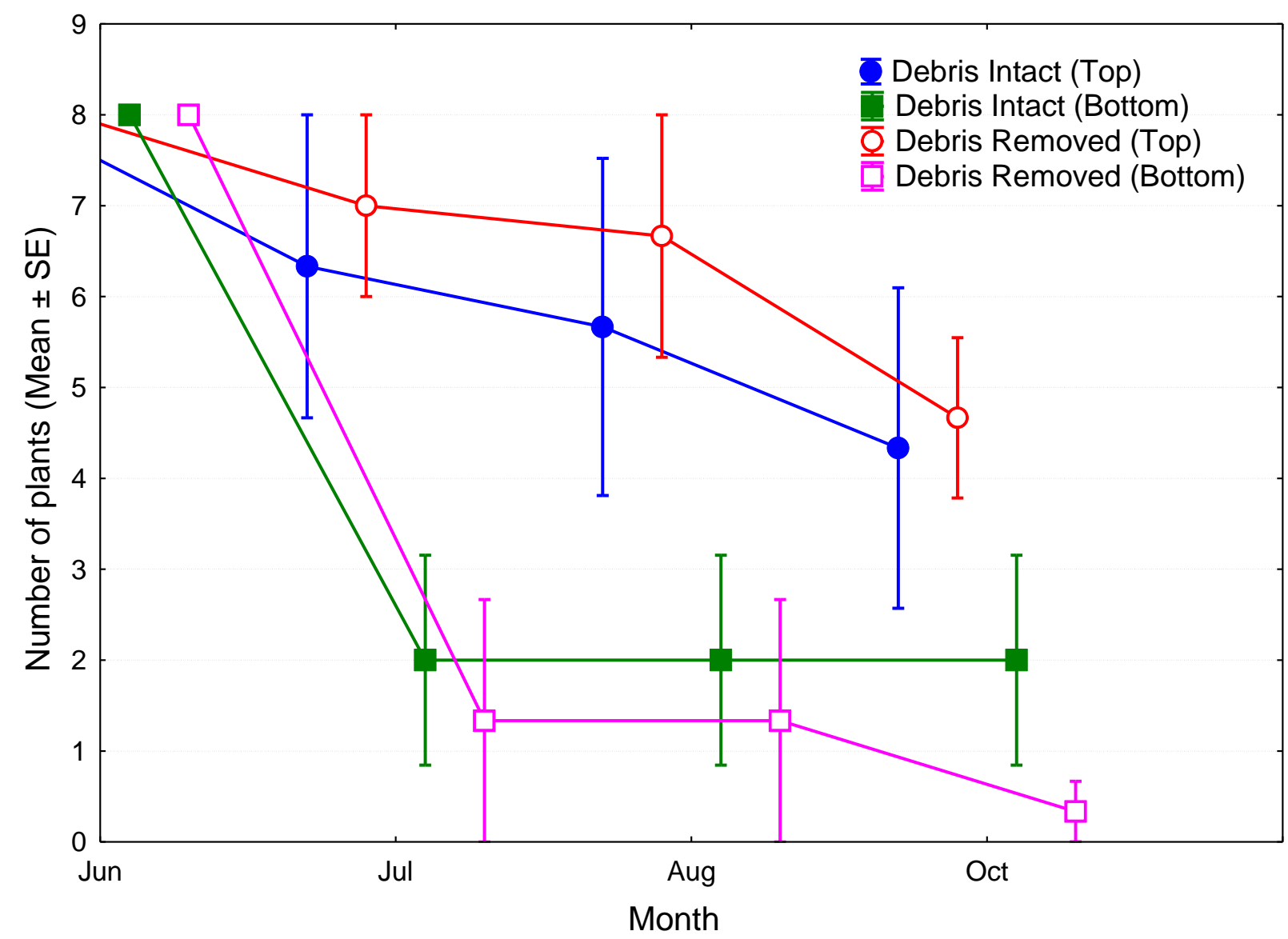

Fig. 2.6: Graph of seedlings in the herbicide treated plots showing that treatment had no significant effect on survival but plant location did (points are staggered).

Table 2.3: ANOVA table showing effect of treatment and location on Spinifex seedling survival in the herbicide removal experiment (Location had a significant influence due to storm but treatment or the interaction of the two did not).

\begin{tabular}{llllrrr}
\hline & \multicolumn{3}{c}{ Treatment } & \multicolumn{3}{c}{ Location } \\
\cline { 2 - 7 } Month & $\mathrm{F}$ & $\mathrm{Df}$ & Sig. & $\mathrm{F}$ & $\mathrm{df}$ & Sig \\
July & .031 & 1,8 & .864 & 14.0 & 1,8 & .006 \\
August & .004 & 1,8 & .952 & 10.3 & 1,8 & .012 \\
October & .514 & 1,8 & .494 & 9.2 & 1,8 & .016 \\
\hline
\end{tabular}




\subsubsection{Number of leaves produced by Spinifex seedlings}

\subsubsection{Experiment 1}

On average, Spinifex plants in the removal plots had a higher number of leaves from month to month while the plants in iceplant stands had the lowest (Fig. 2.7). There was a highly significant effect of treatment on the number of leaves from March through to June (all $P<0.002$; Fig. 2.6; Table 2.4). Plant location however, did not seem to have any effect on the number of leaves for the plants (Fig. 2.8) although plants at the bottom of iceplant plots had significantly higher numbers of leaves than their counterparts at the top of the dune until the condition was reversed by loss of plants in July $\left(F_{1,201}=5.392 ; P=0.021 ;\right.$ Fig. 2.9). The interaction between treatment and location did not have any effect on leaf production.

Table 2.4: ANOVA table showing effect of treatment and location on the cumulative number of leaves produced by plants in experiment 1 from March 2011 through October 2011 (treatment mostly had a highly significant effect but location and interaction of the two factors did not).

\begin{tabular}{|c|c|c|c|c|c|c|c|}
\hline \multirow[b]{2}{*}{ Month } & \multicolumn{3}{|c|}{ Treatment } & \multicolumn{3}{|c|}{ Location } & \multirow[b]{2}{*}{ Sig } \\
\hline & $\mathrm{N}$ & $\bar{F}$ & $\mathrm{df}$ & Sig. & $\bar{F}$ & $\mathrm{df}$ & \\
\hline March & 115 & 6.537 & 2,109 & .002 & .331 & 1,109 & .566 \\
\hline April & 115 & 8.401 & 2,109 & $<.001$ & .327 & 1,109 & .569 \\
\hline May & 115 & 9.434 & 2,109 & $<.001$ & .077 & 1,109 & .783 \\
\hline June & 115 & 8.157 & 2,109 & $<.001$ & 1.011 & 1,109 & .317 \\
\hline July & 36 & 4.835 & 2,32 & .015 & .722 & 1,32 & .402 \\
\hline August & 35 & 4.945 & 2,31 & .014 & .005 & 1,31 & .945 \\
\hline October & 27 & 3.997 & 2,23 & .032 & .010 & 1,23 & .920 \\
\hline
\end{tabular}




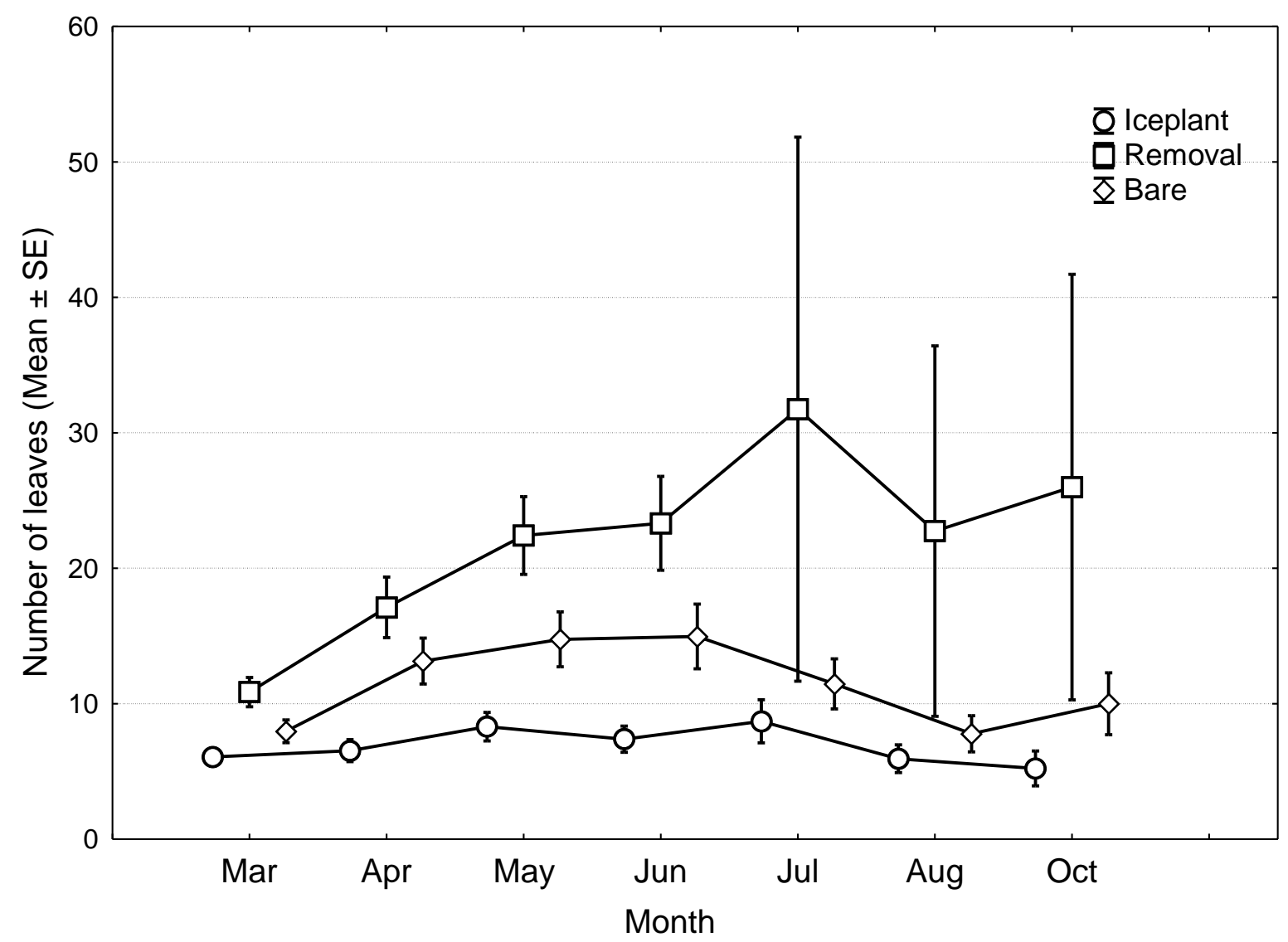

Fig. 2.7: Mean cumulative number of leaves produced by Spinifex plants in experiment 1 in relation to treatment over time (points are staggered). Treatment had a highly significant effect on number of leaves produced from March through to June (all $P<0.002$ ). 


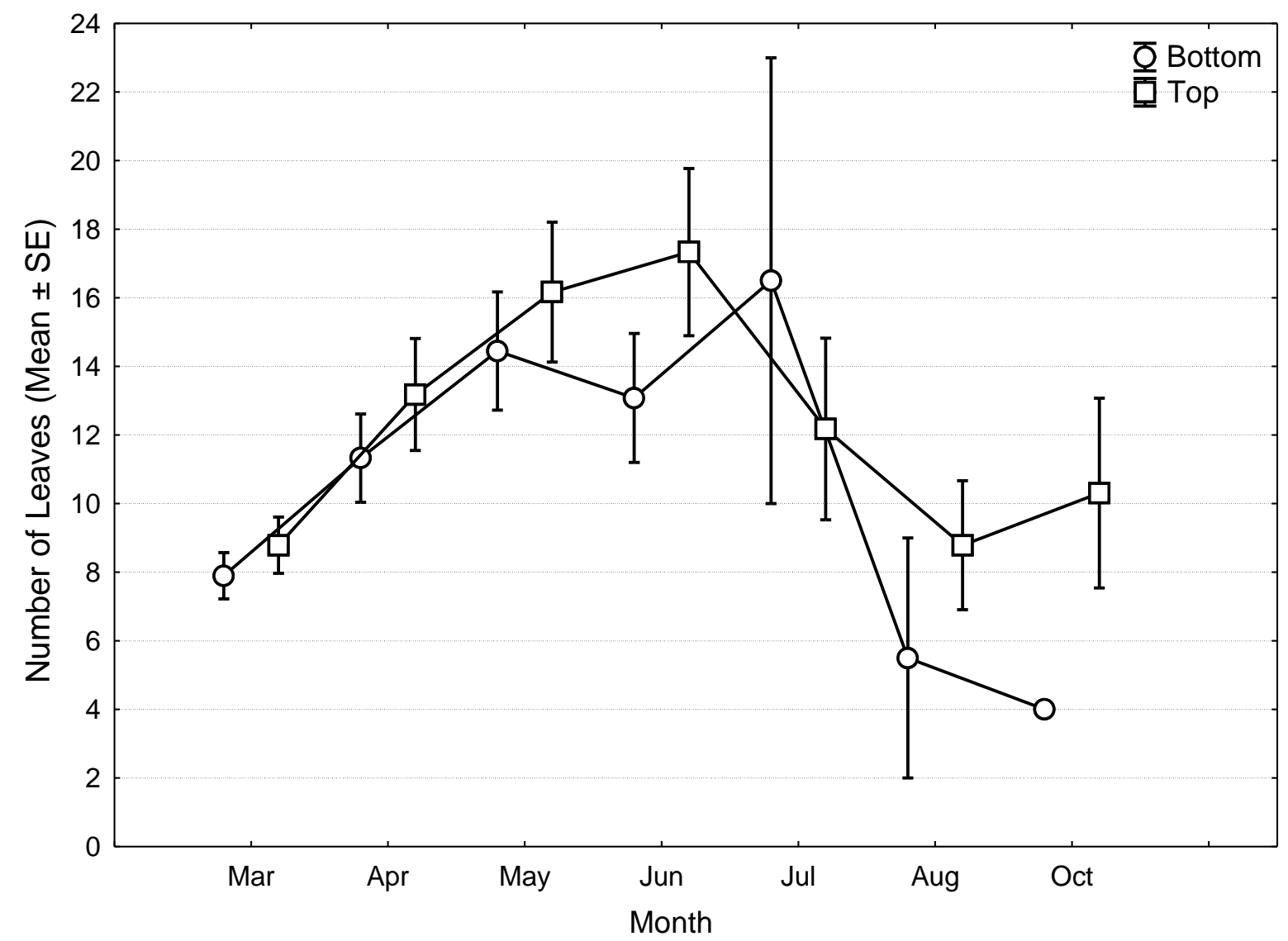

Fig. 2.8: Mean cumulative number of leaves per plant in Experiment 1 in relation to plant location over time (points are staggered). Plant location had no effect on number of leaves produced. The decline in leaf number from July to October was partially caused by dieback of surviving plants, but also from the loss of large plants to storm events. 


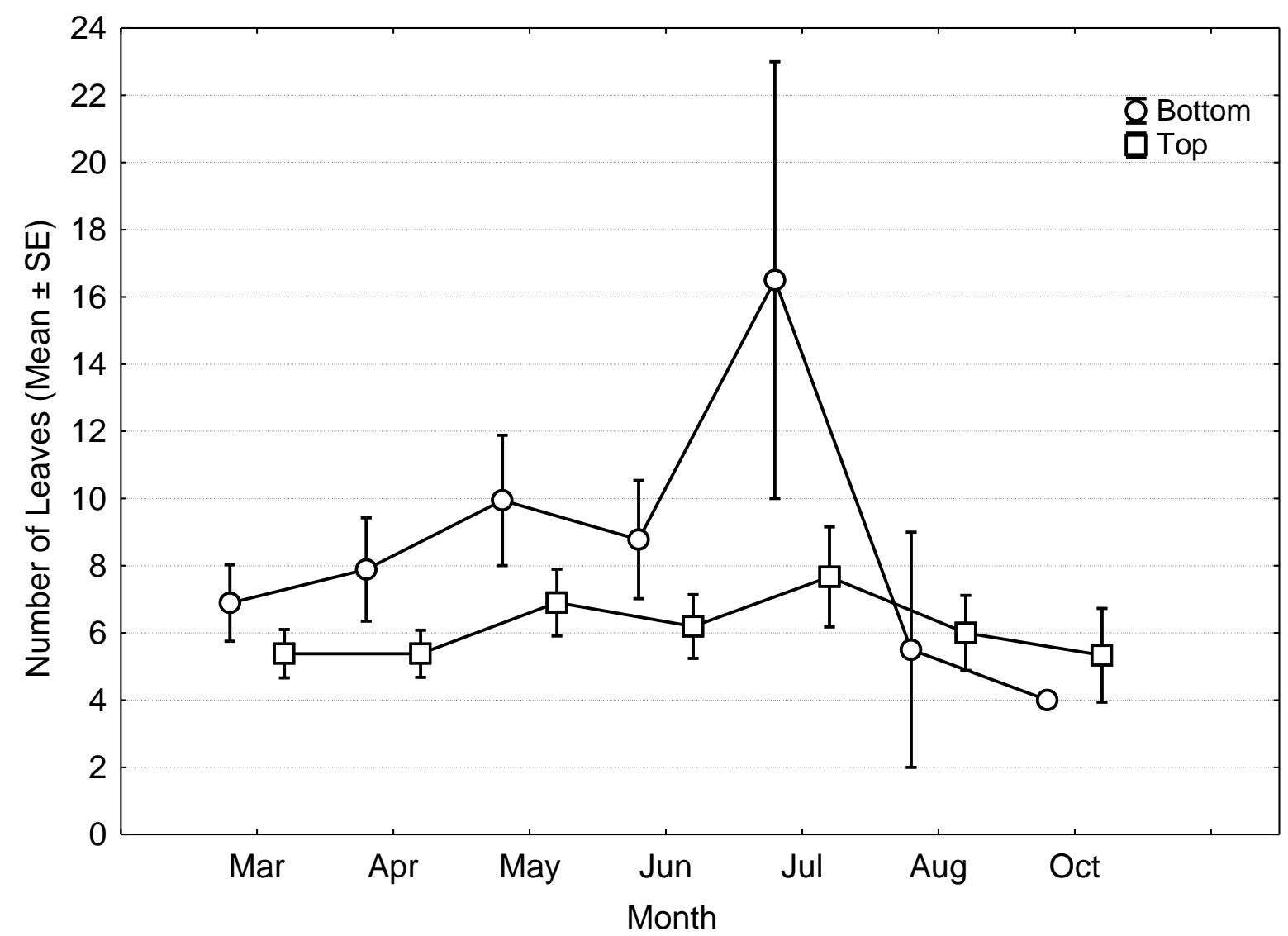

Fig. 2.9: Average number of leaves produced by each Spinifex plant in the Iceplant treatment of Experiment 1 in relation to plant location over time (points are staggered).

\subsubsection{Experiment 2 (herbicide removal)}

Leaf production of the seedlings in the herbicide-treated experiment was not affected by either treatment or location except in August where the interactive effect of treatment and location was highly significant $\left(F_{1,43}=9.864 ; P=0.003\right.$; Fig. 2.10; Table 2.5). This was because all plants except the ones at the top of "debris intact" plots lost a lot of leaves between July and August (Fig. 2.10). 
Table 2.5: ANOVA table showing a highly significant interactive effect of treatment and location on survival of Spinifex plants in experiment 2 (herbicide removal) during August.

\begin{tabular}{lrrrrr}
\hline Source & $\begin{array}{c}\text { Type III Sum } \\
\text { of Squares }\end{array}$ & df & Mean Square & F & Sig. \\
\hline Treatment & 4.299 & 1 & 4.299 & 1.390 & .245 \\
Location & 5.519 & 1 & 5.519 & 1.785 & .189 \\
Treatment * Location & 30.493 & 1 & 30.493 & 9.864 & .003 \\
Error & 132.932 & 43 & 3.091 & & \\
& & & & & \\
\hline
\end{tabular}

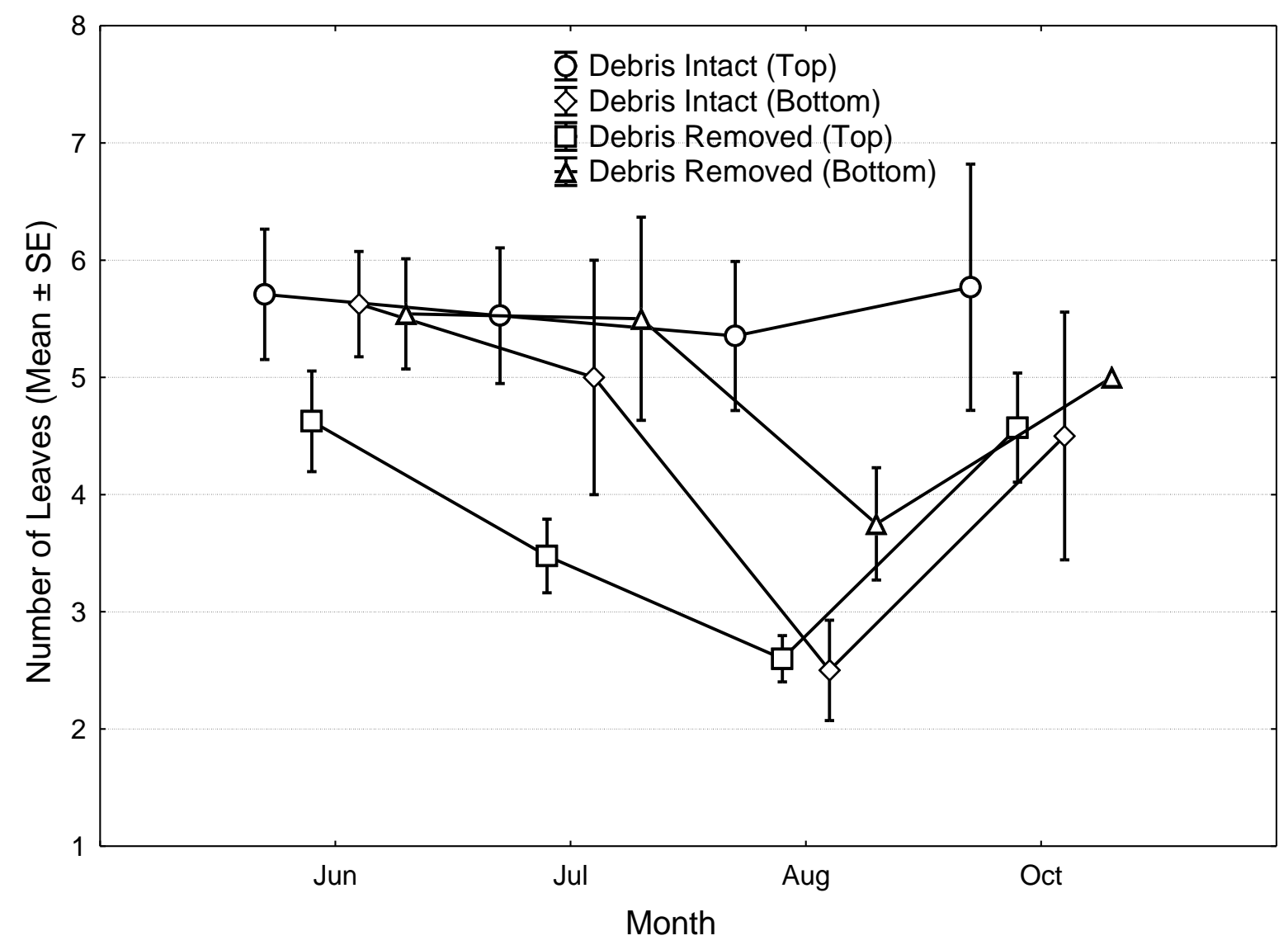

Fig. 2.10: Graph showing leaf production of Spinifex in the herbicide-treated plots (points are staggered). Plant location and treatment only had an effect in August. 


\subsubsection{Physical parameters}

\subsubsection{Slope gradient}

Gradients in bare plots were significantly gentler $\left(32^{\circ}-38^{\circ}\right)$ than the removal $\left(32^{\circ}-\right.$ $\left.52^{\circ}\right)$ and iceplant plots $\left(38^{\circ}-50^{\circ}\right)$ (Fig. 2.11).

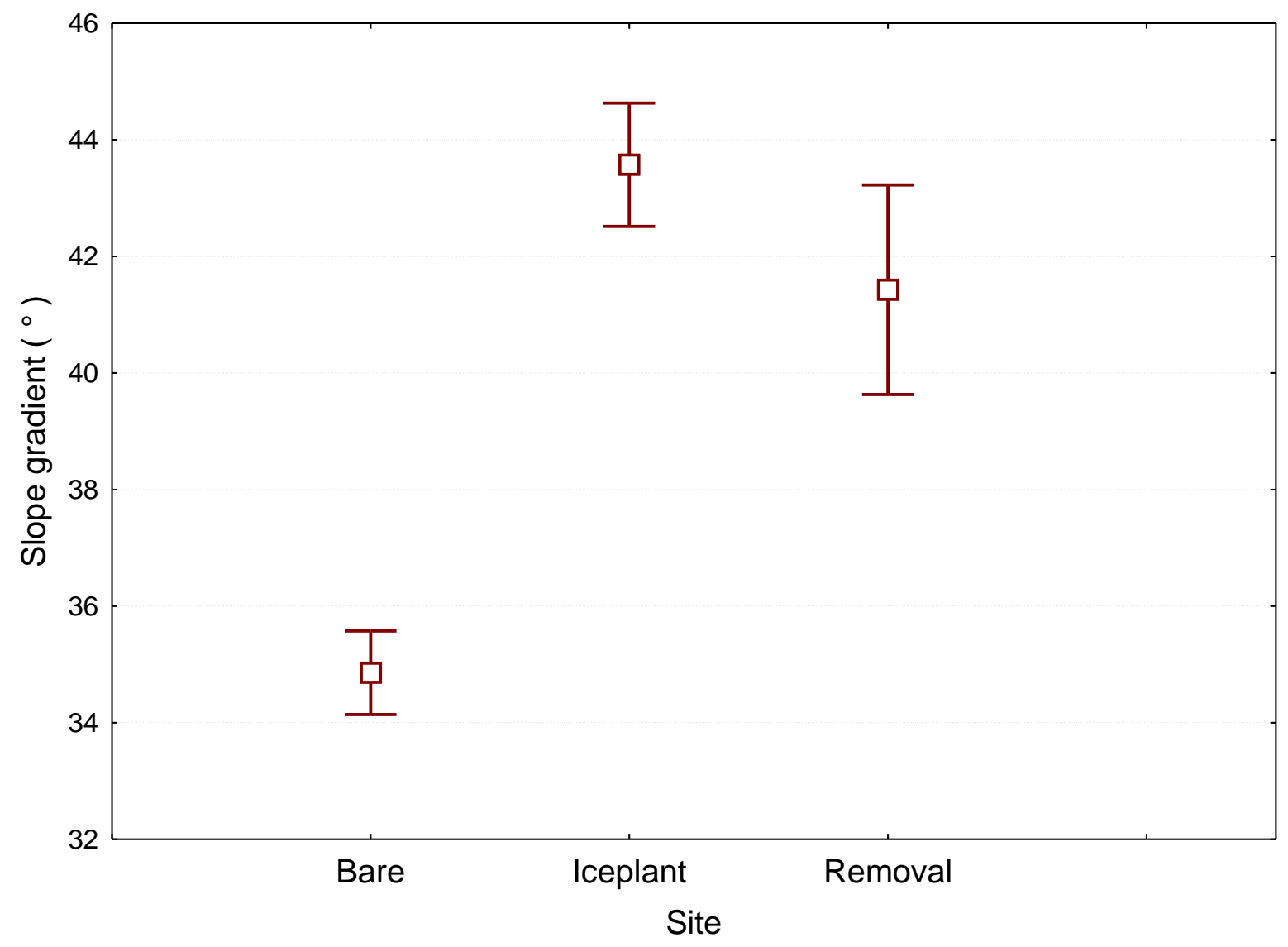

Fig. 2.11: Slope gradients (mean $\pm \mathrm{SE}$ ) of the plots of the different treatments in experiment 1 (Bare plots were significantly gentler).

\subsubsection{Soil moisture and organic matter}

There was a significantly higher amount of organic matter in the soil samples from the iceplant plots than in bare plots but not between locations within a site (Table 2.6; Fig. 2.12; $\left.F_{1,16}=21.127 ; P<0.001\right)$. Soil moisture content did not differ either between sites or 
locations (Fig. 2.13) although the difference approaches significance for bare plots $\left(F_{1}\right.$, $15.62=4.53 ; P=0.066)$.

Table 2.6: Soil organic matter difference between bare and iceplant sites

\begin{tabular}{lrrrrr}
\hline \multicolumn{1}{c}{ Source } & $\begin{array}{l}\text { Type III } \\
\text { Sum of } \\
\text { Squares }\end{array}$ & df & Mean Square & F & \multicolumn{1}{c}{ Sig. } \\
& .238 & 1 & & & \\
\hline Site & .002 & 1 & .238 & 21.127 & $<.000$ \\
Location & .015 & 1 & .002 & .182 & .676 \\
Site * Location & .180 & 16 & .015 & 1.291 & .273 \\
Error & & & .011 & & \\
\hline
\end{tabular}

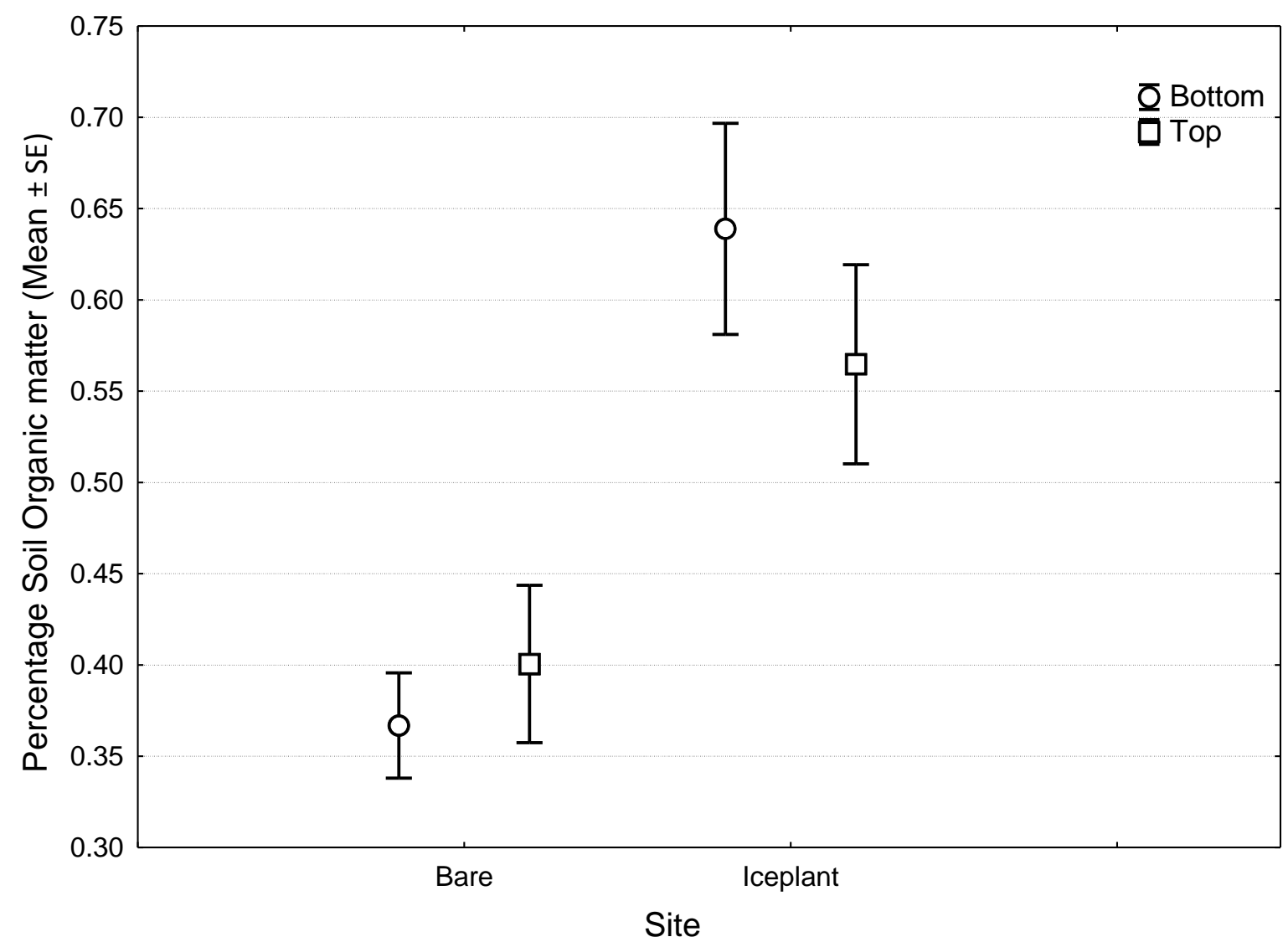

Fig. 2.12: Percentage soil organic matter at the bottom and top of the dunes of the iceplant and bare sites 


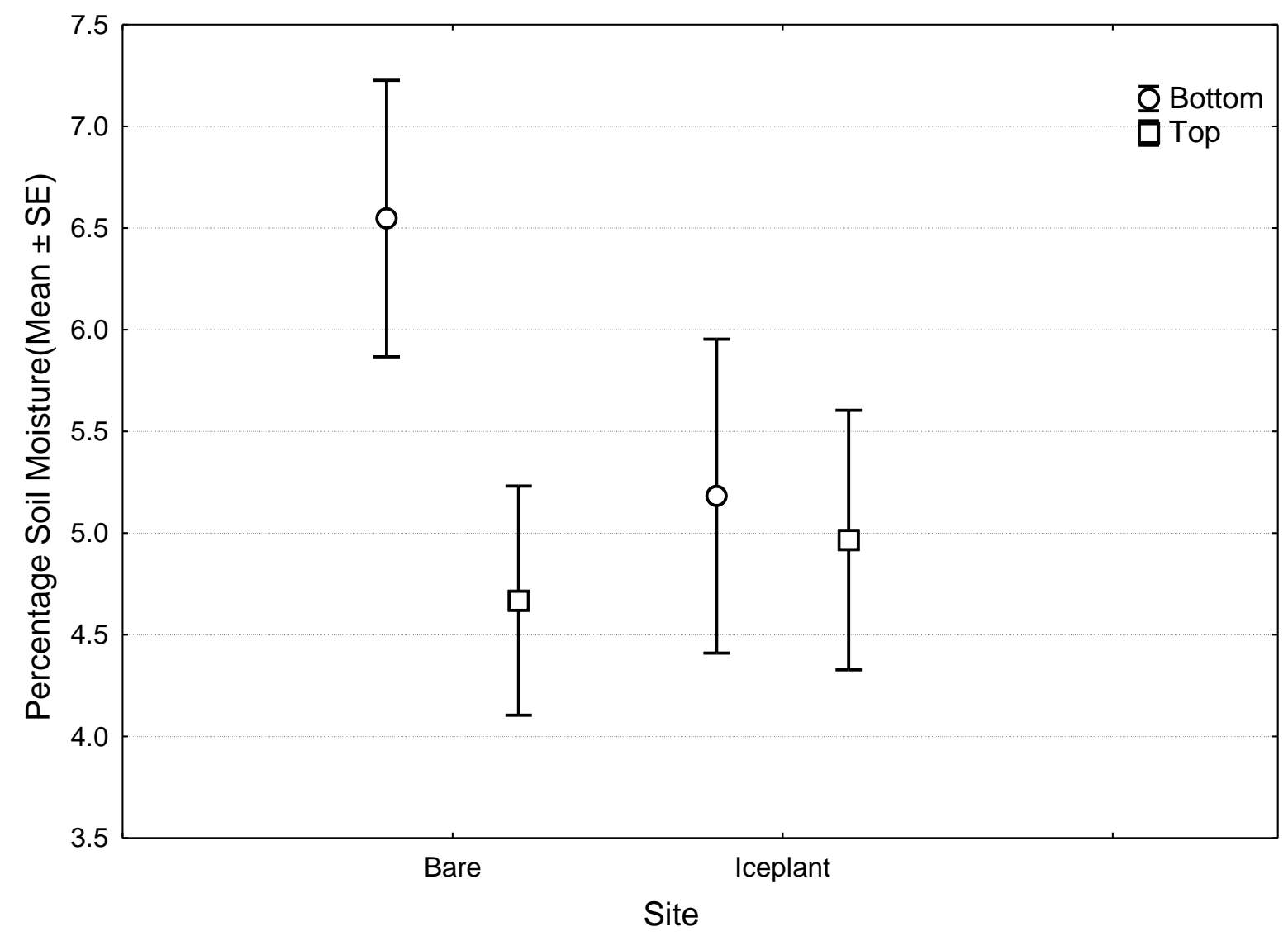

Fig. 2.13: Percentage soil moisture content of soil obtained from the two sites and locations of the dunes. 


\subsubsection{Electrical conductivity}

Soil samples obtained from sites under the canopies of $C$. edulis were significantly more saline than the samples from sites in the bare plots $\left(F_{1,16}=31.7 ; P<0.001\right.$; Fig. 2.14). Although there was a slight trend in salinity in soil samples from the bottom of the dunes when compared with those from the top, this was not statistically significant.

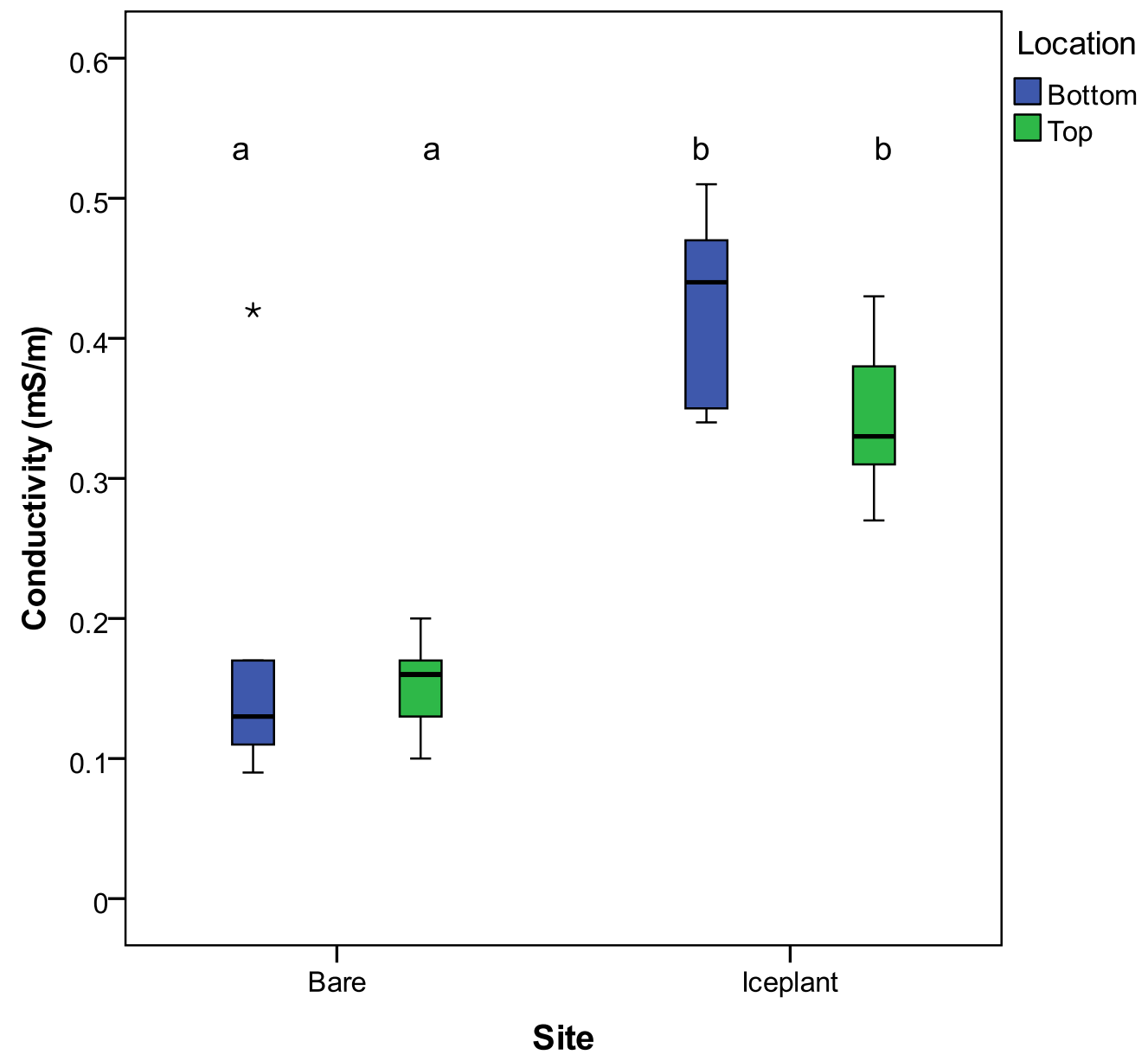

Fig. 2.14: Electrical conductivity of soil samples obtained from the top and bottom of the dunes at the iceplant and bare sites. 


\subsection{DISCUSSION}

\subsubsection{Confounding factors to Spinifex seedling survival and growth}

There was generally a low Spinifex seedling survival rate regardless of treatment. This was not surprising because it has been reported that species capable of vegetative propagation, such as Spinifex sericeus, often exhibit low levels of seedling survival (Cook 1979; Maze and Whalley 1992a). During the first month (December 2010), seedling survival was significantly higher at the bottom of the dune, regardless of the treatment, showing that Carpobrotus edulis did not have any influence on initial Spinifex survival.

The period during planting from November 2010 to early January 2011, was characterised by a dry spell, requiring us to spray the plots with about 500L of water two weeks after planting. Since soil moisture is one of the most limiting factors in sand dunes (Lichter 1998), drought may have had an influence on the overall initial survival. The higher survival of seedlings at the foot of the dune during the initial periods may be a result of more soil moisture due to inundation during high tides and wave splashes. Although this water is not expected to be readily available because of salinity, it has been observed from electrical conductivity measurements of macerated Spinifex tissue that it picks up some salt, either through leaves or by roots (Maze and Whalley 1992). Uptake of salt helps plants in water absorption or retention, enabling them to survive better. Therefore the ability of Spinifex to utilise salty water may have been responsible for better survivorship at the foot of the dune during the month of December 2010. Death of plants in plots A4, B1, C3 and C4 between January and March, can be attributed to drought, storm erosion and trampling by humans.

During planting it was noted that the soil under the iceplant and in the removal plots was moister than the soil in bare plots, though this was not empirically determined at the time. However, in subsequent months, soil samples collected from under the canopy of iceplant and in bare spaces did not show any significant difference in moisture content (Fig. 2.13). Variability in soil moisture changes through time (Wilson and Sykes 1999), and these results, do not rule out existence of a moisture gradient. Soil moisture content did not 
differ between the bottom and the top of the dunes either, in agreement with Wilson and Sykes (1999), although other studies (e.g. Gooding 1947) suggest otherwise.

Planting technique is an important determinant of seedling survival, especially in sand dunes where the substrate is unstable. It is recommended that planting depth for Spinifex seedlings should be up to the lower third of crown (Auckland Regional Council) to guard against exposure of the root region by erosion. However, our seedlings were planted at the same level as they were in their root trainer sleeves. Therefore, insufficient planting depth coupled with storm erosion may also have had an impact on the initial overall survival since by January some seedlings had about $5 \mathrm{~cm}$ of their root trainer soil exposed due to erosion. This root exposure was more pronounced for plants in the removal and bare treatments than in the iceplant treatment since surface erosion of sand is greater where there is a lack of above-ground vegetation.

Plant location on the dune and the presence/absence of dead debris interacted in their effect on Spinifex leaf production in the herbicide treated plots such that plants in the "debris intact" plots at the top of the dune put on the greatest number of leaves, although this effect was only significant in August $(P=0.003)$. The fact that location of the plants did not have any effect on their performance means that the $2-4 \mathrm{~m}$ space between plants at the bottom and the top of the dune was not enough to produce a gradient to which plants could respond differentially. This is confirmed by the lack of difference in soil moisture and organic matter content, as well as in electrical conductivity between the two sampling locations separated by $5-8 m$ (Fig. $2.12-2.14$ ).

The factor that most significantly affected Spinifex seedling survival was storm disturbance that decimated plants nearer to high tide mark in the second week of July. The storm caused slumping of the dunes, creating a near-vertical scarp which destabilised even the plants that survived. 


\subsubsection{Positive effects of $C$. edulis on Spinifex seedlings}

It is generally argued that in harsh environments like the sand dunes, facilitative processes are more important than competition to community structure (Bertness and Shumway 1993; Didham, Tylianakis et al. 2007). Spinifex plants in the removal and bare treatments of Experiment 1 had their leaves dying back from the tips, probably as a result of salt spray (Maze and Whalley 1992; Wilson and Sykes 1999). Abrasive leaf damage by sand blasting was also quite evident in the plants growing in absence of iceplant. Yura and Ogura (2006) observed that sand blasting followed by salt spray caused serious injury to Imperata cylindrica and Miscanthus sinensis. The leaves of Spinifex plants in the iceplant treatment, on the other hand, appeared intact, suggesting a buffering by iceplant against sand blasting and excessive salt spray. Normally, a stress-tolerant neighbour can ameliorate the harsh environmental conditions in its immediate vicinity, thereby providing favorable sites where other species can then succeed (King 2008). Subjective observations of the plants in the different treatments also showed that plants within the iceplant stands had leaves that appeared darker green than those in the removal and bare treatments. The positive effect of an adult plant on seedlings of another species is called the "nurse-plant" effect (Bertness and Callaway 1994; Padilla and Pugnaire 2006) and has been found in harsh habitats, suggesting that habitat amelioration by neighbours is important for positive recruitment events (Bertness and Callaway 1994). Therefore, the expectation that facilitation would be the dominant effect of extant adult plants on seedlings of other species at the fore dune seems plausible, at least in buffering against abrasive damage by sand blasting and necrosis, due to salt spray. Moreover, plants at the bottom of the iceplant plots (presumed to be the harsher section) had significantly higher numbers of leaves than their counterparts at the top of the dune (Fig. 2.9; $P=0.021$ ). In this study, we have determined that soil salinity was higher under the canopy of the iceplant, which may cause the Spinifex seedlings internal toxicity or some difficulty in absorbing water (Wilson and Sykes 1999), rendering iceplant plots harsher. In contrast to Wilson and Sykes (1999) however, I did not find a significant difference in salinity of soil samples obtained from the bottom and the top of the dune. 
Despite being statistically insignificant, Spinifex survival was higher in the manual removal plots until July. Soil sample analysis here showed that there was a higher percentage of organic matter under the canopy of iceplant, which may have improved soil micro-conditions to the benefit of the Spinifex seedlings. In addition, seedlings in removal plots consistently had significantly higher numbers of leaves (Fig. 2.7). Leaf litter of some plants has been observed to improve the structure of the soil, and increase its cation exchange capacity and water holding capacity (Hunter and Aarssen 1988).

Spinifex plants within iceplant plots best survived the July storm because of the soilbinding nature of the iceplant's extensive fibrous root system. Sand-binding species are said to stabilize the substrate, contributing to eventual colonization by successive sand dune plants (Lichter 2000). However, there is no evidence that Carpobrotus spp. lead to a succession resulting in dominance by native species.

\subsubsection{Negative effects of $C$. edulis on Spinifex seedlings}

The lessening abundance of many native species around the world has been considered to be the result of the better "competitive ability" of exotics (D'Antonio and Mahall 1991). A review of competitive interactions between native and exotic plants suggested that the spread and establishment of exotic species is related to their ability to competitively suppress resident species (Levine, Vilà et al. 2003). In the current study, there was a highly significant difference in Spinifex leaf production from March through June (Fig. 2.6; Table 2.4) with plants in the iceplant treatment having significantly lower numbers of leaves, suggesting that the presence of iceplant suppresses growth of Spinifex sericeus. In addition, Spinifex seedlings within the iceplant plots appeared more slender. Carpobrotus edulis has been reported to compete aggressively (D'Antonio 1990; Albert, D'Antonio et al. 1997; Vilà and D'Antonio 1998) and suppress the growth and establishment of other plants while achieving high rates of space colonization (D'Antonio and Mahall 1991; Suehs, Affre et al. 2004; Vilà, Tessier et al. 2006). Interspecific competition, being an important determinant of structure and dynamics of plant communities (Aerts 1999), has been 
suggested as a mechanism for the success of invasive plant species (Hierro and Callaway 2003) such as iceplant. It was reported that removal of $C$. edulis from around individuals of Haplopappus ericoides shrub species resulted in increased predawn xylem pressure, suggesting that the surrounding $C$. edulis was utilizing water that would otherwise have been available to the shrubs (D'Antonio and Mahall 1991). Carpobrotus edulis has a very dense fibrous root system concentrated in the upper $50 \mathrm{~cm}$ of the soil that makes it very effective at interfering with water uptake by other shallowly rooted species (D'Antonio and Mahall 1991).

Spinifex plants in the removal plots were worst affected by the July storm because they were located on a steeper unstable slope (Fig. 2.11) built by sand accretion activity of the previously extant iceplant. The disadvantage of iceplant for dune integrity against such a heavy storm is that cracks develop on the sand surface as a result of storm undercutting, leading to eventual slumping of the dune ridge (Carter, Hesp et al. 1990). This slumping led to the loss of almost all Spinifex plants at the foot of the dune (Fig. 2.5; Table 2.2).

Carpobrotus edulis is reported to indirectly interact with native species by altering soil chemistry (Conser and Connor 2009), causing changes in soil pH and nutrient regimes (Bartomeus and Vilà 2009). It has been suggested to have residual effects on the soil that inhibit reestablishment of native plant species after it has been removed (Conser and Connor 2009). However, Spinifex in our removal plots (where iceplant had been present) produced a significantly higher number of leaves than plants in the other treatments. In another removal study, Haplopappus ericoides shrubs were shown to have had a marked increase in canopy area after removal of C. edulis (D'Antonio and Mahall 1991). While this improved response may be attributed to elimination of competition, plants in the removal plots actually performed better that those in bare plots where there was no preexisting iceplant. This suggests that $C$. edulis did not have a net allelopathic legacy but may have actually improved soil micro-conditions. It has been put forward that for allelopathic chemicals to be important in structuring a plant community they must have had a significant resident time (Choesin and Boerner 1991). However, the residence time of iceplant at the field site is unknown and it may yet be too early for it to be able to significantly alter soil chemistry to the detriment of succeeding plants. In addition, biotic components of 
ecosystem such as herbivores, competitors, pathogens and decomposers, (Inderjit, Wardle et al. 2011) as well as seasons (Barto and Cipollini 2009) can alter concentrations of allelochemicals. Response of plants to inhibitory exudates of neighbours is also said to be species-specific (Gómez-Aparicio and Canham 2008). Since we did not investigate these confounding factors we cannot claim that $C$. edulis is not allelopathic, but we can say that Spinifex plantings do not seem to suffer from allelopathic legacies of iceplant.

\subsubsection{Soil seed bank legacy}

Assessment of individual removal plots during each monthly visit over a period of one year did not reveal any iceplant seedling suggesting that in the short-term, buried seed bank is not a major route for its recolonization after eradication. However, soil cores were not analysed for presence or absence of seed bank.

\subsection{Conclusion and management recommendations}

As far as seedling survivorship is concerned, we conclude that low soil moisture, storm-induced erosion, steep slope and insufficient planting depth were the influential factors affecting Spinifex survival rather than the presumed negative effects of iceplant. In fact, the presence of iceplant ameliorated some of these negative effects. Carpobrotus edulis is a stabilizer and improved soil moisture and organic matter content for other plants that also provided buffering against salt spray, as evidenced by less leaf die-back of Spinifex within its stand. Additionally, C. edulis provided protection against abrasive leaf damage by sand-blasting, unlike in other treatments where plants had their leaves severely damaged.

On the other hand, C. edulis had a strong suppressing effect on biomass production, as shown by lower numbers of leaves and slenderer stems of Spinifex seedlings growing within its stands, and the long-term outcome may have been a failure of these Spinifex plants to thrive in the presence of iceplant. There was no evidence of allelopathy since plants in the removal treatment showed the best performance among the three treatments. If $C$. edulis is a highly competitive and allelopathic species, Spinifex plants in bare plots in the 
absence of competition and the inhibitory legacy, would have shown the best performance. However, this was not the case.

Using iceplant as a mulching material did not, in general, result in better survival or growth performance of Spinifex seedlings.

Iceplant has been shown here to create steep slopes, despite its diminutive height which has been implicated in its unsuitability for sand accretion (Bergin, Miller et al. 2007). This portends poorly for the physical integrity of dunes in the face of storm disturbances, especially along high energy coasts.

Because of the constant storm disturbance along this coast, succession by other plants and establishment of pioneer seedlings is made difficult, and it is not advisable to remove the iceplant unless the dune morphology is mechanically reshaped to withstand wave actions. Spinifex seedlings may establish successfully at this field site if planted in winter on the upper parts of the dune face, away from wave impact. At other sites where moisture, not storm disturbance, is the main limiting factor, planting Spinifex closer to the foot of the dune, where inundation is more likely, may enhance seedling survivorship.

The combination of increased survival of Spinifex against storms, but lower growth in the presence of iceplant, suggests that an intermediate strategy for planting of Spinifex may be appropriate. As a result, I suggest that Spinifex could be interplanted into existing stands of iceplant if, at the time of planting, the iceplant is reduced to $25-50 \%$ of its original cover. This should still provide some nurse effect to aid the establishment of Spinifex, but also allow enough space to delay negative competitive effects. In the longer-term, we would like to see the Spinifex replace the iceplant. This may not occur through "natural" competition. Hence, to achieve the conversion, a second round of manual removal of iceplant may be necessary after 1-2 years, once the Spinifex has established. 


\section{REFERENCES}

Aerts, R. (1999). "Interspecific competition in natural plant communities: mechanisms, trade-offs and plant-soil feedbacks." Journal of Experimental Botany 50(330): 29-37.

Albert, M. E., C. M. D'Antonio, et al. (1997). "Hybridization and introgression in Carpobrotus spp. (Aizoaceae) in California .1. Morphological evidence." American Journal of Botany 84(7): 896-904.

Andreu, J., M. Vila, et al. (2009). "An Assessment of Stakeholder Perceptions and Management of Noxious Alien Plants in Spain." Environmental Management 43(6): 1244-1255.

Auckland Regional Council. "Coastal planting guide 2." Retrieved October 2011 from http://www.arc.govt.nz/albany/fms/main/Documents/Environment/Plants\%20and\%20animals/coas tal\%20planting\%20guide\%202.pdf.

Baker, H. G. (1974). "The Evolution of Weeds." Annual Review of Ecology and Systematics 5: 1-24.

Barto, E. K. and D. Cipollini (2009). "Half-lives and field soil concentrations of Alliaria petiolata secondary metabolites." Chemosphere 76(1): 71-75.

Bartomeus, I. and M. Vila (2009). "Breeding system and pollen limitation in two supergeneralist alien plants invading Mediterranean shrublands." Australian Journal of Botany 57(2): 109-115.

Bergin, D., E. Miller, et al. (2007). Performance of indigenous sand-binders planted on a reshaped foredune at Oakura beach, New Plymouth. Coastal Dune Vegetation Network (Retrieved October 2011 from http://www.dunestrust.org.nz/OakuraReshapingTrial.pdf).

Bertness, M. D. and R. Callaway (1994). "Positive interactions in communities." Trends in Ecology \& Evolution 9(5): 191-193.

Bertness, M. D. and S. W. Shumway (1993). "Competition and Facilitation in Marsh Plants." American Naturalist 142(4): 718-724.

Biosecurity New Zealand (2008). Pests and diseases - Iceplant, Ministry of Agriculture and Forestry, New Zealand (http://www.biosecurity.govt.nz/pests/iceplant).

Brooker, R. W. and T. V. Callaghan (1998). "The balance between positive and negative plant interactions and its relationship to environmental gradients: a model." Oikos 81(1): 196-207.

Carter, R. W. G. (1991). "Near-future sea level impacts on coastal dune landscapes." Landscape Ecology 6: 29-39.

Carter, R. W. G., P. A. Hesp, et al. (1990). Erosional landforms in coastal dunes. . Coastal Dunes Form and Process. K. Nordstrom, N. Psuty and B. Carrter. London, John Wiley and Sons: 217-249.

Chinnock, R. J. (1971). "Studies in Disphyma - Genus Related to Mesembryanthemum- Part 1 a Revision of Disphyma australe." New Zealand Journal of Botany 9(2): 331-344.

Choesin, D. N. and R. E. J. Boerner (1991). "Allyl Isothiocyanate Release and the Allelopathic Potential of Brassica napus (Brassicaceae)." American Journal of Botany 78(8): 1083-1090. 
Connor, H. E. (1984). "Breeding systems in New Zealand grasses IX. Sex ratios in dioecious Spinifex sericeus." New Zealand Journal of Botany 22(4): 569-574.

Conser, C. and E. F. Connor (2009). "Assessing the residual effects of Carpobrotus edulis invasion, implications for restoration." Biological Invasions 11(2): 349-358.

Cook, R. E. (1979). "Asexual Reproduction: A Further Consideration." The American Naturalist 113(5): 769-772.

D'Antonio, C. M. (1990). "Seed production and dispersal in the non-native, invasive succulent Carpobrotus edulis (aizoaceae) in coastal strand communities of central California." Journal of Applied Ecology 27(2): 693-702.

D'Antonio, C. M. (1993). "Mechanisms controlling invasion of coastal plant communities by the alien succulent Carpobrotus edulis." Ecology 74(1): 83-95.

D'Antonio, C. M. and B. E. Mahall (1991). "Root profiles and competition between the invasive, exotic perennial, Carpobrotus edulis, and two native shrub species in California coastal scrub." American Journal of Botany 78(7): 885-894.

Dahm, J., G. Jenks, et al. (2005). Community-based Dune Management for the mitigation of Coastal Hazards and Climate Change Effects: A Guide for Local Authorities (http://www.Ignz.co.nz/projects/EnvironmentalSustainability/ClimateChange/CommunityBasedDun eMangementpart1.pdf).

DERM (2011). Coastal sand dunes - their vegetation and management: Descriptions of major plants. D. o. E. a. R. Management. Queensland (http://www.derm.qld.gov.au/register/p00278aa.pdf).

Didham, R. K., J. M. Tylianakis, et al. (2007). "Interactive effects of habitat modification and species invasion on native species decline." Trends in Ecology \& Evolution 22(9): 489-496.

Diez, J. M., J. J. Sullivan, et al. (2008). "Darwin's naturalization conundrum: dissecting taxonomic patterns of species invasions." Ecology Letters 11(7): 674-681.

Dopson, S. R., P. J. de Lange, et al. (1999). The Conservation Requirements of New Zealand's Nationally Threatened Vascular Plants. Threatened Species Occasional Publication No. 13. Wellington, Department of Conservation.

Draper, D., A. Rossello-Graell, et al. (2003). "Application of GIS in plant conservation programmes in Portugal." Biological Conservation 113(3): 337-349.

Ehrenfeld, J. G. (2003). "Effects of exotic plant invasions on soil nutrient cycling processes." Ecosystems 6(6): 503-523.

Ewel, J. J. and F. E. Putz (2004). "A place for alien species in ecosystem restoration." Frontiers in Ecology and the Environment 2(7): 354-360.

Gadgil, R. L. and F. J. Ede (1998). "Application of scientific principles to sand dune stabilization in New Zealand: Past progress and future needs." Land Degradation \& Development 9(2): 131-142.

Gómez-Aparicio, L. and C. D. Canham (2008). "Neighbourhood analyses of the allelopathic effects of the invasive tree Ailanthus altissima in temperate forests." Journal of Ecology 96(3): 447-458. 
Gooding, E. G. B. (1947). "Observations on the Sand Dunes of Barbados, British West Indies." Journal of Ecology 34(1): 111-125.

Hartnett, D. C. and F. A. Bazzaz (1983). "Physiological integration among intraclonal ramets in Solidago canadensis." Ecology 64(4): 779-788.

Hierro, J. L. and R. M. Callaway (2003). "Allelopathy and exotic plant invasion." Plant and Soil 256(1): 29-39.

Hilton, M. J. (2006). "The loss of New Zealand's active dunes and the spread of marram grass (Ammophila arenaria)." New Zealand Geographer 62(2): 105-120.

Hilton, M. J., U. Macauley, et al. (2000). Inventory of New Zealand's active dunelands. Science for Conservation 157. D. o. Conservation. Wellington.

Hunter, A. F. and L. W. Aarssen (1988). "Plants helping plants." Bioscience 38(1): 34-40.

Inderjit, D. A. Wardle, et al. (2011). "The ecosystem and evolutionary contexts of allelopathy." Trends in Ecology \& Evolution 26(12): 655-662.

Jay, M., M. Morad, et al. (2003). "Biosecurity, a policy dilemma for New Zealand." Land Use Policy 20(2): 121-129.

King, E. G. (2008). "Facilitative effects of Aloe secundiflora shrubs in degraded semi-arid rangelands in Kenya." Journal of Arid Environments 72(4): 358-369.

Kolar, C. S. and D. M. Lodge (2001). "Progress in invasion biology: predicting invaders." $\underline{\text { Trends in }}$ Ecology \& Evolution 16(4): 199-204.

Levine, J. M., M. Vilà, et al. (2003). "Mechanisms underlying the impacts of exotic plant invasions." Proceedings of the Royal Society of London Series B-Biological Sciences 270(1517): 775-781.

Lichter, J. (1998). "Primary succession and forest development on coastal Lake Michigan sand dunes." Ecological Monographs 68(4): 487-510.

Lichter, J. (2000). "Colonization constraints during primary succession on coastal Lake Michigan sand dunes." Journal of Ecology 88(5): 825-839.

Lockwood, J. L., P. Cassey, et al. (2005). "The role of propagule pressure in explaining species invasions." Trends in Ecology \& Evolution 20(5): 223-228.

Mack, R. N., D. Simberloff, et al. (2000). "Biotic invasions: Causes, epidemiology, global consequences, and control." Ecological Applications 10(3): 689-710.

Maltez-Mouro, S., F. T. Maestre, et al. (2010). "Weak effects of the exotic invasive Carpobrotus edulis on the structure and composition of Portuguese sand-dune communities." Biological Invasions 12(7): 2117-2130.

Maze, K. M. and R. D. B. Whalley (1992). "Effects of salt spray and sand burial on Spinifex sericeus R. Br." Australian Journal of Ecology 17(1): 9-19.

Maze, K. M. and R. D. B. Whalley (1992a). "Germination, seedling occurrence and seedling survival of Spinifex sericeus R. Br. (Poaceae)." Australian Journal of Ecology 17(2): 189-194. 
Michalet, R., R. W. Brooker, et al. (2006). "Do biotic interactions shape both sides of the humpedback model of species richness in plant communities?" Ecology Letters 9(7): 767-773.

Milne, R. and J. Sawyer (2002). Coastal fore dune vegetation in the Wellington Conservancy: Current status and future management. D. o. Conservation. Wellington.

Muasya, A. M. and P. J. de Lange (2010). "Ficinia spiralis (Cyperaceae) a new genus and combination for Desmoschoenus spiralis." New Zealand Journal of Botany 48(1): 31-39.

NIWA (2008). Climate change projections for New Zealand. NIWA National Climate Centre Auckland (http://www.niwa.co.nz/node/82219).

Noble, I. R., Ed. (1989). Attributes of invaders and the invading process: terrestrial and vascular plants. Biological invasions a global perspective, John Wiley \& Sons, Ltd (Retrieved October 2011 from http://www.icsu-scope.org/downloadpubs/scope37/scope37-ch12.pdf).

Noble, J. C. and C. Marshall (1983). "The Population Biology of Plants with Clonal Growth: II. The Nutrient Strategy and Modular Physiology of Carex arenaria." Journal of Ecology 71(3): 865-877.

Olden, J. D., N. L. Poff, et al. (2004). "Ecological and evolutionary consequences of biotic homogenization." Trends in Ecology \& Evolution 19(1): 18-24.

Padilla, F. M. and F. I. Pugnaire (2006). "The role of nurse plants in the restoration of degraded environments." Frontiers in Ecology and the Environment 4(4): 196-202.

Partridge, T. R. (1995 ). Interaction between Pīngao and Marram on Sand Dunes - completion of permanent plot studies. Science for Conservation 3. D. o. Conservation. Wellington.

Patrick, B. (2002). Conservation status of the New Zealand red Katipō spider (Latrodectus katipō). Science for Conservation 194. D. o. Conservation. Wellington.

Pimentel, D., R. Zuniga, et al. (2005). "Update on the environmental and economic costs associated with alien-invasive species in the United States." Ecological Economics 52(3): 273-288.

Price, E. A. C. and C. Marshall (1999). "Clonal Plants and Environmental Heterogeneity: An Introduction to the Proceedings." Plant Ecology 141(1/2): 3-7.

Ravine, D. A. (1992). Foxton Ecological District. Survey Report for the Protected Natural Areas Programme. New Zealand Protected Natural Areas Programme No. 19. D. o. Conservation. Wanganui. $264 \mathrm{pp}$.

Richardson, D. M. and P. Pyšek (2006). "Plant invasions: merging the concepts of species invasiveness and community invasibility." Progress in Physical Geography 30(3): 409-431.

Roiloa, S. R. and R. Retuerto (2006). "Small-scale Heterogeneity in Soil Quality Influences Photosynthetic Efficiency and Habitat Selection in a Clonal Plant." Annals of Botany 98(5): 1043-1052.

Roiloa, S. R., S. Rodriguez-Echeverria, et al. (2010). "Physiological integration increases the survival and growth of the clonal invader Carpobrotus edulis." Biological Invasions 12(6): 1815-1823.

Salehi, M. H., O. H. Beni, et al. (2011). "Refining Soil Organic Matter Determination by Loss-onIgnition." Pedosphere 21(4): 473-482. 
Salzman, A. G. and M. A. Parker (1985). "Neighbors ameliorate local salinity stress for a rhizomatous plant in a heterogeneous environment." Oecologia 65(2): 273-277.

Sawyer, J. D. (2004). Plant Conservation Strategy: Wellington Conservancy 2004-2010. D. o. Conservation. Wellington.

Shaw, R. H. (2003). Biological control of invasive weeds in the UK: opportunities and challenges.

Plant Invasions: Ecological Threats and Management Solutions. L. B. J. H. B. G. P. K. P. P. W. P. M. C. L. Child and J. H. B. G. P. K. P. P. W. P. M. W. M. Brock: 337-354.

Sheppard, A. W., R. H. Shaw, et al. (2006). "Top 20 environmental weeds for classical biological control in Europe: a review of opportunities, regulations and other barriers to adoption." Weed Research 46(2): 93-117.

Shumway, S. W. (1995). "Physiological Integration among Clonal Ramets during Invasion of Disturbance Patches in a New England Salt Marsh." Annals of Botany 76(3): 225-233.

Spence, H. R., D. O. Bergin, et al. (2007). Ten Years of Research and Implementation: Dune Restoration Trust of New Zealand. International Conference on the Management and Restoration of Coastal Dunes. Santander, Spain.: 3-5th October, 2007.

SPSS (2008). SPSS for Windows Release 16.0.2. Chicago, SPSS Inc.

Stuefer, J. F., H. Dekroon, et al. (1996). "Exploitation of environmental heterogeneity by spatial division of labour in a clonal plant." Functional Ecology 10(3): 328-334.

Suehs, C. M., L. Affre, et al. (2004). "Invasion dynamics of two alien Carpobrotus (Aizoaceae) taxa on a Mediterranean island: II. Reproductive strategies." Heredity 92(6): 550-556.

Suehs, C. M., S. Charpentier, et al. (2006). "The evolutionary potential of invasive Carpobrotus (Aizoaceae) taxa: are pollen-mediated gene flow potential and hybrid vigor levels connected?" Evolutionary Ecology 20(5): 447-463.

Taylor, R. and I. Smith (1997). The State of New Zealand's Environment. The State of Our Biodiversity. T. M. f. t. Environment. Wellington. 9: 1 - 53.

Traveset, A., G. Brundu, et al. (2008). "Consistent performance of invasive plant species within and among islands of the Mediterranean basin." Biological Invasions 10(6): 847-858.

Vilà, M. and C. M. D'Antonio (1998). "Hybrid Vigour for Clonal Growth in Carpobrotus (Aizoaceae) in Coastal California." Ecological Applications 8(4): 1196-1205.

Vilà, M., A.-S. D. Siamantziouras, et al. (2008). "Widespread resistance of Mediterranean island ecosystems to the establishment of three alien species." Diversity and Distributions 14(5): 839-851.

Vilà, M., M. Tessier, et al. (2006). "Local and regional assessments of the impacts of plant invaders on vegetation structure and soil properties of Mediterranean islands." Journal of Biogeography 33(5): 853-861.

Vilà, M., E. Weber, et al. (1998). "Flowering and mating system in hybridizing Carpobrotus (Aizoaceae) in coastal California." Canadian Journal of Botany 76(7): 1165-1169. 
Villarreal-Barajas, T. and C. Martorell (2009). "Species-specific disturbance tolerance, competition and positive interactions along an anthropogenic disturbance gradient." Journal of Vegetation Science 20(6): 1027-1040.

Vitousek, P. M. (1990). "Biological invasions and ecosystem processes - towards an integration of population biology and ecosystem studies." Oikos 57(1): 7-13.

Vitousek, P. M., C. M. D'Antonio, et al. (1997). "Introduced species: A significant component of human-caused global change." New Zealand Journal of Ecology 21(1): 1-16.

Webb, C. J., W. R. Sykes, et al. (1988). Flora of New Zealand: Naturalised Pteridophytes, Gymnosperms, Dicotyledons. Christchurch, Department of Scientific and Industrial Research.

Wilcove, D. S., D. Rothstein, et al. (1998). "Quantifying Threats to Imperiled Species in the United States." Bioscience 48(8): 607-615.

Williams, J. A. and C. J. West (2000). "Environmental weeds in Australia and New Zealand: issues and approaches to management." Austral Ecology 25(5): 425-444.

Wilson and Sykes (1999). "Is zonation on coastal sand dunes determined primarily by sand burial or by salt spray? A test in New Zealand dunes." Ecology Letters 2(4): 233-236.

Yu, F., M. Dong, et al. (2004). "Clonal integration helps Psammochloa villosa survive sand burial in an inland dune." New Phytologist 162(3): 697-704.

Yura, H. and A. Ogura (2006). "Sandblasting as a Possible Factor Controlling the Distribution of Plants on a Coastal Dune System." Plant Ecology 185(2): 199-208. 


\section{Chapter three}

\section{Substrate preference and breeding systems in introduced Carpobrotus spp., native Disphyma australe and their hybrid.}

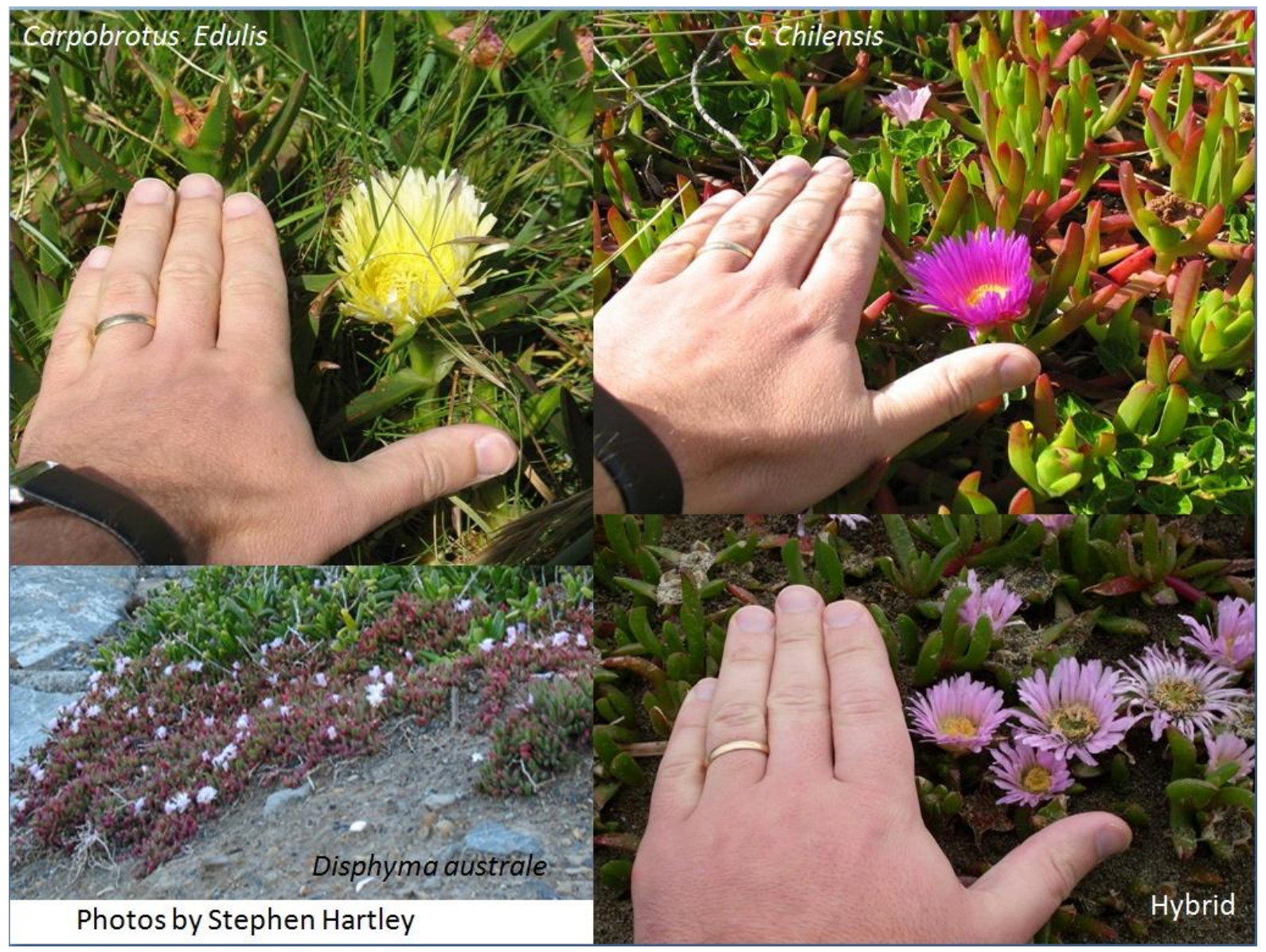

Fig. 3.1. Photos showing flower colours of the different iceplant taxa found in New Zealand 


\subsection{Abstract}

Biological invasion by non-native plant species has often been cited as a cause of native biodiversity loss. Some exotic plant species tend to hybridise with related native taxa, altering genetic diversity while a majority grow aggressively to competitively displace the pre-existing native flora. In this study, I compared the growth rates of the most widely distributed iceplant taxa in New Zealand in different substrates and the breeding systems of the exotic taxa. The exotic Carpobrotus spp. put on greater dry matter content than the native Disphyma australe and the Carpobrotus-x-Disphyma hybrid. The hybrid displayed a fast vegetative growth rate whereas $D$. australe allocated relatively more biomass to the roots than the shoot. Carpobrotus chilensis put on relatively lower biomass in gravel but the other taxa did equally well across the different substrate types. Both Carpobrotus spp. are self compatible and highly capable of intrageneric and intergeneric hybridisation.

\subsection{Introduction}

Increased worldwide human travel and trade have moved species beyond their native ranges both intentionally and inadvertently (Mack, Simberloff et al. 2000), breaking down the biogeographic barriers that have shaped and maintained the major floral and faunal regions of the Earth (Vitousek, D'Antonio et al. 1997). Many of these species become established and proliferate in their new habitat (Vitousek, D'Antonio et al. 1997). When an introduced species establishes new self-perpetuating populations in the wild and becomes incorporated within the resident flora it is said to have naturalised (Richardson, Allsopp et al. 2000). Naturalised species that proliferate, spread and endure in ecosystems in which they were formerly absent to the detriment of the pre-existing native ecosystem are considered invasive (Mack, Simberloff et al. 2000). (Vilà, Siamantziouras et al. 2008) further suggested that a species should be considered invasive when it has spread more than $6 \mathrm{~m}$ away from the input focus in less than three years, and if its reproduction is vegetative through rhizomes or stolons. Naturalised species that have become invasive constitute only around $1 \%$ of all exotic introductions (Williamson 1996; Richardson and Pyšek 2006) but they can still 
cause substantial modifications to indigenous biodiversity and ecosystem functions (Williams and West 2000). In due course, invasive species lead to a progressive and often irreparable homogenization of plant communities, with a single species dominating and influencing the processes of the whole ecosystem (Vitousek, D'Antonio et al. 1997; Mack, Simberloff et al. 2000). Nowadays, biological invasions by non-native plant species are considered to be among the most important triggers of biodiversity loss and one of the main drivers of environmental modifications (Sala, Chapin et al. 2000) at both the global and local scales (Zedda, Cogoni et al. 2010). Globally, biological invasions have been considered the second most important cause of change in the composition, structure, and functioning of natural ecosystems, after habitat destruction (Walther, Post et al. 2002; Simberloff, Parker et al. 2005; Thuiller, Richardson et al. 2005).

Many invasive plant species were deliberately introduced, often for their aesthetic value and sale as garden ornamentals (Carboni, Santoro et al. 2010). In New Zealand for example, almost all exotic plant species that have naturalised have been purposely introduced by people (Jay, Morad et al. 2003). The New Zealand Department of Conservation considers more than 240 naturalised exotic plant species as weeds that actually or potentially jeopardise the survival of nationally rare or endangered native plants (Green, 2000 as cited by Jay, Morad et al. 2003). Alien plant species are largely restricted to human dominated habitats (Affre, Suehs et al. 2010) as a result of both higher disturbance and propagule pressure (Chytrý, Pyšek et al. 2009). This is particularly pertinent for coastal dune communities, since human pressure on coastal zones with sandy interfaces around the world has progressively increased in the last 50 years (Curr, Koh et al. 2000). Although extreme abiotic factors such as low soil fertility, sand burial, and salt spray may represent a strong filtering mechanism on which species can survive in sand dunes (Wilson and Sykes 1999; Carboni, Santoro et al. 2010), a relatively large number of alien species have managed to successfully invade. This is because costal dune plant communities are very dynamic ecosystems, with many open spaces that allow the quick settlement of some exotic species with high colonizing ability (Campos, Herrera et al. 2004). Disturbances may take out competitively superior native species, eradicate natural enemies that curb invasion, and/or alter the resource base directly, in favour of non-native species (D'Antonio 1993). 
In New Zealand, South African iceplant (Carpobrotus edulis) is among a highly invasive group of alien plants that were originally introduced as ornamentals (Weber 2003) but have gone on to naturally produce populations in the wild. They were later used for coastal sand dune stabilisation, because of their rapid growth rates and ability to cope with harsh dune environment (D'Antonio, Odion et al. 1993). Furthermore, they regularly form monoculture stands, suggesting a displacement of the pre-existing native flora. Other ecological impacts of iceplant include aggressive competition with native species (D'Antonio and Mahall 1991; Sheppard, Shaw et al. 2006), destabilization of native dune communities (Campos, Herrera et al. 2004; Acosta, Carranza et al. 2008), modification of soil pH (Vilà, Tessier et al. 2006) and likely the alteration of ecosystem function in terms of successional dynamics (Carranza, Carboni et al. 2010). Consequently, C. edulis is considered among the worst invasive alien species threatening biodiversity in Europe (Sheppard, Shaw et al. 2006) and is included in the list of the most invasive alien plants in the World (Weber 2003). Owing to the large extent of invaded areas in coastal communities, it is considered one of the most costly invasive species in Spain (Andreu, Manzano-Piedras et al. 2010). However, invasion success and impacts of $C$. edulis are reported to be habitat and context specific processes (D'Antonio 1993; Maltez-Mouro, Maestre et al. 2010). In New Zealand, as of October 2006, C. edulis and its hybrids are classified as unwanted organisms (Biosecurity New Zealand 2008), yet there is a paucity of information as to their impacts locally. Clonal growth form, flexible mating systems, and ability to hybridise with related taxa may be among the most important characteristics of the exotic iceplant species that contribute to their invasion success.

Hybridisation between native and non-native species as a consequence of species introduction (Abbott 1992) may result in invasive hybrid morphotypes that, in turn, have negative implications for the conservation of native species assemblages (Vilà, Weber et al. 1998). In the invasive ranges of the Aizoaceae, hybridizations have been recorded between C. edulis and different species: native C. chilensis (Molina) N.E. Br. in California (Albert, D'Antonio et al. 1997; Gallagher, Schierenbeck et al. 1997), native C. virescens (Haw.) Schwantes in Australia (Blake 1969 as cited by Verlaque, Affre et al. 2011), native D. australe in New Zealand (Chinnock 1972), and, introduced C. acinaciformis in France (Suehs, Affre et 
al. 2004). While most of these hybridisations are intrageneric, it is only in New Zealand that it is intergeneric. It has been suggested that interbreeding increases the threat of extinction for a number of species due to hybridization introgression (Levin, Francisco-Ortega et al. 1996; Rhymer and Simberloff 1996). Hybrids can exhibit novel characters that neither parental species expresses (Rieseberg, Ellstrand et al. 1993; Rieseberg 1995) and may have advantages over parental individuals in certain habitats (Vilà and D'Antonio 1998). Novel gene combinations can extend the gene pool of a species and its ecological range, including the spread into new habitats (Lewontin and Birch 1966). A classic example of this is where seed-sterile Spartina Xtownsendii, an intrageneric hybrid of native S. maritima and exotic S. alterniflora in southern England, formed a fertile S. anglica by chromosome doubling (Ayres and Strong 2001). Hybridisation has the potential to dilute the gene pool of native species and create highly aggressive genotypes that may be undesirable in terms of management for native species (Ellstrand 1992; Rhymer and Simberloff 1996). It is believed to be a factor that allows the spread of plant species into areas they did not previously occupy (Abbott 1992) and hybrid vigour for vegetative growth may be one of the reasons for displacement of parental morphotypes or native species (Vilà and D'Antonio 1998). In the case of S. anglica, which has now become predominant in the estuarine salt marshes of the British Isles (Thompson 1991), neither of its parental species is present at its presumed site of origin in Hythe, England, and its native parent S. maritima is considered extremely rare or extinct in most of its former British range (Raybould, Gray et al. 1991).

One of the characteristics which increase the probability of successful invasion is the ability of clonal growth (Heger and Trepl 2003; Mack 2003) which is suggested as one of the most successful growth strategies in the plant world (Traveset, Moragues et al. 2008). Carpobrotus species are clonal plants capable of achieving high rates of space colonization (Sintes, Moragues et al. 2007), which suppresses the growth and establishment of other plants (D'Antonio and Mahall 1991; Albert, D'Antonio et al. 1997; Suehs, Affre et al. 2004; Vilà, Tessier et al. 2006). A characteristic of clonal growth that confers competitiveness is the efficient distribution of tasks among ramets which, coupled with phenotypic plasticity, can lead to enhanced resource exploitation (Stuefer, DeKroon et al. 1996). Clonal growth and its ability to survive in extreme environmental conditions make $C$. edulis a very 
competitive plant with a subsequent negative impact on native flora (D'Antonio and Mahall 1991; D'Antonio, Odion et al. 1993; Moragues and Traveset 2005; Vilà, Tessier et al. 2006).

\subsubsection{Aims of the study}

To be able to understand the possible impacts of exotic iceplant species on native biodiversity, a useful starting point is the study of the mechanisms that are implicated for their success as invaders. The aim of this study is to compare growth rates and breeding systems of the iceplant taxa commonly found in New Zealand. The following research questions were explored in this study: (i) how do the field growth rates of the exotic and native iceplant, and their hybrids compare? (ii) What is the substrate preference of the various iceplant species? (iii) What is the potential implication of the growth rates on the native Disphyma australe? (iv) To what extent do flower phenology of the iceplant species overlap? (v) How do the exotic species differ in their mating systems and interbreeding with native Disphyma? This knowledge will then be evaluated in the context of environmental management of coastal dune habitats.

\subsection{STUDY SPECIES}

\subsubsection{Carpobrotus spp. and their intrageneric hybrid}

Carpobrotus species are members of Aizoaceae, many of which are native to the Karoo region of South Africa. They are succulent perennial plants with creeping, prostrate growth habits, capable of crawling over shrubs, fences and other obstacles (D'Antonio 1990). Leaves are opposite and sharply three-angled with variable keel serrations. Carpobrotus forms large mats on coastal rocks, cliffs, and sand dunes owing to its profuse clonal growth (D'Antonio 1990; 1993; Traveset, Brundu et al. 2008). Active growth occurs primarily along main axes, although lateral branches may also grow, particularly following death of the apical meristem of the main axis (D'Antonio 1990). Rooting occurs where nodes contact the soil and they spread radially with an individual branch elongating more than $1 \mathrm{~m}$ in a year 
(D'Antonio 1990). Branches tend to grow over each other, resulting in the accumulation of up to $40 \mathrm{~cm}$ of live and dead plant material (D'Antonio 1990). A single individual of $C$. edulis has been reported to form dense, circular mats up to $20 \mathrm{~m}$ wide and over $50 \mathrm{~cm}$ deep (D'Antonio and Mahall 1991) that are nearly impenetrable and appear to totally eliminate all other vegetation in the immediate area (Campos, Herrera et al. 2004). Carpobrotus chilensis mats are said to be shallower in depth and have more bare space within them (Vilà and D'Antonio 1998).

Flowers are solitary and terminal, borne on vertical shoots and do not seem to require specific pollinators. They are unique within Aizoaceae in that they have fleshy indehiscent fruits (Albert, D'Antonio et al. 1997). In California, C. edulis hybridises with C. chilensis (N.E.Br.) and hybrids are also self-compatible (Vilà and D'Antonio 1998). Introgressive hybridization is very common (Vilà, Weber et al. 1998), occurring throughout coastal California between the non-native Carpobrotus edulis and the putative native $C$. chilensis, leading to a high abundance of invasive hybrid morphotypes that compete aggressively with native plant coastal species (D'Antonio 1990; Albert, D'Antonio et al. 1997; Vilà and D'Antonio 1998). The fleshy fruits bear a large number, often over a thousand, of small seeds (Bartomeus and Vilà 2009)that are eaten and widely dispersed by several mammals such as rabbits (D'Antonio 1990) and rats (Bourgeois, Suehs et al. 2005). Carpobrotus has a long-lived seed bank that can remain viable in the soil for at least two years (D'Antonio 1990).

There are two naturalized species of Carpobrotus (C. edulis (L.) N.E.Br., and C. chilensis (Molina) N.E.Br.) that occur widely in coastal parts of New Zealand (Heenan and Sykes 2010). These species have been introduced in different parts of the world as ornamental plants and for erosion prevention (Weber 2003). While C. edulis is native to South Africa, the origin of C. chilensis is not known (Albert, D'Antonio et al. 1997). Carpobrotus chilensis is no longer present in Chile (Schierenbeck, Symonds et al. 2005) if indeed this was its origin, as suggested by its scientific name. It is widely spread in California and is believed to be native in this region (Schierenbeck, Symonds et al. 2005). Carpobrotus edulis was introduced to New Zealand from South Africa as an ornamental plant and naturalised around 1883 (Webb, Sykes et al. 1988; D'Antonio and Mahall 1991). In New 
Zealand they often occur in association with D. australe subsp. australe (Heenan and Sykes 2010). Of these two exotics, C. edulis and its hybrids are regarded as invasive in New Zealand.

\subsubsection{Disphyma species}

There are two species of the genus Disphyma native to New Zealand. Of these, $D$. papillatum is endemic to Chatham Island (Chinnock 1971; Webb, Sykes et al. 1988). The other, Disphyma australe (W.T. Aiton) N.E.Br is subdivided into two subspecies: D. australe subsp. stricticaule Chinnock is endemic to Kermadec Islands while D. australe subsp. australe occurs on North, South, Stewart and Chatham Islands (Chinnock 1976). Disphyma maclavellatum (Haw.) is of Australian origin but is considered naturalised (Webb, Sykes et al. 1988). There are two forms of $D$. australe subsp. australe that are distinguishable by the colour of their vegetative parts (Chinnock 1971). One produces red betanin pigments in response to changing environmental conditions while the other always remains green (Chinnock 1972). Unlike their exotic counterparts Disphyma spp. have dehiscent, hygrochastic capsules (Chinnock 1971). Very little is known about the ecology of Disphyma. An electronic search of the word "Disphyma" in the Web of Knowledge databases returns only 25 articles, most of which are floras that only mention presence/absence of the species.

\subsection{3. xCarpophyma mutabilis Heenan and Sykes 2010}

xCarpophyma mutabilis is the name given to the hybrid produced by intergeneric hybridisation between C. edulis and D. australe (Heenan and Sykes 2010). These plants have characteristics intermediate to their parents (Chinnock 1971; Heenan and Sykes 2010). They are highly sterile with chromosome count being $2 n=27$ (Chinnock 1972). Flowers rarely develop into fruits and if they do they are seedless (Pers. obs.; Chinnock 1972). Intergeneric hybridisation of $C$. chilensis and $D$. australe results in a hybrid named xCarpophyma pallida that is said to be found in the Canterbury region and on Chatham Island of New Zealand 
(Heenan and Sykes 2010). xCarpophyma mutabilis is said to be the more common intergeneric hybrid in New Zealand (Heenan and Sykes 2010). Detailed morphological descriptions of these hybrids (as well as of their putative parents) have been given by (Chinnock 1972) and (Heenan and Sykes 2010)but they are quite similar and therefore difficult to distinguish. For this study, all the intergeneric sample plants were obtained from Wellington region and are therefore assumed to be xCarpophyma mutabilis.

\subsection{METHODS}

\subsubsection{Experiment 1 (Common garden experiment - growth characteristics in different substrates)}

Cuttings of the four different taxa of iceplant were obtained from 2-5 different populations around Wellington (Fig. 3.2; Appendix 1, Table 3) and planted in gravel $(7.5 \mathrm{~mm}$ diameter), coarse sand (commercial propagation sand No.2, 0.3-4.75mm) and fine sand (commercial propagation sand No.1, $0.15-2.35 \mathrm{~mm}$ ) in the Victoria University glasshouse between $13^{\text {th }}$ and $19^{\text {th }}$ June 2011 . Samples of cuttings of each taxon were dried in an oven at $70^{\circ} \mathrm{C}$ for 48 hours to compare their initial biomass. Morphometric data (Chinnock 1972), especially flower colour, was used in identifying the different species earlier in the previous year when plants were flowering. It is possible that the two exotic species (Carpobrotus spp.) do not always (or often) exist as pure species in New Zealand and may in fact be thought of as different colour morphs or different ends of a hybrid swarm between $C$. edulis and C. chilensis (see Gallagher et al. 1997; Schierenbeck et al. 2005; Suehs et al. 2004). For the purposes of this thesis we continue to use the two names $C$. edulis for large yellowflowered Carpobrotus and C. chilensis for large magenta-flowered Carpobrotus. Due to the limited distribution of $C$. chilensis, cuttings were only obtained from two populations. Each cutting was made up of two nodes with two true leaves for Carpobrotus and four true leaves for Disphyma and the hybrid. Leaves were considered true when they were fully open. 

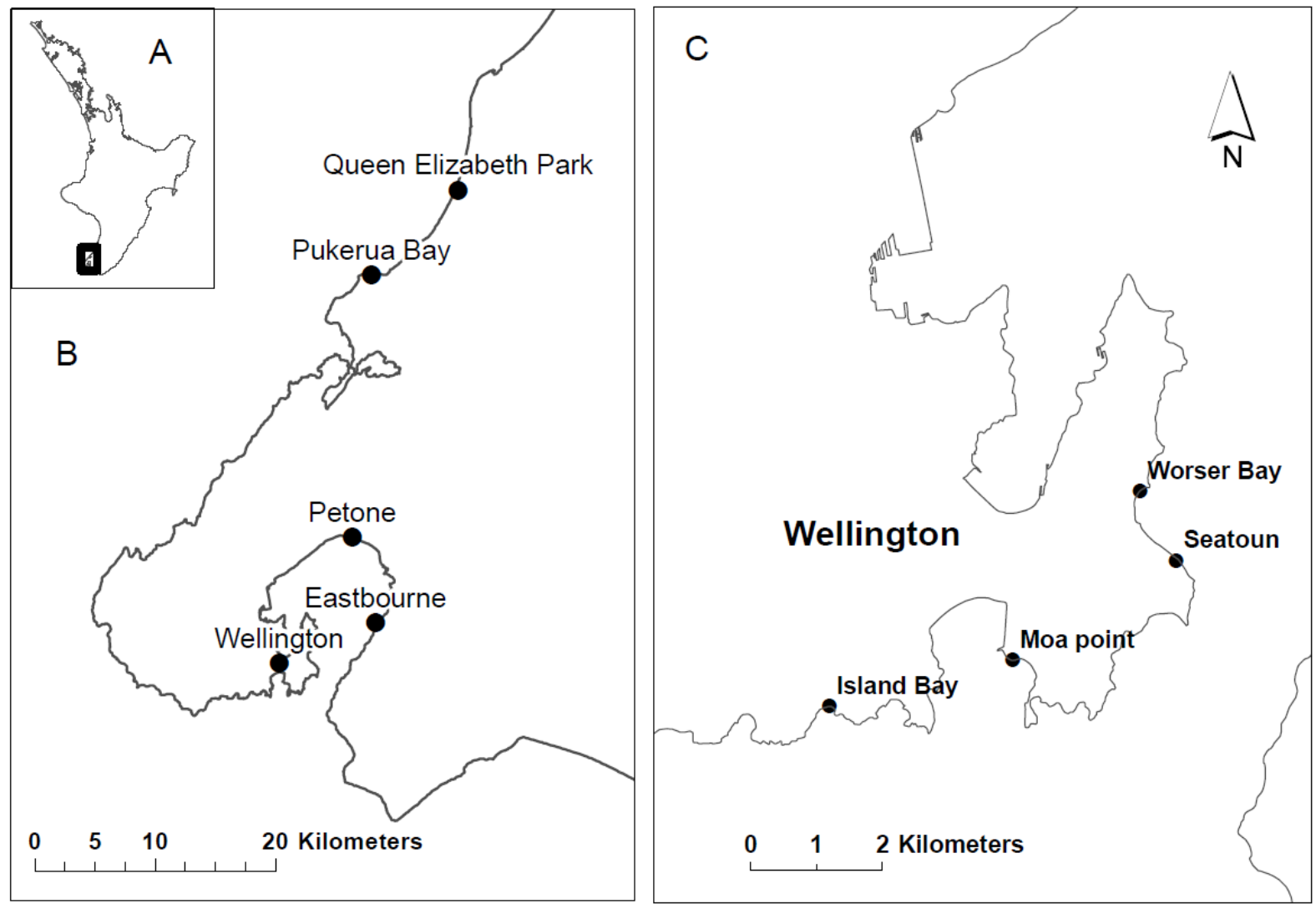

Fig. 3.2: Map of North Island New Zealand (A) showing Wellington region and sites from where the iceplant cuttings were obtained ( $B$ and $C)$.

Twelve cuttings were obtained from each site and four of them planted in each medium except for $C$. Chilensis which was only found at two sites. Each cutting was planted in a container measuring $9 \mathrm{~cm} \times 9 \mathrm{~cm} \times 11 \mathrm{~cm}$ in a medium formed by mixing two parts gravel or sand and one part potting mix. The cuttings were planted with one internode below the soil surface and the terminal node at soil-air interface. In total, 60 cuttings per species were distributed among the three substrate types. The cuttings were watered every second day for the period of the time that they were in the glasshouse (until the end of August) and moved around every two weeks to prevent positional effects.

On $4^{\text {th }}$ of September all plants were relocated to the Victoria University Coastal Ecology Laboratory (VUCEL) at Island Bay. The pots were placed in trays holding 24 plants each arranged in an open area where they are exposed to natural weather elements. The trays were lined parallel to the coastline, $8 \mathrm{~m}$ from the high tide mark so that they received 
similar amounts of salt spray. The number of leaves, length and number of nodes of each plant were measured at the time of relocation and repeated at two-monthly intervals over the spring season. At the end of the experiment $\left(28^{\text {th }}\right.$ December 2011$)$ number of leaves, length of the main axis, number of main axis nodes, number of lateral branches and the number of nodes along lateral branches (Fig. 3.3) were recorded. Plants were then destructively harvested and separated into shoot and root portions. Roots were then thoroughly but gently washed under a running tap to remove all the soil. Each shoot and root was then dried in marked paper envelopes to a constant weight in an oven at $70^{\circ} \mathrm{C}$.

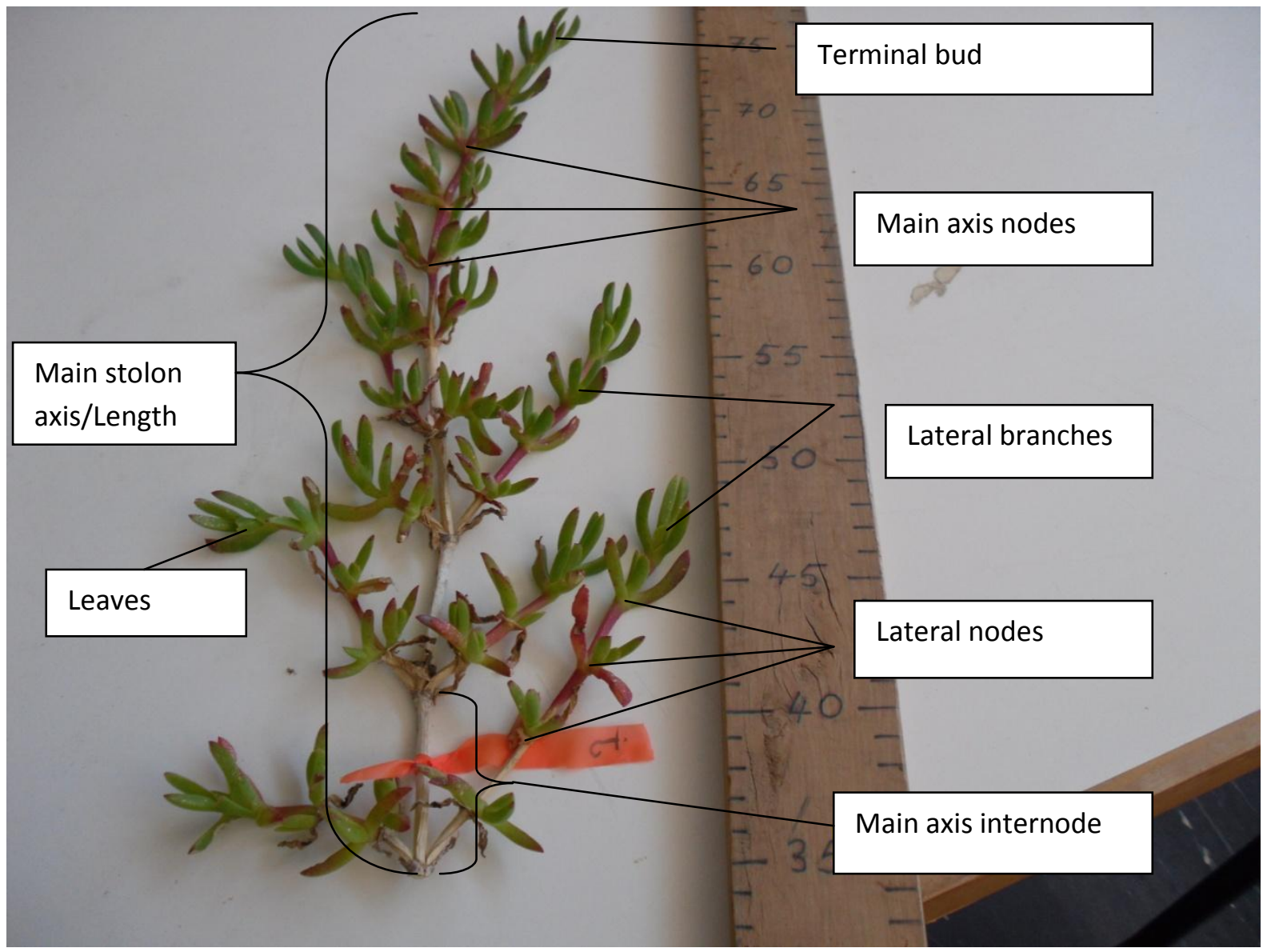

Fig. 3.3: Photo of a hybrid stolon showing morphological features referred to frequently in the sections that follow. The tag was originally placed just below the cut in September and the stolon harvested in December. Growth of the illustrated sample occurred over a three month period. 


\subsubsection{Experiment 2 (Field Growth monitoring)}

On $10^{\text {th }}$ of January 2011 one plant each of $C$. edulis and C. chilensis at the back dune were selected and fifty stolons per plant were tagged at a node just below the terminal bud. These were the only easily identifiable Carpobrotus plants in this section of the dune because they were in flower. Around the same time, ten stolons on each of four $C$. chilensis plants at the foredune were tagged at a node below the terminal bud. Ten stolons each were also tagged on five hybrid and $D$. australe plants at one and two nodes below each terminal bud respectively. The number of nodes along the main axis forward of the tag was counted at two to three month intervals. On $24^{\text {th }}$ of September 2011, the total number of internodes, lateral branches and leaves forward of the tags were counted on all the stolons. Between $21^{\text {st }}$ and $24^{\text {th }}$ September 2011, ten additional stolons were tagged on the old Carpobrotus plants at Eastbourne. In addition, two new $C$. chilensis plants at the backdune and four new $C$. edulis plants (one at the foredune and the others at the rear) were selected and ten stolons tagged on each at the same site. Similarly, new tags were placed on an additional five stolons per plant of the old $D$. australe, and ten per plant on the hybrids at Day's Bay. Around the same time, ten stolons per plant of $C$. edulis at Queen Elizabeth Park were tagged on four plants each at the rear and foredunes. At the end of the experiment (after their vegetative growth characters were measured) 7-10 stolons tagged in September were harvested from a plant of each taxon, except Disphyma australe for conservation reasons. These stolons were transported quickly in air-tight zip-lock polythene bags and their fresh weight determined in the laboratory before they were dried to a constant weight at $70^{\circ} \mathrm{C}$ in an oven and their dry weights measured.

\subsubsection{Experiment 3 (Mating systems)}

A breeding experiment was conducted at Eastbourne between $17^{\text {th }}$ and $18^{\text {th }}$ of September 2011. Fifty flower buds each of C. edulis and C. chilensis were selected and assigned to five breeding treatments (10 flowers per treatment): (i) agamospermy (emasculated, stigmas clipped and flowers bagged), (ii) spontaneous self-fertilisation 
(bagged flowers not manipulated), (iii) artificial self pollination (pollen donor was a different flower of the same individual plant), (iv) artificial pollination with the other congener, and (v) artificial pollination with $D$. australe. The flowers were selected before they opened up to ensure that no self pollination would have taken place naturally before manipulation. All flower buds were bagged using fine meshed nylon bags $(0.25 \mathrm{~mm} \times 0.22 \mathrm{~mm})$ to exclude insect pollinators. However, no insecticides to exclude very small arthropods like mites and aphids that might crawl up the pedicels were applied, although no such potential pollinators were observed. Artificial self pollination involved dusting of pollen of other flowers of the same plant on to the stigmas of experimental flowers. During emasculation, the calyx and corolla were also removed since at that stage it was impossible to remove stamens only. However, I did not remove the corolla and calyx of the non-emasculated flowers to control for any independent effects these structures may have on seed production. Hand pollination was done about eight days later and on two consecutive days by plucking mature flowers of the pollen donor and dusting the fresh pollen onto the stigmas of the recipient using a fine painting brush. Care was taken to ensure that the brush used for one pollen donor was not used with the other. Hand pollination was done one flower at a time, after which the flower was bagged again. The flowers remained bagged until fruits were harvested on $3^{\text {rd }}$ of January 2012. Each fruit was opened up and seeds removed from each carpel. The seeds were washed in a muslin bag under running water to remove the mucilaginous sap and the numbers of seeds contained were recorded.

In addition, five plants per taxon in fixed quadrats measuring $4 \mathrm{~m}^{2}$ were selected at Eastbourne and Day's Bay for monitoring of flower phenology starting $21^{\text {st }}$ of September at about four week intervals until the end of December 2011. All twelve D. australe plants were monitored for flower phenology.

\subsubsection{Statistical analysis}

All data were analysed in SPSS statistical package (SPSS Inc. 2008). 


\subsubsection{Experiment 1: common garden experiment}

For the cuttings, growth was measured as dry weights (root, shoot, total and root mass ratio), and net increase in stolon length, number of nodes and leaves over the field growth period (September to December 2011) at the Island Bay field site. Two-way ANOVA with the substrate and taxon as independent variables, including their interaction, and the measured growth parameters (biomass measurements, number of stolons, etc) as dependent variables were used. The data were then split by taxa and one-way ANOVA run with substrate as the fixed variable to test how plants of the same taxon performed in the different substrate types. Further one-way ANOVA was calculated after splitting the data by substrates to test how plants of the different taxa performed in the same substrate types. In addition, the source plant from which the cuttings were obtained was used as a random factor in a mixed model analysis. Bivariate correlation between biomass and other measured parameters was also assessed to determine which vegetative growth aspect best predicts biomass.

\subsubsection{Experiment 2: field growth monitoring}

Although there were some outliers, the data were mostly distributed normally and there was no need for transformation. For field growth experiments, the data were split into the different growth periods (January-December, January-September, and SeptemberDecember) because additional plants were tagged in September and comprehensive measurements conducted periodically. Therefore, the January-September and SeptemberDecember periods are subsets of the January-December period for most plants. Data for the September period are the difference of the other two periods for most plants and therefore some negative growth is expected. Nested ANOVAs were calculated in SPSS for the growth experiments with net incremental values of the measured parameters (increase in length, number of main axis nodes, etc) for each taxon as the dependent variable and the individual plants as a random variable nested within "taxon." Where variability in a parameter among taxa was found, the values were aggregated and post hoc tests run to 
compare their performance. The data of the sample shoots destructively harvested were combined with those relating to the shoots of the cuttings and used in generating a linear regression model for estimating biomass (dry weights) of the field stolons.

\subsubsection{Experiment 3: breeding and cross-pollination}

Descriptive statistics and one-way ANOVA in SPSS was calculated for the number of seeds produced by the Carpobrotus spp. subjected to different breeding treatments with number of seeds as the dependent variable and the breeding treatment as the independent factor.

\subsection{RESULTS}

\subsubsection{Growth of cuttings in the common garden experiment}

Only 16 cuttings (6.7\%) of the 240 planted died during the life of the experiment, mostly due to herbivory during exposure to field conditions. The initial biomass of the sample cuttings showed that $C$. edulis cuttings had a significantly higher biomass than those of the other taxa $(P<0.001)$. Carpobrotus chilensis also had a higher biomass than $D$. australe and the intergeneric hybrid $(P<0.001)$. However, there was no difference in the initial biomass of $D$. australe and the hybrid sample cuttings (Appendix 2, Table 1).

The final biomass (root plus shoot) was affected by the substrate $\left(F_{2,200}=5.415 ; P=\right.$ 0.005; Table 3.1), taxon $\left(F_{3,200}=77.930 ; P<0.001\right)$ and the interaction of these two $\left(F_{6}\right.$, $200=2.558 ; P=0.021$ ). In post hoc tests there was no difference between the two Carpobrotus species, but both had a significantly higher total biomass than the hybrid and $D$. australe $(P<0.001)$. Comparisons of plants of different taxa growing in the same substrate showed that in all substrate types, $C$. chilensis and $C$. edulis plants accumulated greater 
biomass than $D$. australe $(P<0.001)$ and the hybrid at various levels of significance except in gravel where biomass of $C$. chilensis did not differ from that of the hybrid (Fig. 3.4). The hybrid also had a higher total biomass than Disphyma australe $(P<0.001)$. Only $C$. chilensis showed a significant difference in performance across the various substrates $\left(F_{2,54}=8.951 ; P\right.$ $<0.001$; Table 3.2; Fig. 3.5) where those plants in coarse and fine sand did better than those in gravel $(P=0.011$ and $P<0.001$ respectively).

Table 3.1: Two-way ANOVA table showing that total dry weights of the cuttings varied with substrate type, taxa and interaction of the two factors (Type III Sum of Squares).

\begin{tabular}{|c|c|c|c|c|}
\hline Source & $\mathrm{df}$ & Mean Square & $\mathrm{F}$ & Sig. \\
\hline Substrate & 2 & 4.8 & 5.415 & .005 \\
\hline Taxon & 3 & 68.9 & 77.930 & $<.001$ \\
\hline Substrate $*$ Taxon & 6 & 2.3 & 2.558 & .021 \\
\hline Error & 200 & .9 & & \\
\hline
\end{tabular}




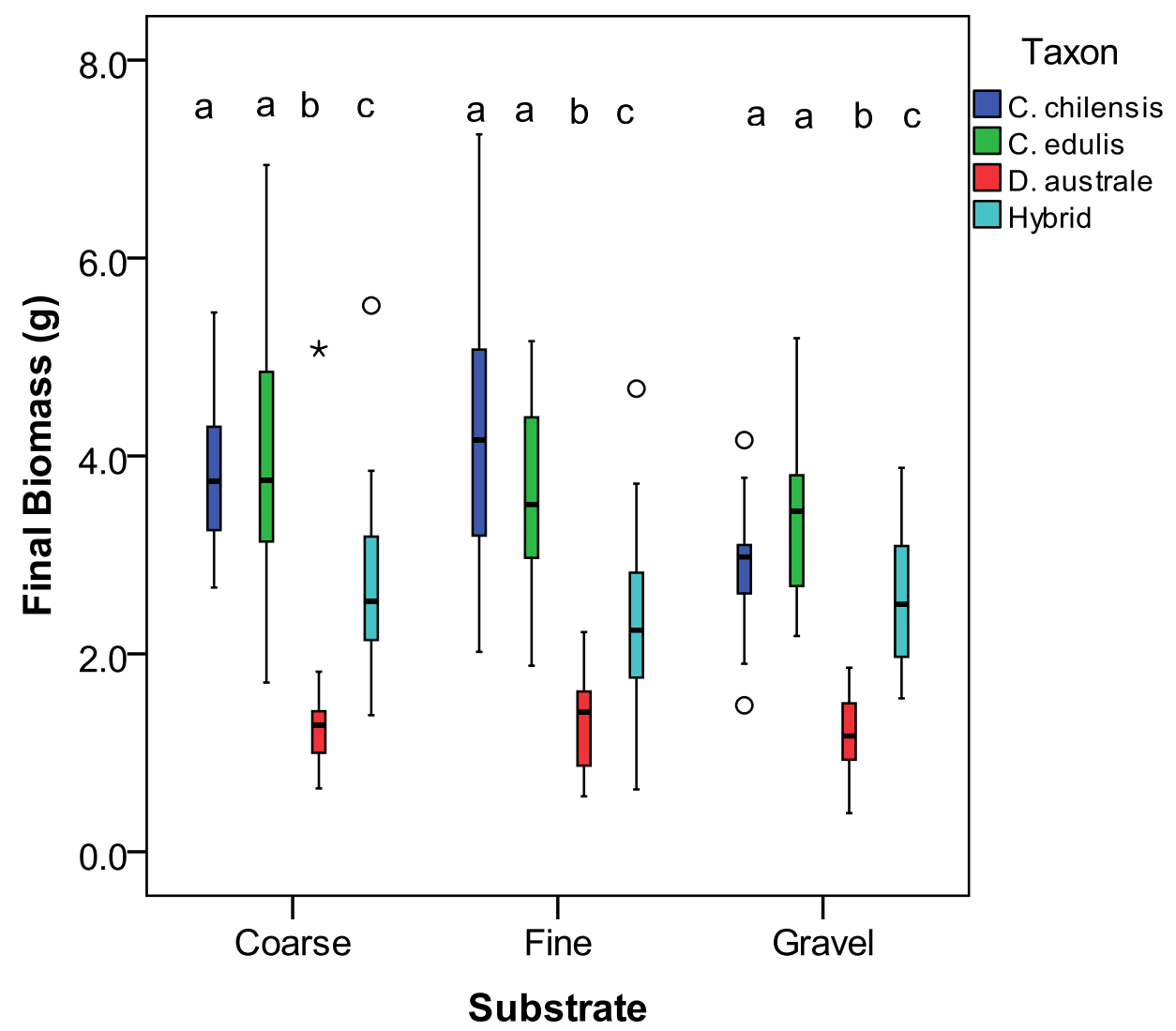

Fig.3.4: Boxplots showing final biomass of the cuttings of the various taxa growing in different substrate types. Different letters at the top of the bars indicate significant $(P<0.05)$ variability in post-hoc test between taxa in the same substrate type.

Table 3.2: Tukey HSD table showing that $C$. chilensis cuttings growing in gravel put on less final biomass than those growing in fine and coarse sand.

\begin{tabular}{lllrrr}
\hline Taxon & (I) Subst & (J) Subst & $\begin{array}{c}\text { Mean Difference } \\
(\mathrm{I}-\mathrm{J})\end{array}$ & Std. Error & \multicolumn{1}{c}{ Sig. } \\
& & & & & \\
\hline C. chilensis & Coarse & Gravel & .96 & .31950 & $\mathbf{0 1 1}$ \\
& Fine & Gravel & 1.33 & .32346 & $<.001$ \\
\hline
\end{tabular}




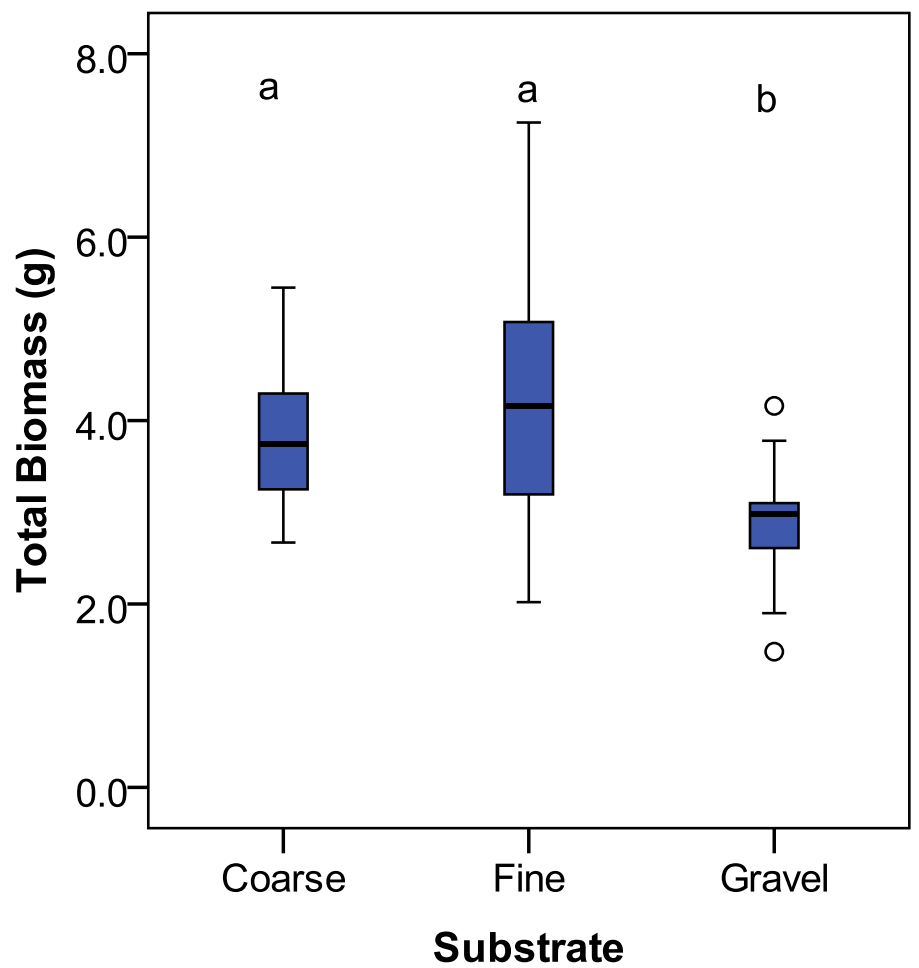

Fig. 3.5: Boxplots showing variability in final biomass of $C$. chilensis cuttings growing in different substrates (different letters above the bars represent significant differences at $P<0.05$ ).

Biomass allocation to above- or below-ground structures, in terms of root mass ratio (root dry weight/total biomass), was not affected by the substrate but regardless, there was significant variability among the various taxa $\left(F_{3,200}=164.799 ; P<0.001 ;\right.$ Table 3.3$)$. On the whole, there was no difference in RMR between Carpobrotus species. Disphyma australe had a significantly higher root mass ratio (RMR) than the other three (Fig. 3.6; $P<0.001$ ), with the hybrid also having a higher RMR than the two Carpobrotus $(P<0.001)$. However, RMR did not differ between $D$. australe and the hybrid in fine sand. Plants of the same taxon growing in different substrate types did not differ in their RMR. 
Table 3.3: Two-way ANOVA table showing root mass ratio of the cuttings was not affected by the substrate but varied among taxa.

\begin{tabular}{|c|c|c|c|c|}
\hline Source & $\mathrm{df}$ & Mean Square & $\mathrm{F}$ & Sig. \\
\hline Substrate & 2 & .003 & 2.618 & .075 \\
\hline Taxon & 3 & .177 & 164.799 & $<.001$ \\
\hline Substrate ${ }^{*}$ Taxon & 6 & .001 & 1.136 & .343 \\
\hline Error & 200 & .001 & & \\
\hline
\end{tabular}

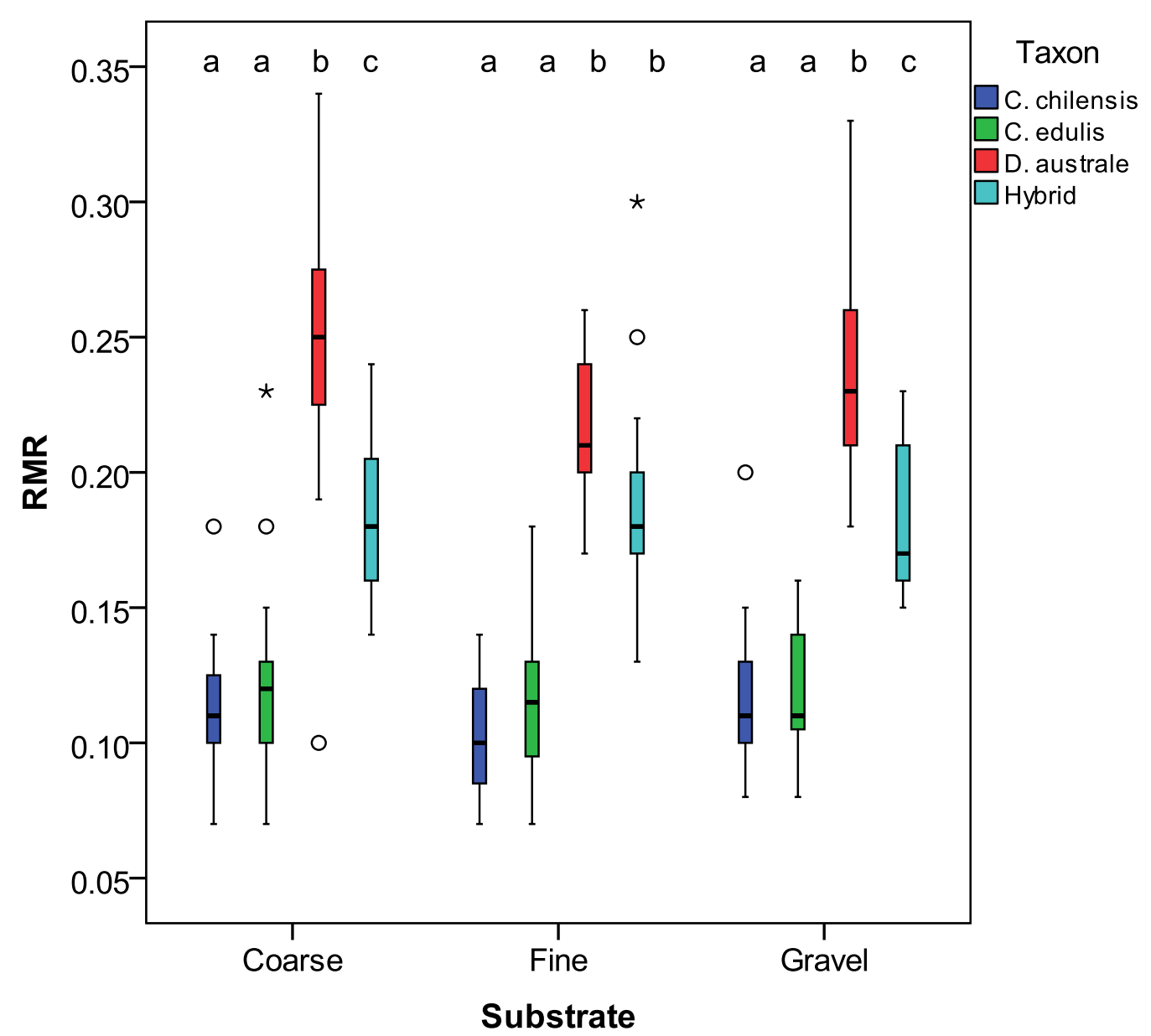

Fig. 3.6: The final root mass ratio (RMR) of cuttings of each taxon growing in the various substrates. Letters above the bars indicate variability among taxa growing in the same substrate at $P<0.05$ significance levels. 
Substrate type did not have any influence on the number of leaves produced in the field but there was significant variability among taxa $\left(F_{3,212}=61.093 ; P<0.001 ;\right.$ Fig. 3.7; Table 3.4), except between the two Carpobrotus species. Comparison of plants of the same taxon in different substrate types showed variability only among $C$. chilensis plants $\left(F_{2,56}=5.74 ; P=\right.$ 0.005; Table 3.5) where plants growing in fine sand, on average, produced four more leaves than those in gravel $(P=0.004)$. There was significant variability among plants of different taxa growing in the same substrate type, except between the two Carpobrotus species. The hybrid produce more leaves than Carpobrotus in all substrates $(P<0.001)$, and more than $D$. australe in coarse sand $(P=0.003)$ as well as in gravel $(P=0.004)$. Disphyma australe performed better than Carpobrotus in coarse sand $(P=0.002)$. In addition, $D$. australe accumulated more leaves than $C$. chilensis $(P=0.004)$ and $C$. edulis $(P=0.001)$ in fine sand as well as gravel ( $P=0.001$ and $P=0.004$ respectively). However, there was no difference between $D$. australe and hybrid in fine sand. 


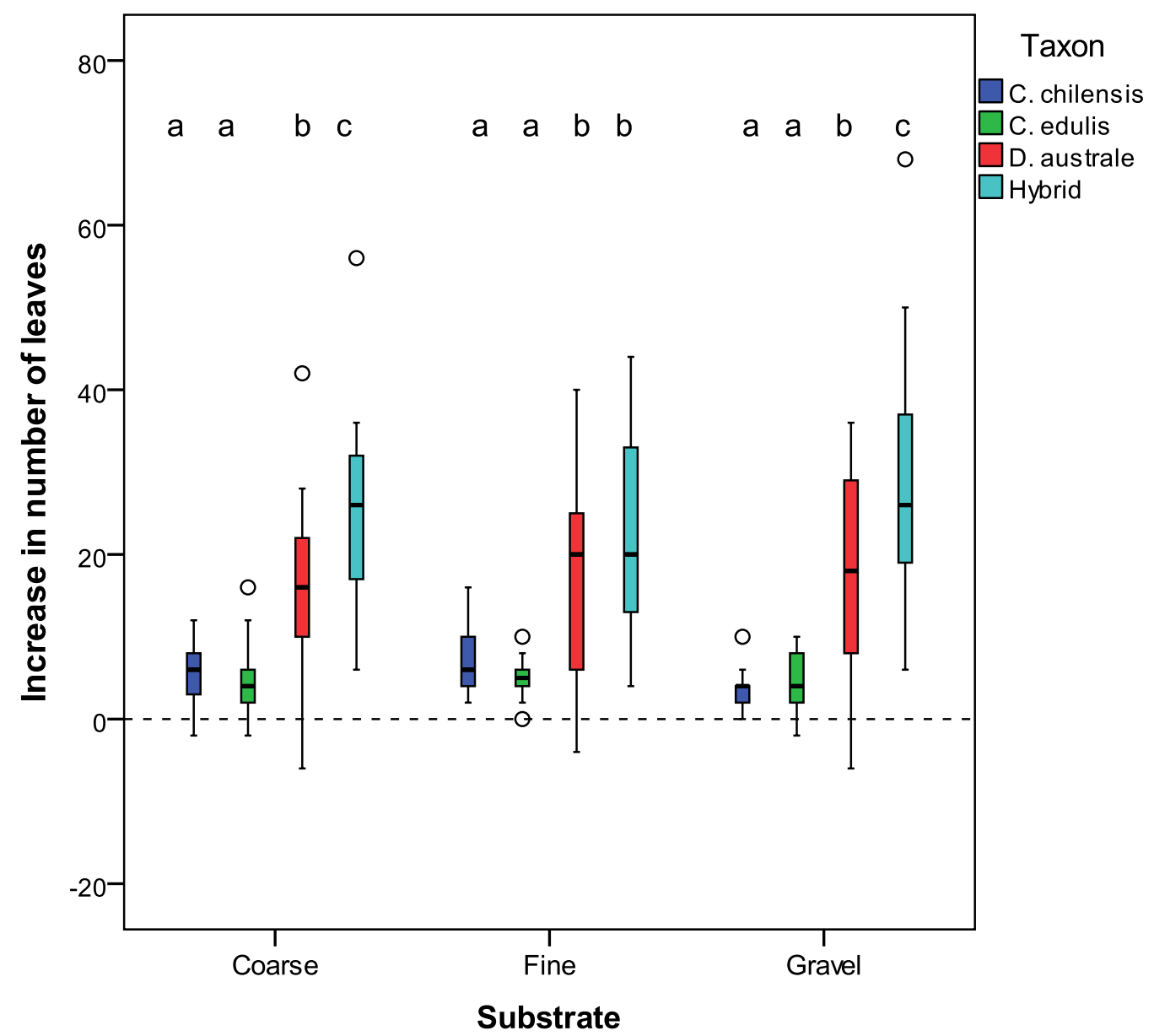

Fig. 3.7: Boxplots showing that the hybrid cuttings produced more leaves in the field than the other taxa and that $D$. australe produced more leaves than Carpobrotus spp. over the four month period. Different letters above the bars represent significant differences between taxa, within each substrate $(P<0.05)$.

Table 3.4: ANOVA table showing substrate and its interaction with taxon did not have any effect on increase in the number of leaves of cuttings over the four-month field exposure period.

\begin{tabular}{|c|c|c|c|c|}
\hline Source & $\mathrm{df}$ & Mean Square & $\mathrm{F}$ & Sig. \\
\hline Substrate & 2 & 10.8 & .117 & .889 \\
\hline Taxon & 3 & 5642.7 & 61.093 & $<.001$ \\
\hline Substrate $*$ Taxon & 6 & 109.5 & 1.185 & .315 \\
\hline Error & 212 & 92.4 & & \\
\hline
\end{tabular}


Table 3.5: Summary of separate ANOVAs showing that over the four month field exposure period substrate had an effect on leaf increase of $C$. chilensis only.

\begin{tabular}{llrrrr}
\hline Taxon & Source & df & Mean Square & \multicolumn{1}{c}{ F } & \multicolumn{1}{c}{ Sig. } \\
\hline C. chilensis & Substrate & 2,56 & 68.1 & 5.740 & .005 \\
C. edulis & Substrate & 2,46 & .6 & .047 & .954 \\
D. australe & Substrate & 2,54 & 26.1 & .161 & .852 \\
Hybrid & Substrate & 2,56 & 246.5 & 1.443 & .245 \\
\hline
\end{tabular}

The net increase in the number of nodes along the main axes did not differ with substrate type but variability among taxa was significant $\left(F_{3,212}=89.969 ; P<0.001\right)$. Both the hybrid and $D$. australe had more nodes than Carpobrotus species $(P<0.001)$. The hybrid also produced more nodes than $D$. australe $(P=0.041)$. There was no variability within members of the same taxon growing in different substrates. Performance of plants of different taxa growing in the same substrate type showed that $D$. australe and the hybrid both had significantly more nodes than Carpobrotus species in all substrates $(P<0.001)$. There was no difference in the number of main axis nodes between the Carpobrotus species as well as between the hybrid and $D$. australe. In addition, there was a highly significant variability among taxa in terms of internode length (total length/ (main axis nodes-1)) $\left(F_{3}\right.$, ${ }_{212}=47.046 ; P<0.001 ;$ Table 3.6) with the hybrid cuttings having longer internodes than all the other taxa $(P<0.001 ;$ Table 3.4; Fig. 3.8). There was no difference in the internode lengths among the other three taxa.

Table 3.6: ANOVA table showing that the lengths of stolon internodes varied among the taxa but the substrate type in which plants were growing did not have any influence.

\begin{tabular}{|c|c|c|c|c|}
\hline Source & $d f$ & Mean Square & $F$ & Sig. \\
\hline Taxon & 3 & 13.432 & 47.046 & $<.001$ \\
\hline Substrate & 2 & .005 & .018 & .982 \\
\hline Taxon * Substrate & 6 & .170 & .596 & .734 \\
\hline Error & 212 & .286 & & \\
\hline
\end{tabular}




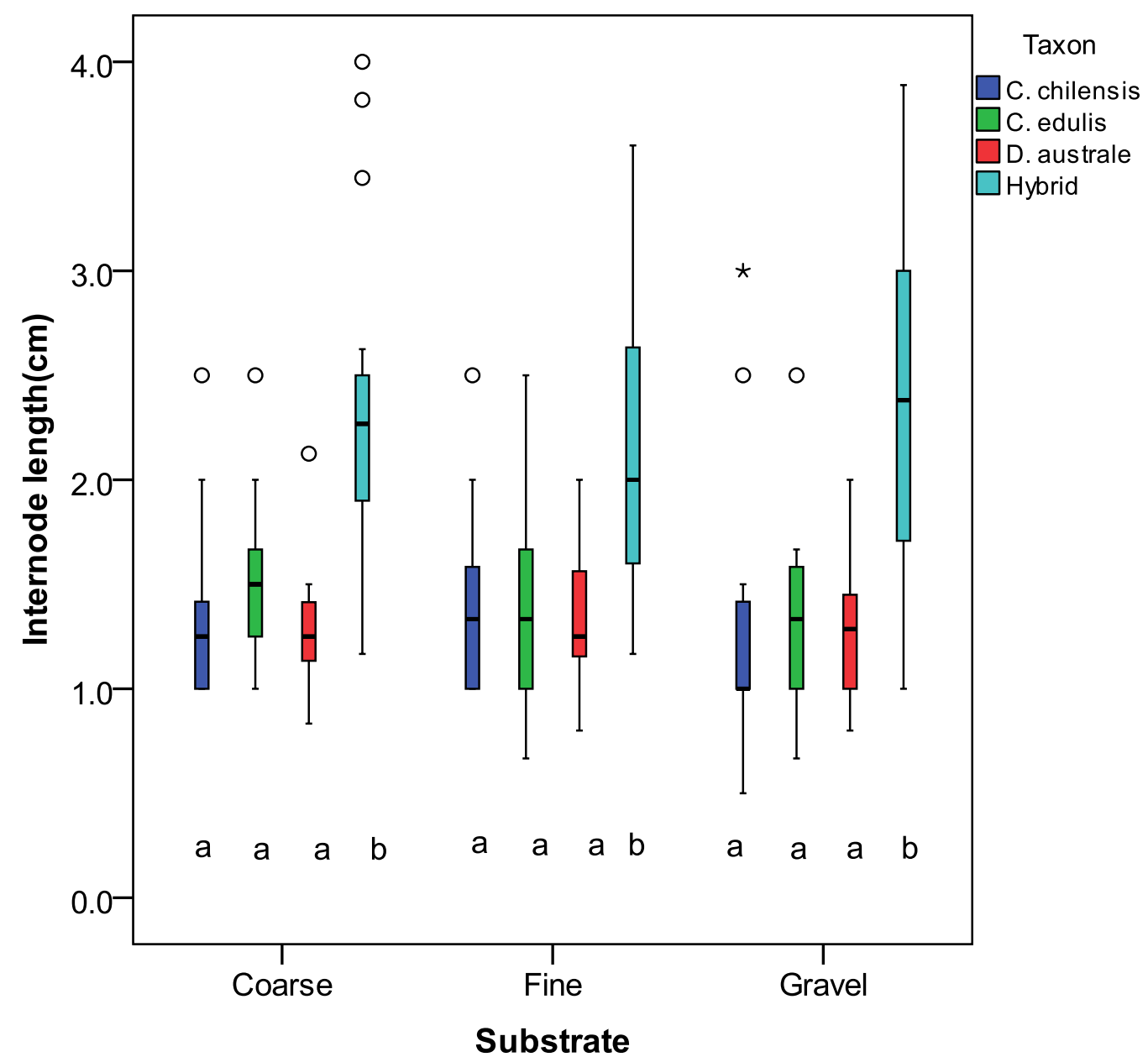

Fig. 3.8: Average internode length of cuttings of each taxon in the various substrates grown over a period of six months. The different letters below the bars indicate variability among plants of different taxa growing in the same substrate $(P<0.001)$.

Net increase in lengths of main axes did not differ with substrate type but variability among taxa was significant $\left(F_{3,212}=68.834 ; P<0.001\right)$. The hybrid stolons were longer than those of the other taxa $(P<0.001)$ while $D$. australe stolons grew longer than $C$. chilensis $(P$ $<0.001)$ and $C$. edulis $(P=0.014)$. There was no variability within members of the same taxon growing in different substrates. Between substrate comparisons (Fig. 3.9) showed that in gravel the hybrid outgrew all the other taxa $(P<0.001)$. In coarse and fine sand the hybrid grew longer than Carpobrotus $(P<0.001)$ as well as $D$. australe $(P<0.001 ; 0.003$ respectively). Disphyma australe grew longer than $C$. chilensis in fine sand only $(P=0.048)$. 


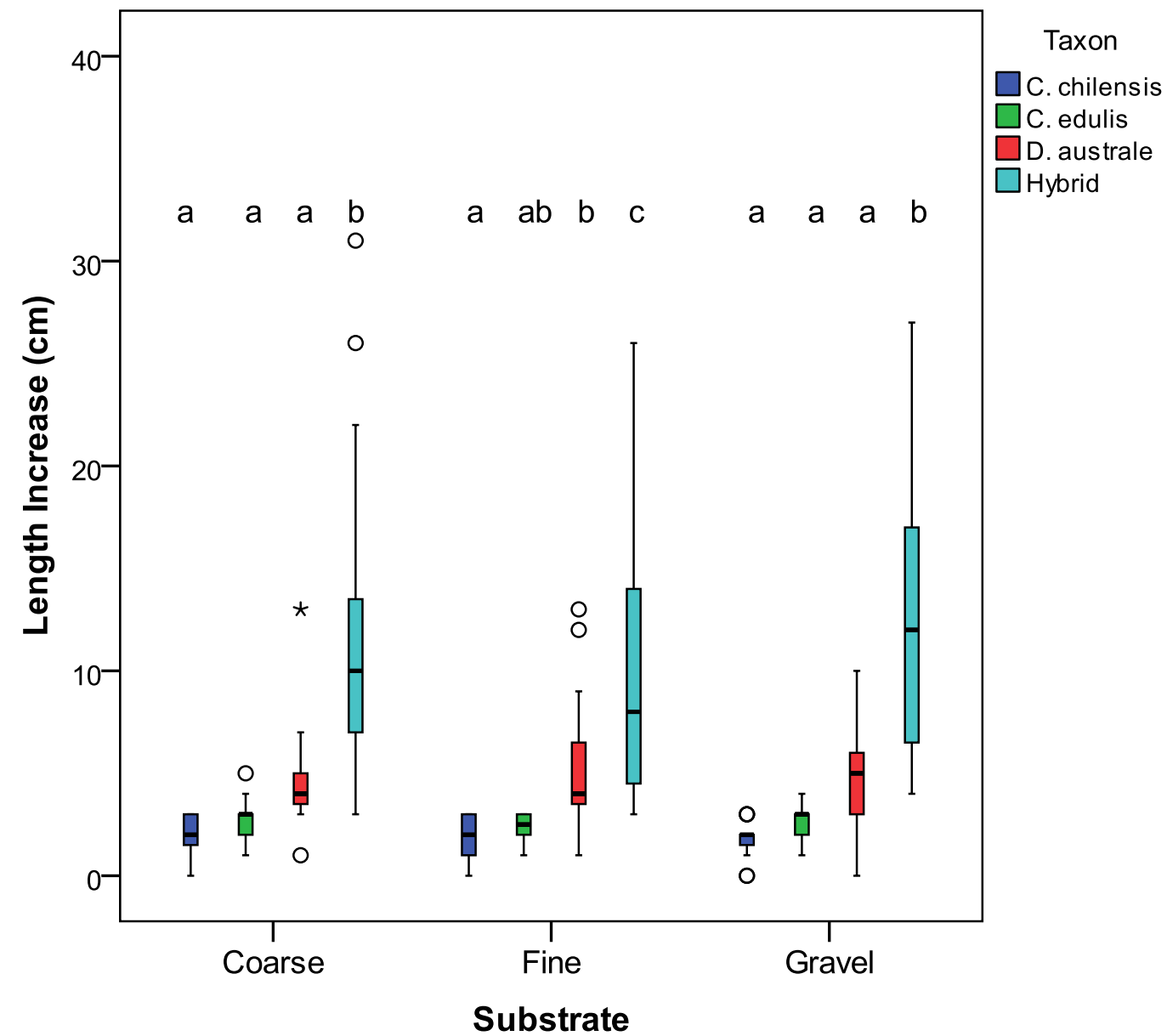

Fig. 3.9: The length by which stolons of the various taxa increased over the four-month period of exposure to field conditions. Letters above the bars refer to variability among taxa growing in the same substrate $(P<0.05)$.

An assessment of correlation between total biomass and net increase in leaves, nodes, and length of the cuttings showed positive relationships (Fig. 3.10; Table 3.7). However, increase in the number of leaves was stronger for all the taxa $\left(R^{2}=0.964 ; P<\right.$ 0.001). 

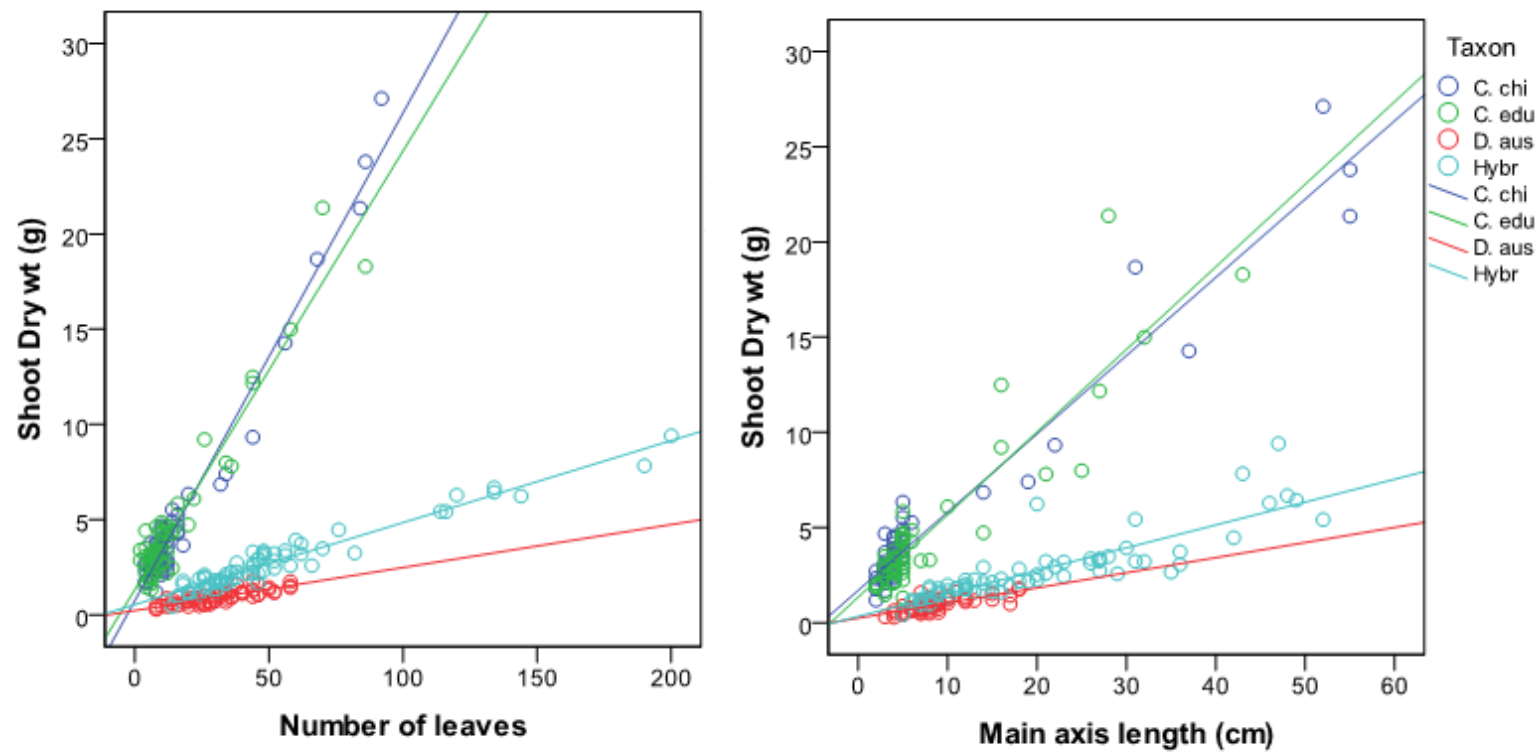

Fig. 3.10: A graph showing a positive correlation between shoot dry weight and number of leaves (Left), and stolon length (Right) of the cuttings and the stolons harvested from the field sample plants.

Table 3.7: Bivariate correlation (Pearson's R-squared) showing positive relationships between shoot dry weight and measured parameters of the cuttings and the stolons harvested from the field sample plants.

\begin{tabular}{|c|c|c|c|c|c|}
\hline Taxon & & $\mathrm{N}$ & Leaves & Nodes & Length \\
\hline C. chilensis & Shoot Dry wt & 67 & .964 & .952 & .944 \\
\hline C. edulis & Shoot Dry wt & 58 & .920 & .883 & .831 \\
\hline D. australe & Shoot Dry wt & 57 & .702 & .447 & .588 \\
\hline Hybrid & Shoot Dry wt & 68 & .938 & .813 & .743 \\
\hline
\end{tabular}

There were no variations in biomass accumulation among cuttings of the same taxon obtained from the different populations (Plants) when site was treated as a random variable and substrate as a fixed variable in a mixed effects ANOVA, except among the hybrids $(P<$ 0.001) where plants obtained from Moa point put on more biomass than those from the other sites (Fig. 3.11). 


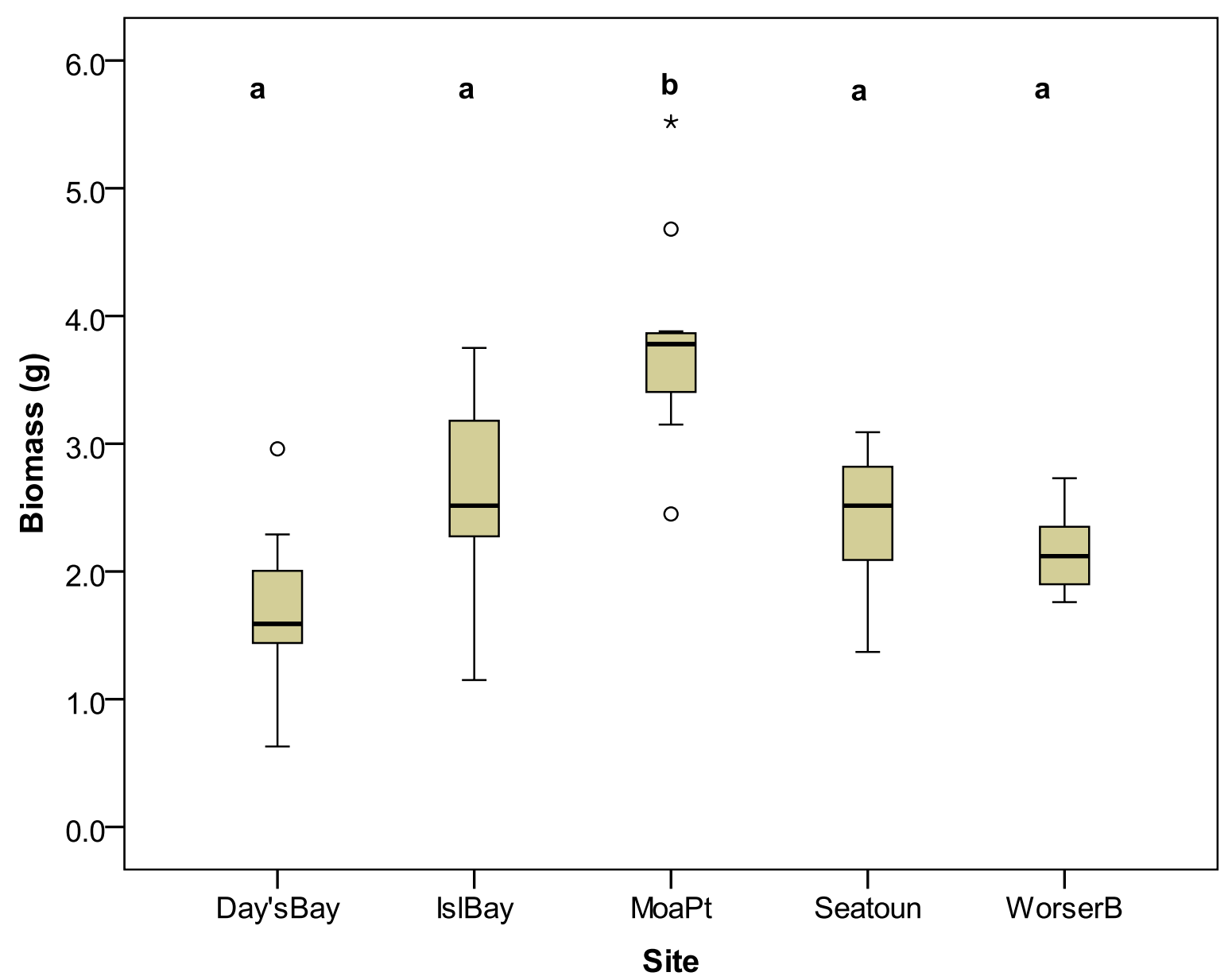

Fig. 3.11: Final biomass put on by the hybrid cuttings from the various populations over a period of six months indicating that cuttings from the plants at Moa Point put on higher biomass than the others.

\subsubsection{Field growth monitoring}

There was no significant variability in the number of leaves produced among the taxa over the total growth period of January-September $(P=0.152)$ and January-December $\left(F_{3}\right.$, 9.01=3.753; $P=0.053$; Table 3.8). There was however, a highly significant variability in the number of leaves among taxa for the period of September-December $\left(F_{3,37.3}=10.109 ; P<\right.$ 0.001). In addition, there was significant variability among the different sample plants 
within each taxon in terms of the number of leaves (all periods $P<0.001$; Table 3.8). The hybrid plants were highly variable in each of the growth periods $(P \leq 0.002)$, unlike plants of other taxa that mostly showed variability in number of leaves during the SeptemberDecember period. There was no variability in the number of leaves among taxa during the January-September period. The hybrid produced more leaves than $D$. australe in the January-December and September-December periods ( $P=0.007$ and $P<0.001$ respectively), and $C$. edulis in the September-December period ( $P=0.006$; Fig. 3.12; Table 3.9). During the September-December period, $C$. edulis also produced more leaves than $D$. australe $(P=$ 0.036). Disphyma australe plants actually lost more leaves than they produced during the period (Fig. 3.12).

Table 3.8: Nested ANOVA summary table comparing the number of leaves produced by the field sample plants of each taxon over the various growth periods. There was significant variability among sample plants of the same taxon in all growth periods. Variability among taxa was only significant in the September-December period.

\begin{tabular}{llrrrrr}
\hline Period & Source & Error df & \multicolumn{1}{c}{ Df } & MS & F & \multicolumn{1}{c}{ Sig. } \\
\hline Jan-Dec & Taxon & 9.010 & 3 & 333913.5 & 3.753 & .053 \\
& Plant(Taxon) & 111 & 11 & 54424.1 & 4.718 & $<.001$ \\
Jan-Sept & Taxon & 9.276 & 3 & 60368.7 & 2.228 & .152 \\
& Plant(Taxon) & 111 & 11 & 16332.9 & 5.481 & $<.001$ \\
\multirow{3}{*}{ Sept-Dec } & Taxon & 37.310 & 3 & 90276.8 & 10.109 & $<.001$ \\
& Plant(Taxon) & 296 & 35 & 10511.5 & 6.619 & $<.001$ \\
& & & & & & \\
\hline
\end{tabular}




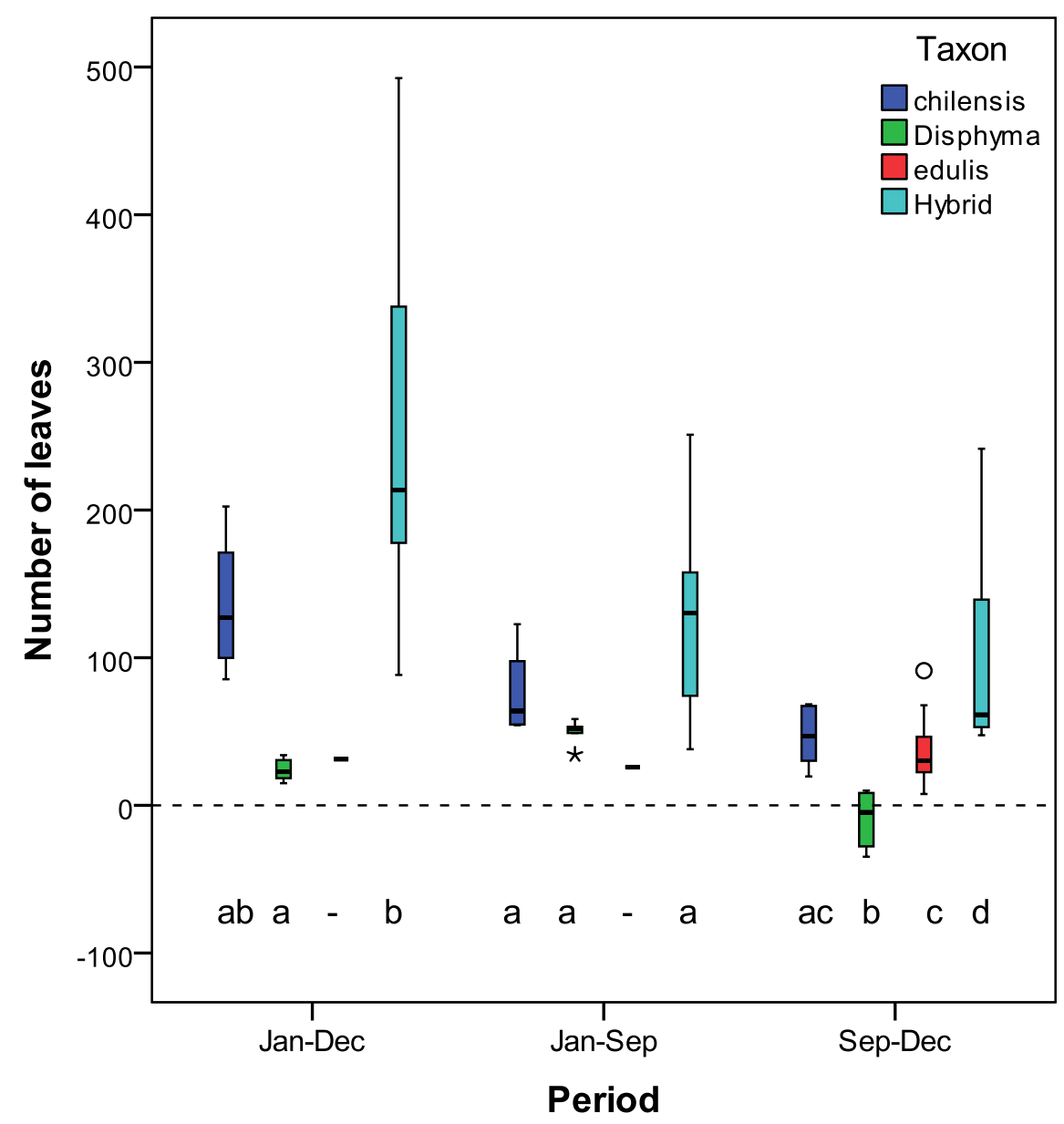

Fig. 3.12: Number of leaves produced by stolons of sample plants of the various taxa over each of the growth periods in the field growth experiment. The letters below the bars indicate variability among taxa at significance levels of $P<0.05$. Carpobrotus edulis was not included in the comparison for the January-September and January-December periods because there was only one sample plant. 
Table 3.9: Tukey HSD table comparing variability in the average number of leaves produced by plants of each taxon over the different growth periods in the field growth experiment. The table shows only combinations where variability was significant.

\begin{tabular}{lllrrr}
\hline Period & (I) Taxon & (J) Taxon & $\begin{array}{c}\text { Mean Difference } \\
\text { (I-J) }\end{array}$ & Std. Error & Sig. \\
\hline Jan-Dec & Hybrid & Disphyma & 237.8 & 62.1 & .007 \\
Sep-Dec & C. chilensis & Disphyma & 55.7 & 20.2 & .043 \\
& Hybrid & Disphyma & 104.8 & 17.5 & $<.001$ \\
& & C. edulis & 58.1 & 16.4 & .006 \\
& C. edulis & Disphyma & 46.6 & 16.5 & .036 \\
& & & & & \\
\hline
\end{tabular}

Lengths of the main axes stolons did not differ between the taxa, except during the September-December period $\left(F_{3,36.5}=7.588 ; P<0.01\right.$; Table 3.10). However, there was a highly significant variability among plants of the same taxon over all of the growth periods (all periods $P<0.001$ ), except Disphyma australe plants which differed in the lengths of their main axes only over the September-December period $\left(F_{9,29}=2.329 ; P=0.041\right)$. In both the January-September and January-December periods, only the hybrid grew longer than $D$. australe ( $P=0.003$ and 0.008 respectively). During the September-December period, all the other taxa lengthened more than $D$. australe (least significant $P=0.029$ ) and the hybrid lengthened more than $C$. chilensis $(P=0.026)$ while the two Carpobrotus species did not differ in length (Fig. 3.13; Table 3.11).

Table 3.10: Nested ANOVA table showing lengths of the main axes stolons did not vary among the taxa except in the September-December period but a highly significant variability among plants of the same taxon in each growth period.

\begin{tabular}{clrrrrr}
\hline Period & Source & Error df & df & MS & F & \multicolumn{1}{c}{ Sig. } \\
\hline Jan-Dec & Taxon & 9.804 & 3 & 16815.9 & 2.888 & .090 \\
& Plant(Taxon) & 111 & 11 & 3415.2 & 7.995 & $<.001$ \\
\multirow{3}{*}{ Jan-Sept } & Taxon & 9.902 & 3 & 7659.5 & 2.658 & .106 \\
& Plant(Taxon) & 111 & 11 & 1681.7 & 8.731 & $<.001$ \\
Sep-Dec & Taxon & 36.473 & 3 & 3586.7 & 7.588 & $<.001$ \\
& Plant(Taxon) & 296 & 35 & 562.8 & 10.331 & $<.001$ \\
& & & & & & \\
\hline
\end{tabular}




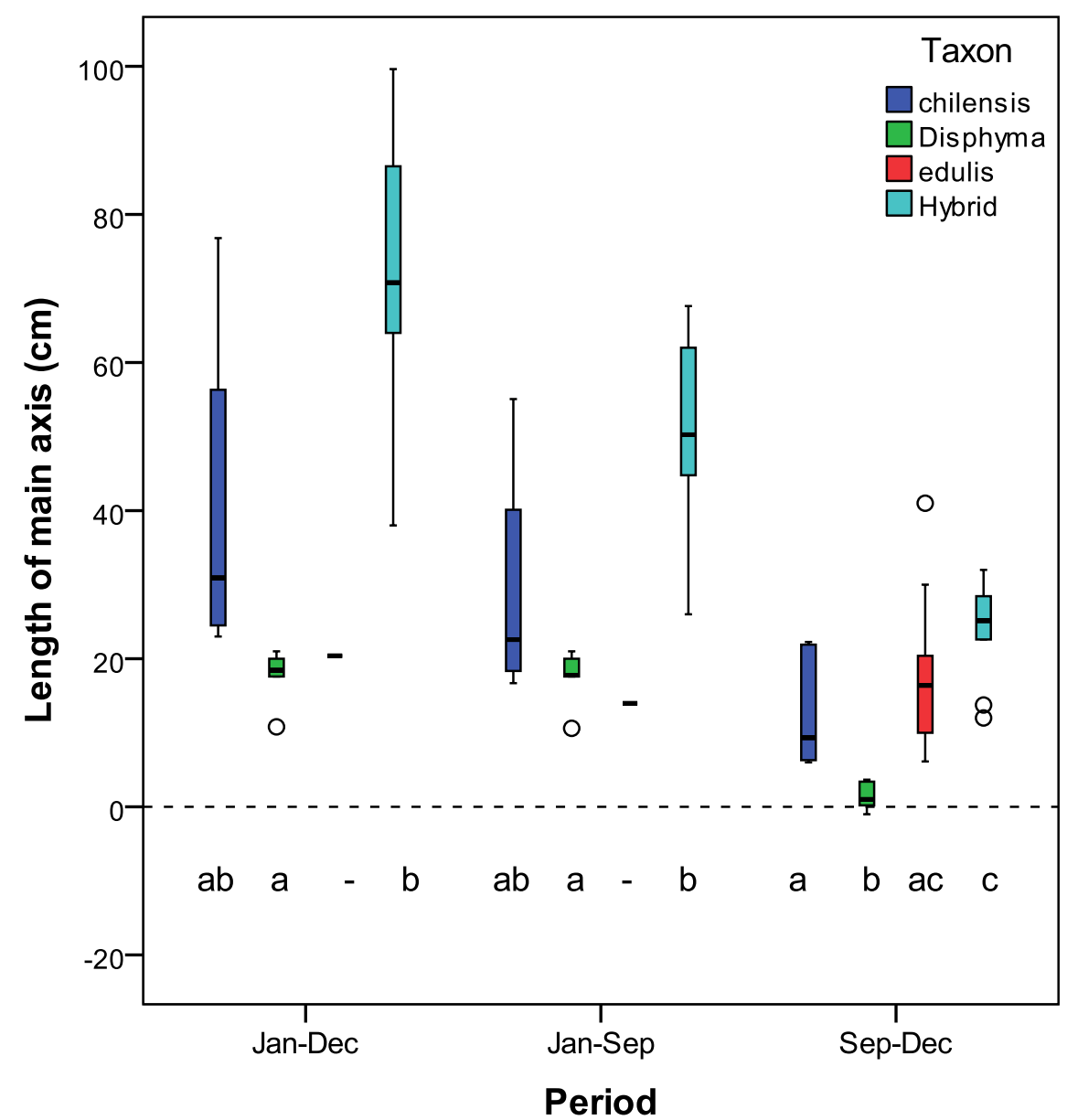

Fig. 3.13: Mean lengths of stolons of each taxon over the various growth periods in the field growth experiment. The letters below the bars indicate variability among taxa at significance levels of $P<$ 0.05 .

Table 3.11: A summary Tukey HSD test table comparing mean stolon lengths of plants of the different taxa over the various growth periods in the field growth experiment. The table shows only where significant variability was found.

\begin{tabular}{lllrrr}
\hline Period & (I) Taxon & (J) Taxon & $\begin{array}{c}\text { Mean Difference } \\
(\mathrm{I}-\mathrm{J})\end{array}$ & Std. Error & Sig. \\
\hline Jan-Dec & Hybrid & Disphyma & 54.2 & 12.2 & $\mathbf{. 0 0 3}$ \\
Jan-Sep & Hybrid & Disphyma & 32.7 & 8.6 & $\mathbf{. 0 0 8}$ \\
Sep-Dec & C. chilensis & Disphyma & 11.1 & 3.8 & $\mathbf{0 2 9}$ \\
& Hybrid & C. chilensis & 11.3 & 3.8 & .026 \\
& & Disphyma & 22.4 & 3.3 & $<.001$ \\
& C. edulis & Disphyma & 15.8 & 3.1 & $<.001$ \\
\hline
\end{tabular}


The number of nodes along the main axes and lateral branches differed significantly among the various taxa during all the periods (least significant: $P=0.037$; Table 3.12). Similarly, there was a high degree of variability among plants of the same taxon in all the periods $(P<0.001)$ except for Disphyma australe plants, which did not show variability in any of the growth periods. The hybrid plants generally produced more nodes than the other taxa in all the growth periods except for $C$. chilensis in the September-December period $(P=$ 0.057; Fig. 3.14; Table 3.13). There was no difference among the other taxa in the number of their nodes in any of the periods.

Table 3.12: Nested ANOVA table showing significant variability among taxa and among plants of the same taxon in the total number of their nodes over each growth period.

\begin{tabular}{llrrrr}
\hline Period & Source & df & MS & \multicolumn{1}{l}{ F } & \multicolumn{1}{c}{ Sig. } \\
\hline Jan-Dec & Taxon & $3,9.283$ & 235832.1 & 4.322 & $\mathbf{0 3 7}$ \\
& Plant(Taxon) & 11,111 & 32888.3 & 5.505 & $<.001$ \\
\multirow{3}{*}{ Jan-Sept } & Taxon & $3,9.251$ & 22370.3 & 5.147 & $\mathbf{0 2 3}$ \\
& Plant(Taxon) & 11,111 & 2623.9 & 5.398 & $<.001$ \\
Sept-Dec & Taxon & $3,36.848$ & 84468.7 & 8.394 & $<.001$ \\
& Plant(Taxon) & 35,296 & 11919.3 & 8.252 & $<.001$ \\
& & & & & \\
\hline
\end{tabular}




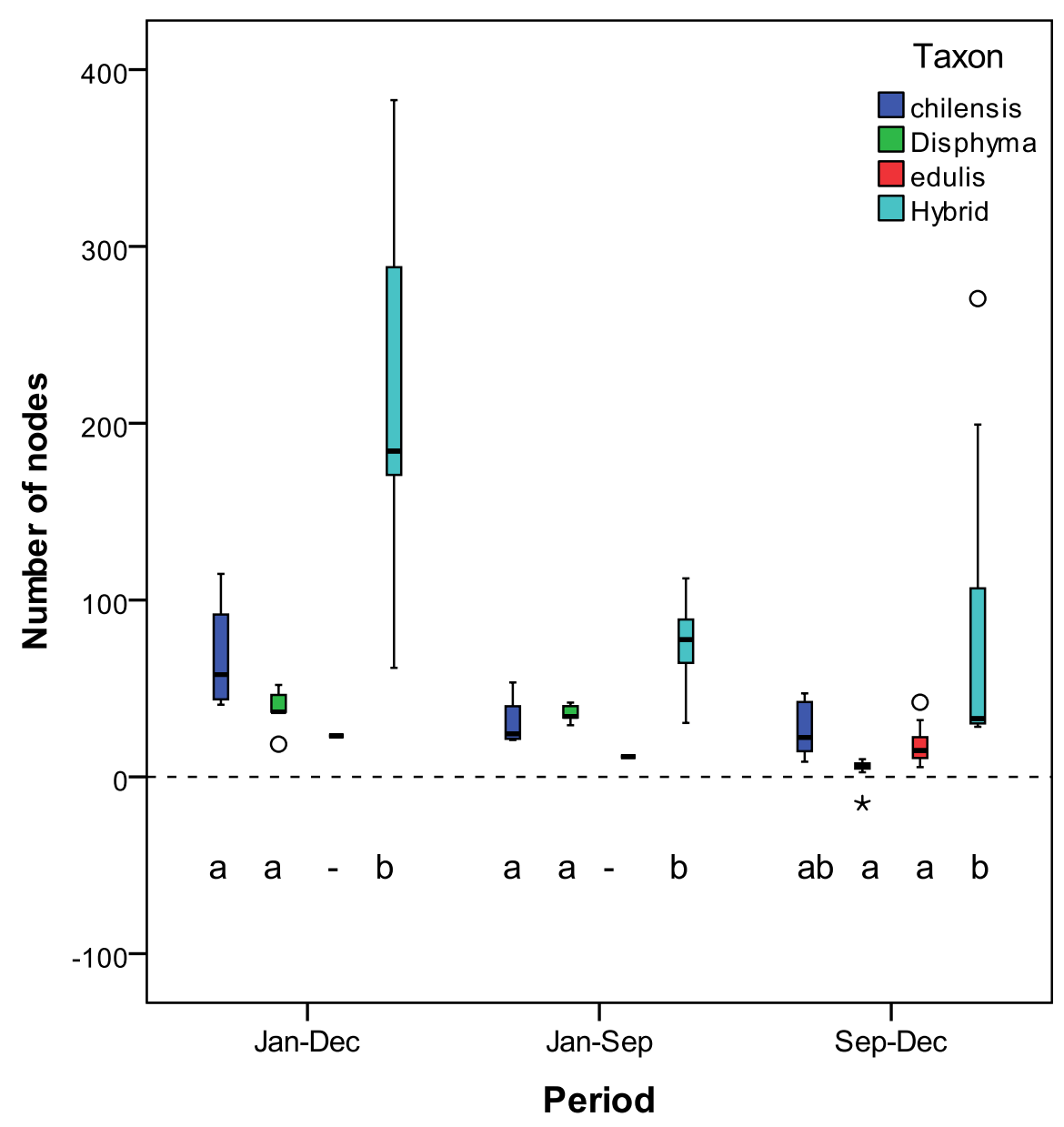

Fig. 3.14: Net number of nodes produced along the main axes of stolons of plants of each taxon during the various growth periods in the field growth experiment. The letters below the bars indicate variability among taxa at significance levels of $P<0.05$. 
Table 3.13: A summary Tukey HSD test table comparing the aggregate number of nodes produced along the main stolons and lateral branches by plants of the various taxa over the different growth periods in the field growth experiment. The table shows only where variability was significant $(P<$ 0.05 ) or approaching significance.

\begin{tabular}{lllrrr}
\hline Period & (I) Taxon & (J) Taxon & $\begin{array}{c}\text { Mean Difference } \\
(\mathrm{I}-\mathrm{J})\end{array}$ & Std. Error & Sig. \\
\hline Jan-Dec & Hybrid & C. chilensis & 149.7 & 51.1 & $\mathbf{. 0 3 4}$ \\
& & Disphyma & 179.5 & 48.2 & $\mathbf{. 0 0 9}$ \\
Jan-Sep & Hybrid & C. chilensis & 44.0 & 13.6 & $\mathbf{. 0 2 0}$ \\
& & Disphyma & 39.0 & 12.8 & $\mathbf{. 0 2 7}$ \\
Sep-Dec & \multirow{2}{*}{ Hybrid } & C. chilensis & 60.5 & 22.9 & .057 \\
& & Disphyma & 82.4 & 19.9 & $\mathbf{. 0 0 1}$ \\
& & C. edulis & 68.2 & 18.7 & $\mathbf{. 0 0 4}$
\end{tabular}

Number of lateral branches produced along the tagged main axes differed significantly among the taxa as well as between plants within a taxon during all or some of the growth periods (least significant $P=0.007$; Table 3.14). The hybrid produced more lateral branches than $C$. chilensis in all the periods $(P<0.023)$ and more than $D$. australe in January-December and September-December (both periods $P<0.002$; Fig. 3.15; Table 3.15). Carpobrotus spp. produced more lateral branches than D. australe during SeptemberDecember $(P<0.002)$. There were no differences in number of lateral branches between $C$. edulis and the hybrid and between the two Carpobrotus species in September-December.

Table 3.14: Nested ANOVA table showing that there was significant variability in the number of lateral branches produced by plants of the various taxa and among plants of the same taxon in all the growth periods in the field growth experiment.

\begin{tabular}{llrrrr}
\hline Period & Source & \multicolumn{1}{l}{ df } & MS & \multicolumn{1}{l}{ F } & \multicolumn{1}{l}{ Sig. } \\
\hline Jan-Dec & Taxon & $3,9.283$ & 2672.1 & 7.795 & .007 \\
& Plant(Taxon) & 11,111 & 207.8 & 5.160 & $<.001$ \\
\multirow{3}{*}{ Jan-Sept } & Taxon & $3,9.251$ & 1185.8 & 7.032 & .010 \\
& Plant(Taxon) & 11,111 & 102.7 & 4.934 & $<.001$ \\
Sept-Dec & Taxon & $3,36.848$ & 775.1 & 11.804 & $<.001$ \\
& Plant(Taxon) & 35,296 & 78.0 & 9.180 & $<.001$ \\
& & & & & \\
\hline
\end{tabular}




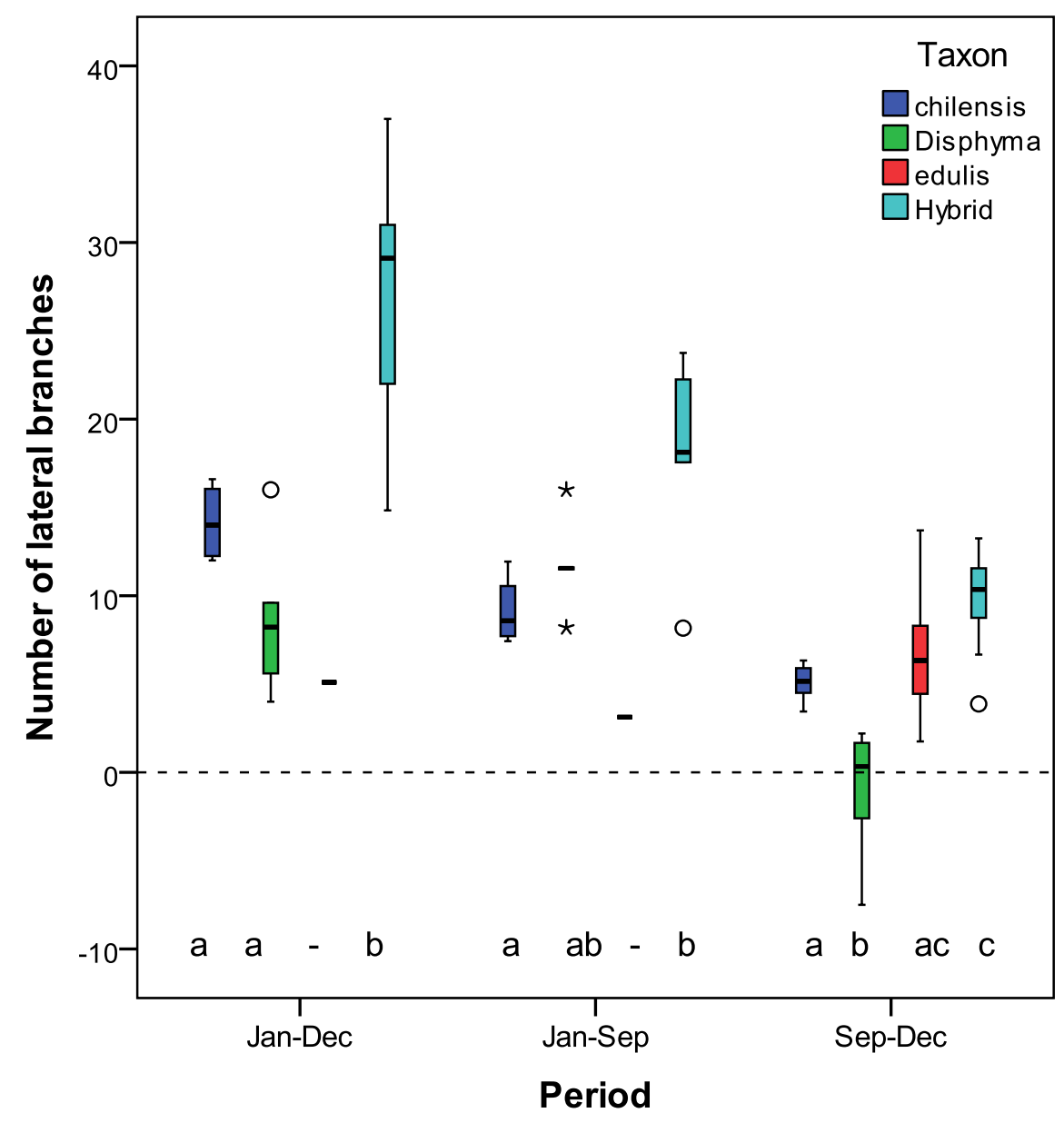

Fig. 3.15: Number of lateral branches produced by a stolon of plant of each taxon over the various growth periods in the field growth experiment. The letters below the bars indicate variability among taxa at significance levels of $P<0.05$. Disphyma australe showed loss of lateral branches in the September-December period. 
Table 3.15: A Tukey HSD table comparing the mean number of lateral branches produced by plants of the various taxa in the different growth periods in the field growth experiment. The table only summarises where variability was significant.

\begin{tabular}{lllrrr}
\hline Period & (I) Taxon & (J) Taxon & $\begin{array}{c}\text { Mean Difference } \\
(\mathrm{I}-\mathrm{J})\end{array}$ & Std. Error & Sig. \\
\hline Jan-Dec & Hybrid & C. chilensis & 12.6 & 4.0 & $\mathbf{. 0 2 3}$ \\
& & Disphyma & 18.1 & 3.8 & .002 \\
Jan-Sep & Hybrid & C. chilensis & 8.8 & 2.8 & .023 \\
Sep-Dec & C. chilensis & Disphyma & 5.9 & 1.5 & .002 \\
& Hybrid & C. chilensis & 4.7 & 1.5 & .019 \\
& \multirow{2}{*}{ C. edulis } & Disphyma & 10.6 & 1.3 & $<.001$ \\
& & Disphyma & 7.4 & 1.2 & $<.001$ \\
& & & & \\
\hline
\end{tabular}

The sample stolons that were destructively harvested and their dry weights measured showed strong positive correlation between each of the measured parameters and the dry weight for each taxon. Similar observations were made for the experimental cuttings. Therefore, these parameters were all put in a multiple regression model to generate an equation for estimation of dry weight of the shoots of the field plants (Table 3.16). The estimated biomass was then analysed using a two-level nested ANOVA analysis with taxon as a fixed factor and individual plants as a random factor (Table 3.17). There was a highly significant variability among the different taxa $\left(\mathrm{F}_{3,39.5}=9.192 ; P<0.001\right)$ as well as among sample plants of the same taxon $\left(F_{35,548}=4.885 ; P<0.001\right)$. 
Table 3.16: Summary of multiple linear regressions used to estimate shoot dry weights of plants in the field growth experiment. The data were derived from number of leaves, number of nodes and main axis length of common-garden cuttings, and the sample stolons harvested from the field.

\begin{tabular}{llrrrr}
\hline Taxon & \multicolumn{2}{c}{ Unstandardized Coefficients } & T & Sig. \\
& & B & Std. Error & & \\
\hline C. chilensis & (Constant) & .920 & .185 & 4.975 & $<.001$ \\
& Leaves & .184 & .038 & 4.807 & $<.001$ \\
& Nodes & .065 & .107 & .614 & .541 \\
& Length & .066 & .070 & .939 & .351 \\
C. edulis & (Constant) & 1.346 & & & \\
& Leaves & .247 & .206 & 6.538 & $<.001$ \\
& Nodes & -.017 & .049 & 5.054 & $<.001$ \\
& Length & -.018 & .128 & -.130 & .897 \\
& & & .075 & -.248 & .805 \\
D. australe & (Constant) & .167 & & & \\
& Leaves & .016 & .141 & 1.184 & .242 \\
& Nodes &. .008 & .003 & 5.998 & $<.001$ \\
& Length & .038 & .028 & -.284 & .778 \\
& & .013 & 2.953 & .005 \\
Hybrid & (Constant) & .350 & .103 & 3.388 & .001 \\
& Leaves & .032 & .004 & 8.406 & $<.001$ \\
& Nodes & .004 & .005 & .788 & .434 \\
& Length & .035 & .006 & 5.950 & $<.001$ \\
\hline
\end{tabular}

Table 3.17: Nested ANOVA table showing variability in estimated shoot dry weights among the various taxa and plants of each taxon in the field growth experiment.

\begin{tabular}{lrrrr}
\hline Source & df & Mean Square & F & \multicolumn{1}{l}{ Sig. } \\
\hline Taxon & 3 & 3477.3 & 9.192 & $<.001$ \\
Plant(Taxon) & 35 & 464.8 & 4.885 & $<.001$ \\
& & & & \\
\hline
\end{tabular}




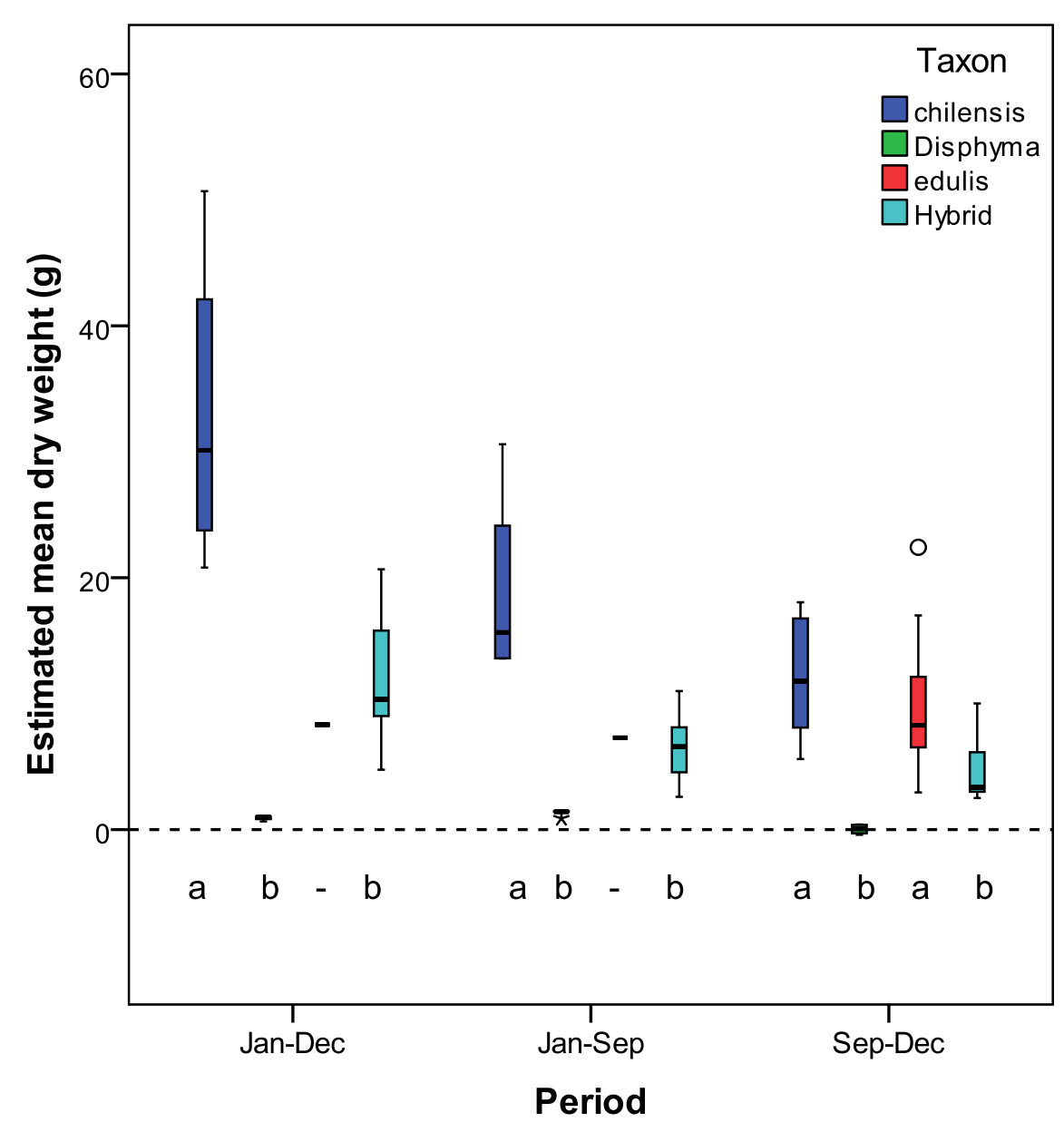

Fig. 3.16: Estimated shoot dry weight put on by the sample plants of each taxon over the various growth periods in the field growth experiment. The different letters below the bars indicate variability among taxa at $P<0.01$. Carpobrotus edulis was excluded from the comparison in the JanDec and Jan-Sep periods because there was only one sample plant.

On aggregating the dataset and running a post hoc test to discriminate the variability among taxa, it was found that all the other taxa had a significantly higher estimated dry weight than $D$. australe $(P<0.001$; Fig. 3.16). Carpobrotus edulis did not vary from $C$. chilensis but both had a higher dry weight than the hybrid as well $(P<0.05$; Table 3.18). 
Table 3.18: A Tukey HSD table comparing the means of the aggregate estimated dry weights put on by the shoots of the various taxa over the different growth periods in the field growth experiment. The table summarises only where variability between taxa was significant.

\begin{tabular}{|c|c|c|c|c|c|}
\hline Period & (I) Taxon & (J) Taxon & $\begin{array}{c}\text { Mean Difference } \\
(I-J)\end{array}$ & Std. Error & Sig. \\
\hline \multirow[t]{2}{*}{ Jan-Dec } & C. chilensis & Disphyma & 32.0 & 5.2 & $<.001$ \\
\hline & & Hybrid & 20.8 & 5.2 & .005 \\
\hline \multirow[t]{2}{*}{ Jan-Sep } & C. chilensis & Disphyma & 17.5 & 3.1 & $<.001$ \\
\hline & & Hybrid & 12.3 & 3.1 & .006 \\
\hline \multirow[t]{4}{*}{ Sep-Dec } & C. chilensis & Disphyma & 12.0 & 2.1 & $<.001$ \\
\hline & & Hybrid & 7.4 & 2.1 & .005 \\
\hline & C. edulis & Disphyma & 9.9 & 1.7 & $<.001$ \\
\hline & & Hybrid & 5.4 & 1.7 & .015 \\
\hline
\end{tabular}

While $C$. edulis is bigger in stature, its biomass was not higher than that of $C$. Chilensis, probably because it stores more water than organic compounds, as shown by the ratio of dry weights to fresh weights of the harvested sample stolons (Fig. 3.17). 


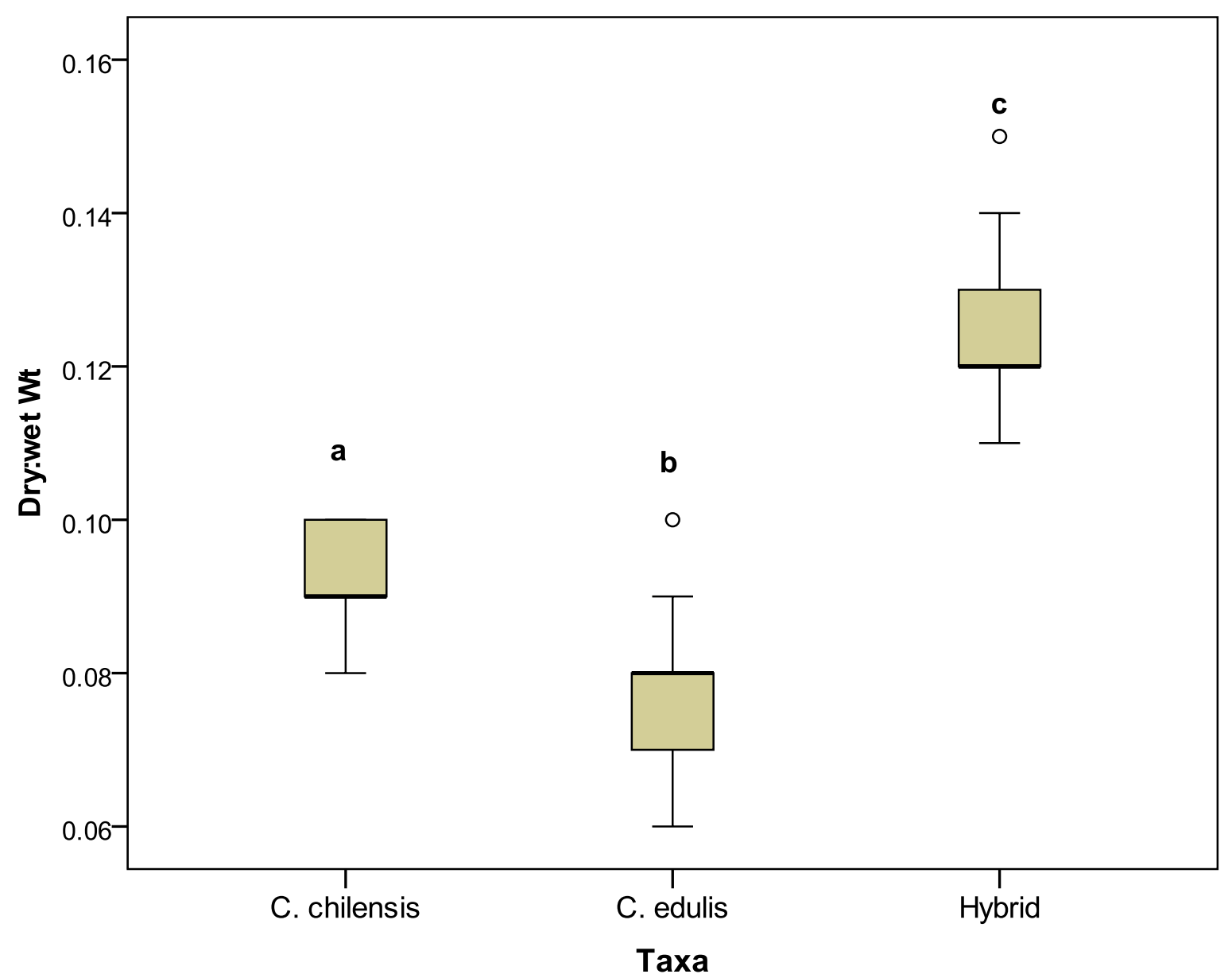

Fig. 3.17: The ratios of shoot dry weight of the stolons harvested from the field to their fresh weight showing that the hybrid was the least succulent, with the greatest dry weight: fresh weight ratio.

\subsubsection{Breeding systems}

The main flowering season was from September to November with peak flowering for all the taxa being October-November (Fig. 3.18). A few plants continued flowering into December. Some $C$. edulis plants also flowered from May to June, although at much lower density and at fewer sites. 


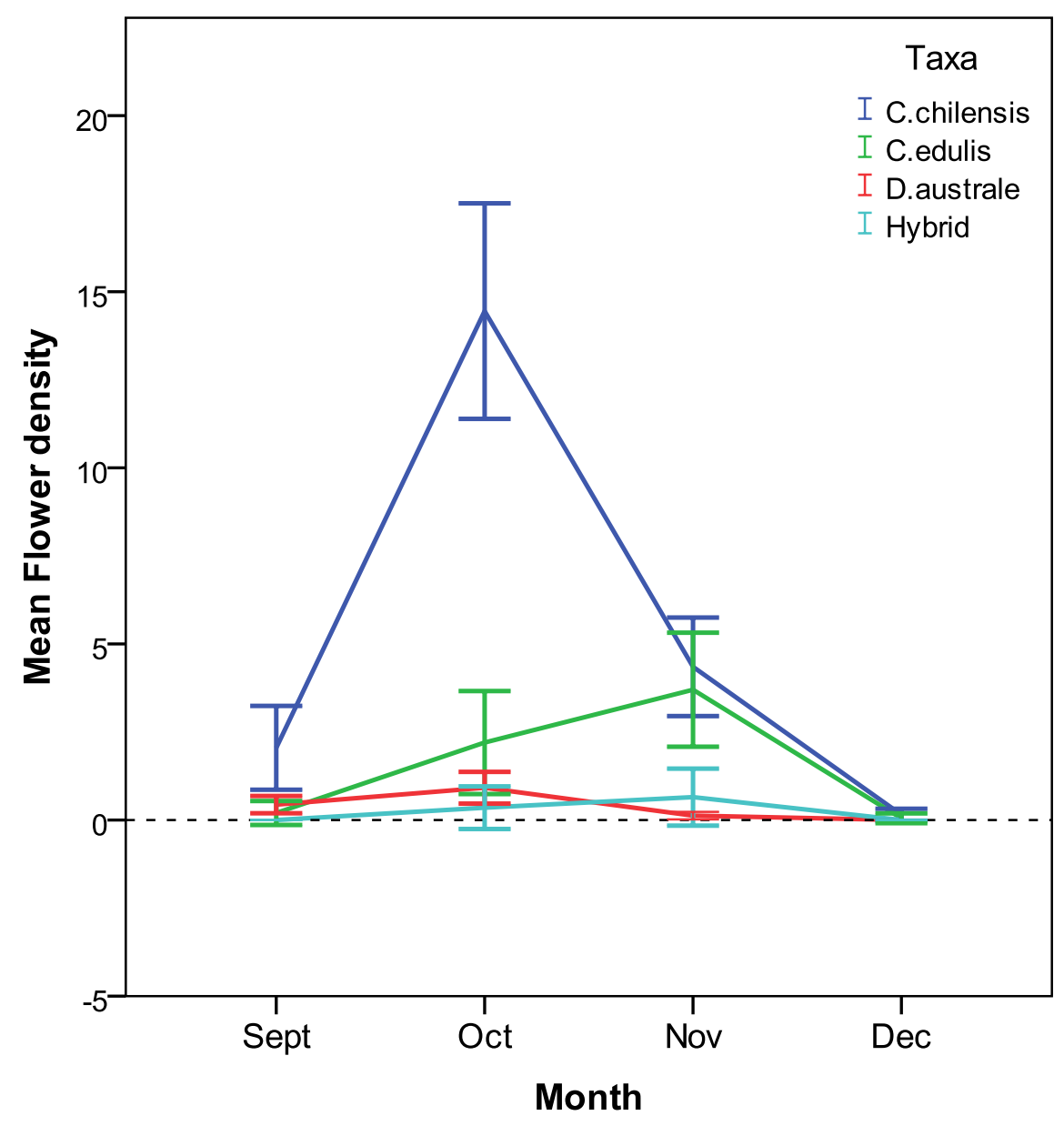

Fig. 3.18: Mean flower density per sample plant (number of flowers $/ \mathrm{m}^{2}$ ) of the various taxa during the flowering season of the year 2011.

It is important to note that although at least ten flower buds were assigned to each breeding treatment per taxon, not all were sustained to maturity due to human interference. The two exotic iceplant taxa responded differently to the mating experiments in terms of seed set $\left(\mathrm{F}_{4,60}=15.833 ; P<0.001\right)$. Carpobrotus edulis fruits did not produce any seeds in the agamospermy treatment while less than a third of fruits produced an average of only two seeds each in the spontaneous selfing treatment. In artificial selfing, three fruits from one plant produced seeds while the fruits of the other plant did not. Carpobrotus edulis produced a lot of seeds when supplied with pollen of C. chilensis and D. australe. Carpobrotus chilensis plants, on the other hand, responded positively to all treatments, although at low levels for agamospermy, where one of the two fruits produced only a single seed and the other produced 36 seeds (Table 3.19; Fig. 3.19). 
Table 3.19: Descriptive statistics of number of seeds produced per fruit by the two Carpobrotus species subjected to different breeding treatments.

\begin{tabular}{|c|c|c|c|c|c|c|}
\hline Taxon & Statistic & Agamospermy & $\begin{array}{l}\text { Spontaneous } \\
\text { selfing }\end{array}$ & $\begin{array}{l}\text { Artificial } \\
\text { selfing }\end{array}$ & $\mathrm{X}$ congener & X D. australe \\
\hline \multirow[t]{3}{*}{ chilensis } & $\begin{array}{l}\text { Mean } \pm \\
\text { S.D. }\end{array}$ & $18.5 \pm 24.7$ & $442.0 \pm 87.2$ & $317.2 \pm 97.5$ & $377.6 \pm 114.6$ & $231.1 \pm 36.9$ \\
\hline & Range & $1-36$ & $325-568$ & $212-422$ & $234-545$ & $160-285$ \\
\hline & $\mathrm{N}$ & 2 & 5 & 5 & 7 & 10 \\
\hline \multirow[t]{4}{*}{ C. edulis } & Mean \pm & .00 & $2.0 \pm 3.5$ & $77.7 \pm 98.9$ & $1310.4 \pm 694.5$ & $493.8 \pm 323.0$ \\
\hline & S.D & & & & & \\
\hline & Range & 0 & $0-9$ & $0-202$ & $805-2663$ & $55-1095$ \\
\hline & $\mathrm{N}$ & 7 & 9 & 7 & 9 & 10 \\
\hline
\end{tabular}




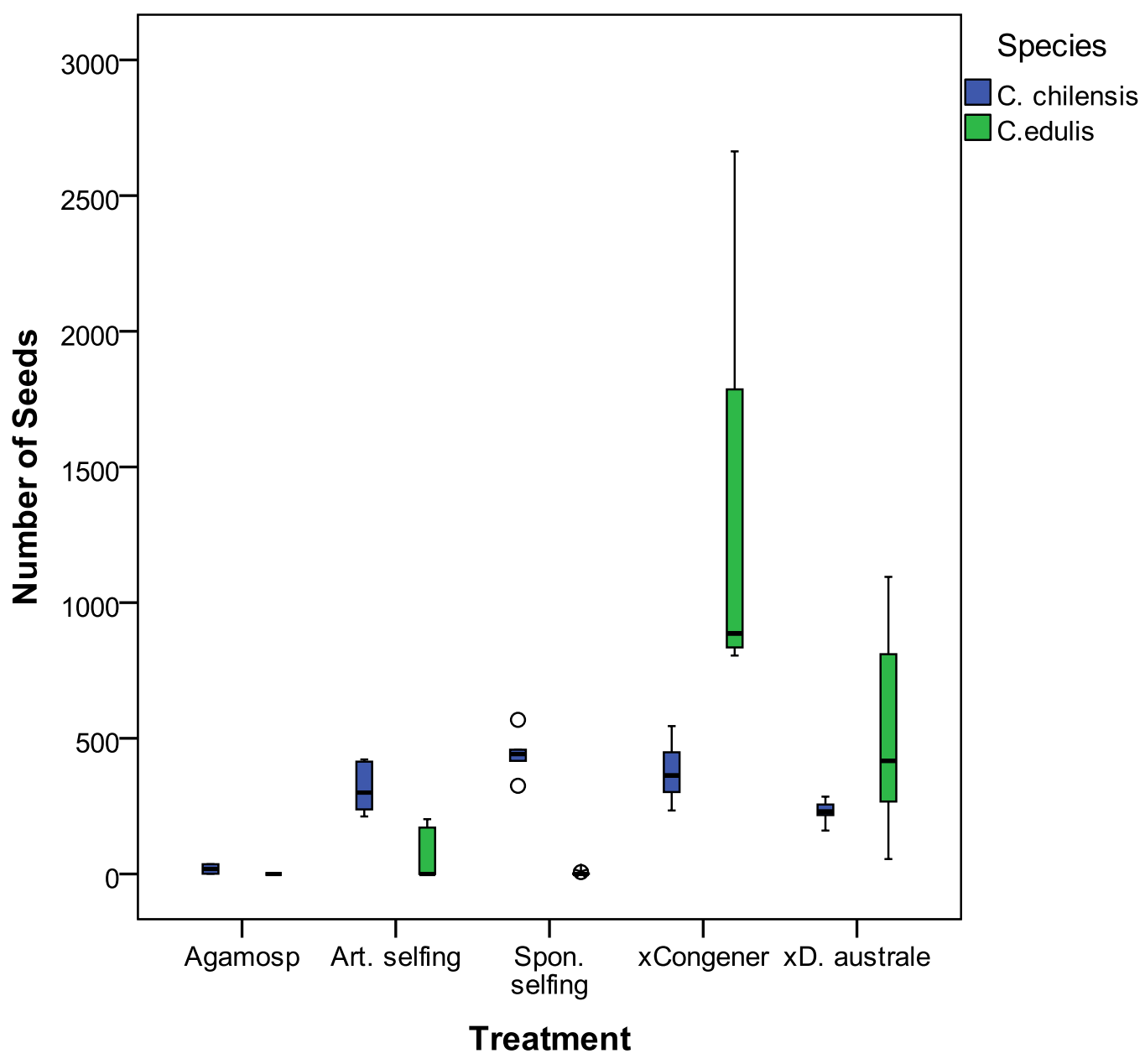

Fig. 3.19: Number of seeds per fruit produced by each of the two Carpobrotus species subjected to the different breeding treatments. 


\subsection{DISCUSSION}

\subsubsection{Growth comparison and substrate preference}

The results of the experimental study showed that there was no difference in the final biomass of the two Carpobrotus spp., regardless of the substrate, although $C$. edulis cuttings had a higher indicative initial biomass. In a field study in several Mediterranean islands, (Traveset, Brundu et al. 2008) found that Carpobrotus species displayed similar growth rates in dune systems and rocky shores, concluding that their growth rate was more dependent on microsite type than on habitat type (Traveset, Brundu et al. 2008). The two exotics performed comparably in the field growth monitoring study. The actual and estimated final dry weights of the Carpobrotus cuttings were significantly higher than those of their hybrid and $D$. australe counterparts. This was not surprising because the same trend was evident from the initial biomass of the sample cuttings. The hybrids had significantly higher final dry weights (actual and estimated) than D. australe plants even though the initial dry weights of their sample cuttings did not differ. Carpobrotus chilensis cuttings growing in sand accumulated significantly higher dry weight and produced more leaves than those growing in gravel, showing some substrate preference. In terms of actual biomass allocation, Disphyma australe allocated relatively more to the roots than the shoot, compared to the other taxa, while the hybrid also invested relatively more in the roots than the two Carpobrotus spp.

In the present study, stolons of Carpobrotus spp. elongated by up to $130 \mathrm{~cm}$ over the eleven month field growth period, although there was high variability among stolons because of smothering of some by others. Similarly, the hybrids elongated by up to $127 \mathrm{~cm}$ over the same time period. The main stolons of iceplant species have the capacity to form functional individuals (ramets) by rooting at some nodes and spreading independently (Traveset, Moragues et al. 2008). The hybrids had the highest mean number of nodes along the main axes and lateral branches that could potentially root and form ramets. Such ramets act as cooperative entities with efficient distribution of tasks that can lead to enhanced resource exploitation in heterogeneous habitats (Stuefer, DeKroon et al. 1996). 
This kind of clonal growth has been proposed as one of the most successful strategies in the plant world (Traveset, Moragues et al. 2008), which together with other life history traits (Mack 2003) has been shown to increase the probability of successful invasion (Heger and Trepl 2003). The exotics and the hybrid (xCarpophyma mutabilis Heenan and Sykes 2010) seem to grow more aggressively than the native $D$. australe, whose longest stolon was $30 \mathrm{~cm}$. The high stolon elongation and branching rates allow the exotics and hybrids to rapidly occupy and dominate space (Sammul, Kull et al. 2004; Sintes, Moragues et al. 2007). Clonality further enhances access to unevenly distributed resources, thereby conferring competitiveness with subsequent negative consequences for the native flora (Stuefer, DeKroon et al. 1996).

The average number of lateral branches produced by an individual stolon over the period of just under a year was 16 for the hybrid, 9 for $C$. chilensis, 4 for $D$. australe and 5 for C. edulis. Lateral branches are vegetative propagules, which are an alternative means of dispersal that subsequently root and produce new individuals (Traveset, Moragues et al. 2008). It is suggested that vegetative propagules generally result in larger-sized plants with higher survival and growth rates than seeds (Nishitani, Takada et al. 1999). Success of iceplant propagules is further enhanced by clonal integration with the parent plant since resources can be translocated from the established parent to the developing ramets (Price and Marshall 1999). It is therefore not surprising that the hybrid, being sexually sterile, seems to have invested a lot in lateral branches as its only means of proliferation.

The parent plants (sites) from which the cuttings were obtained did not seem to have conferred differential advantages except for the hybrid plant from Moa point, whose cuttings performed better than the others in terms of total biomass. The two varieties of $D$. australe (green and red), did not differ in their performance in either of the substrate types, even though in nature the green one seems to predominate at rocky shores (K. Gould pers. comm.). Disphyma australe plants in the field growth study showed some negative growth for the period of September to December in all the measured variables, mainly as a result of smothering by the hybrid plants with which they grow at the study site. 
The revelation by nested analysis that there was a high degree of variability among plants of the same taxon in all the measured characters suggests that, in future studies, more sample plants are needed to increase the sample size. However, the variability among plants in the current study may also be explained in terms of habitat heterogeneity (especially for $C$. Chilensis), where some plants were at the backdune where substrate is sandy, while others were at the foredune where soil structure is predominantly shingles. Furthermore, plants at the backdune, where the substrate is more stable, were intermingled with other plants that would normally curtail their growth compared to those at the foredune where storm and wave disturbance would ideally eliminate biotic resistance by removing the native residents.

The Eastbourne site where Carpobrotus spp were growing is about two kilometres from Day's Bay where $D$. australe and the hybrids were. The climatic conditions of these two sites are quite similar and not much ecotypic difference was expected.

\subsubsection{Mating systems}

A highly flexible mating system can be a key element in the establishment and success of invasive plants (Baker 1955). Aizoaceae species have been shown to have a high capability for intrageneric and intergeneric hybridization (Chinnock 1972; Hammer and Liede 1990). Mating experiments in the present study have shown that Carpobrotus species are highly fertile to intrageneric and intergeneric pollen. However, $C$. edulis was not agamospermic but slightly self-fertile and needing intervention of a pollinator, while $C$. chilensis was slightly agamospermic and self-fertile, contrary to findings of (Vilà, Weber et al. 1998). It has been pointed out that ideal weeds (and by extension invasive plants) are selfcompatible, but not completely autogamous or apomictic (Baker 1965 as cited by Vilà, Weber et al. 1998). Unfortunately, there was no time to germinate the seeds to test their viability, even using laboratory techniques. Self-fertilization and agamospermia are said to give the advantage for invasive species to start a seed-reproducing colony from a single individual and to build up a population quickly (Vilà, Weber et al. 1998). According to morphometric (Albert et al. 1997) and isozyme analyses (Gallagher et al. 1997), C. chilensis 
appears to be hybridizing and backcrossing with C. edulis individuals (Vila and D'Antonio 1998), casting doubts on the species integrity of our experimental plants, whose exact source is unknown. In New Zealand, yellow-flowered $C$. edulis and magenta-flowered $C$. chilensis co-occur at most sites but there are no presence records of their intrageneric hybrids (Heenan and Sykes, 2010). Due to the general lack of morphometric differences, it seems possible that they may in fact be two colour morphs of a $C$. edulis and $C$. chilensis hybrid swarm.

Both Carpobrotus species in our breeding experiment were highly fertile to intergeneric $D$. australe pollen. Hybridization between native and non-native plants may result in invasive hybrid morphotypes that, in turn, have dramatic effects on the communities in which they occur (Thompson 1991). The hybrid cuttings in my trials performed better than those of the other taxa in the characters relating to vegetative growth such as number of leaves, number of nodes, main axes length and internode length. In the field growth study, performance of the hybrids, in terms of growth characters, was always better or comparable to those of the Carpobrotus spp. For example, they grew longer and produced more leaves than $C$. edulis but were not different from $C$. chilensis. Additionally, they produced more nodes and lateral branches than both Carpobrotus spp. The differential fitness of hybrid and parental genotypes can have important evolutionary consequences (Ellstrand and Schierenbeck 2000). Hybridizations between formerly allopatric species may result in new alien-derived genotypes (Verlaque, Affre et al. 2011) that are frequently competitive (Vilà, Weber et al. 2000) or stress tolerant (Milne and Abbott 2000). They may differently affect the structure and function of native ecosystems (Verlaque, Affre et al. 2011). For instance, Spartina anglica has been shown to cause sediment rise by accumulating large volumes of tidal sediment, making intertidal habitats more terrestrial (Ainouche, Fortune et al. 2009). Hybridisation has the potential to create highly aggressive genotypes that may be undesirable in terms of management for native species (Ellstrand 1992; Rhymer and Simberloff 1996). Xcarpophyma mutabilis, the intergeneric hybrid of $C$. edulis and $D$. australe is a perennial and clonal plant. Perennial hybrids will persist longer, giving more time for genetic stabilization opportunities to occur, especially if clonal reproduction is available (Ellstrand and Schierenbeck 2006). Clonality on 
the other hand, would tend to stabilize lineages that would suffer sterility as F1 hybrids while fixing hybridity and novelty (Grant 1981). Alien species and their native-derived hybrids can also influence the evolution of natives by exposing them to novel interactions (Parker, Simberloff et al. 1999). For example, Carpobrotus edulis has been shown to interact indirectly with native vegetation by altering soil chemistry (Conser and Connor 2009), thereby exposing the natives to novel soil micro-conditions.

\subsubsection{Implications of the Hybrid (xCarpophyma mutabilis Heenan and Sykes 2010) for $D$. australe}

The field growth monitoring and experimental growth of the cuttings have shown that the hybrid is at least as aggressive as its exotic parent in space colonisation. Disphyma australe at the Day's Bay site seem to have been negatively affected by the hybrid where the hybrids grew over their stolons, smothering them in some seasons of the year. In addition, the fact that the hybrid cuttings in the common garden experiment did quite well in all the substrate types may mean that they are capable of growing in the same natural habitats as $D$. australe. Hybrid vigour for vegetative growth is thought to contribute to displacement of parental morphotypes or native species (Vilà and D'Antonio 1998). More research needs to be done on how the hybrids influence growth and survival of $D$. australe. If they were to grow intermingled, Disphyma australe is likely to stand no chance against the exotic mat-forming (Albert, D'Antonio et al. 1997)Carpobrotus spp. that have also been shown to crawl over other vegetation (D'Antonio 1990).

In other systems, hybrid genotypes originating from $C$. edulis and native congeners have been shown to present a major obstacle for managers (Vilà and D'Antonio 1998; Schierenbeck and Ellstrand 2009) with negative implications for the conservation of native species assemblages (Vilà, Weber et al. 1998). Human mediated gene flow between congeners or conspecific populations is regarded as a form of biotic homogenization both at the genetic and community level (Olden, Poff et al. 2004). However, little is known about how non-native taxa or the spread of their foreign alleles to native taxa may affect local 
adaptation of a species, community composition, or ecosystem function (Levine, Vilà et al. 2003).

\subsection{Conclusion and implications for management}

The growth rates of the iceplant taxa in my common garden experiment suggest that all of them are capable of colonizing both sandy and shingle coastal habitats, although $C$. chilensis performed comparatively worse in gravel. The intergeneric hybrid displayed more aggressive growth characteristics than its putative parents but its stolons are slender and more sparsely spread, with sufficient spaces for other vegetation to grow. However, it negatively affected growth of $D$. australe in the field at a site where they were planted in an intermingled pattern. It is therefore possible that the exotic iceplant and the intergeneric hybrid may pose serious threats to native coastal plants. Thus, it is important to investigate the influence of other environmental filters such as salinity and sand burial on these taxa to be able to predict in which habitats they are more likely to be a management problem. Such a study would also help determine the ability of $D$. australe to tolerate sand burial and therefore its suitability for sand dune restoration. Due to its sexual sterility, the intergeneric hybrid is easier to manage since it does not leave behind any seed legacy and is therefore more suitable than Carpobrotus spp. for dune stabilisation. 


\section{REFERENCES}

Abbott, R. J. (1992). "Plant invasions, interspecific hybridization and the evolution of plant taxa " Trends in Ecology \& Evolution 7(12): 401-405.

Acosta, A. T. R., M. L. Carranza, et al. (2008). Patterns of native and alien plant species occurrence on coastal dunes in Central Italy. Plant invasions: human perception, ecological impacts and management. B. Tokarska-Guzik, J. H. Brock, G. Brunduet al: 235-248.

Affre, L., C. M. Suehs, et al. (2010). "Consistency in the habitat degree of invasion for three invasive plant species across Mediterranean islands." Biological Invasions 12(8): 2537-2548.

Ainouche, M., P. Fortune, et al. (2009). "Hybridization, polyploidy and invasion: lessons from Spartina (Poaceae)." Biological Invasions 11(5): 1159-1173.

Albert, M. E., C. M. D'Antonio, et al. (1997). "Hybridization and introgression in Carpobrotus spp. (Aizoaceae) in California .1. Morphological evidence." American Journal of Botany 84(7): 896-904.

Andreu, J., E. Manzano-Piedras, et al. (2010). "Vegetation response after removal of the invasive Carpobrotus hybrid complex in Andalucia, Spain." Ecological Restoration 28(4): 440-448.

Ayres, D. R. and D. R. Strong (2001). "Origin and genetic diversity of Spartina anglica (Poaceae) using nuclear DNA markers." American Journal of Botany 88(10): 1863-1867.

Baker, H. G. (1955). "Self compatibility and establishment after long distance dispersal." Evolution 9(3): 347-349.

Bartomeus, I. and M. Vilà (2009). "Breeding system and pollen limitation in two supergeneralist alien plants invading Mediterranean shrublands." Australian Journal of Botany 57(2): 109-115.

Biosecurity New Zealand (2008). Pests and diseases - Iceplant, Ministry of Agriculture and Forestry, New Zealand (Retrieved October 2011 from http://www.biosecurity.govt.nz/pests/iceplant).

Bourgeois, K., C. M. Suehs, et al. (2005). "Invasional meltdown potential: Facilitation between introduced plants and mammals on French Mediterranean islands." Ecoscience 12(2): 248-256.

Campos, J. A., M. Herrera, et al. (2004). "The role of alien plants in the natural coastal vegetation in central-northern Spain." Biodiversity and Conservation 13(12): 2275-2293.

Carboni, M., R. Santoro, et al. (2010). "Are some communities of the coastal dune zonation more susceptible to alien plant invasion?" Journal of Plant Ecology-Uk 3(2): 139-147.

Carranza, M. L., M. Carboni, et al. (2010). "Landscape-scale patterns of alien plant species on coastal dunes: the case of iceplant in central Italy." Applied Vegetation Science 13(2): 135-145.

Chinnock, R. J. (1971). "Studies in Disphyma - Genus Related to Mesembryanthemum - Part 1 a Revision of Disphyma australe." New Zealand Journal of Botany 9(2): 331-344.

Chinnock, R. J. (1972). "Natural Hybrids between Disphyma and Carpobrotus (Aizoaceae) in New Zealand." New Zealand Journal of Botany 10(4): 615-626. 
Chinnock, R. J. (1976). "Studies in Disphyma - a genus related to Mesembryanthemum - Part 2 Infraspecific subdivision of Disphyma australe and notes on the Australian species of Disphyma." New Zealand Journal of Botany 14(1): 77-78.

Chytrý, M., P. Pyšek, et al. (2009). "European map of alien plant invasions based on the quantitative assessment across habitats." Diversity and Distributions 15(1): 98-107.

Conser, C. and E. F. Connor (2009). "Assessing the residual effects of Carpobrotus edulis invasion, implications for restoration." Biological Invasions 11(2): 349-358.

Curr, R. H. F., A. Koh, et al. (2000). "Assessing Anthropogenic Impact on Mediterranean Sand Dunes from Aerial Digital Photography." Journal of Coastal Conservation 6(1): 15-22.

D'Antonio, C. M. (1990). "Seed production and dispersal in the non-native, invasive succulent Carpobrotus edulis (aizoaceae) in coastal strand communities of central California." Journal of Applied Ecology 27(2): 693-702.

D'Antonio, C. M. (1993). "Mechanisms controlling invasion of coastal plant communities by the alien succulent Carpobrotus edulis." Ecology 74(1): 83-95.

D'Antonio, C. M. and B. E. Mahall (1991). "Root profiles and competition between the invasive, exotic perennial, Carpobrotus edulis, and two native shrub species in California coastal scrub." American Journal of Botany 78(7): 885-894.

D'Antonio, C. M., D. C. Odion, et al. (1993). "Invasion of maritime chaparral by the introduced succulent Carpobrotus edulis." Oecologia 95(1): 14-21.

Ellstrand, N. C. (1992). "Gene flow by pollen - Implications for plant conservation genetics." Oikos 63(1): 77-86.

Ellstrand, N. C. and K. A. Schierenbeck (2000). "Hybridization as a stimulus for the evolution of invasiveness in plants?" Proceedings of the National Academy of Sciences of the United States of America 97(13): 7043-7050.

Ellstrand, N. C. and K. A. Schierenbeck (2006). "Hybridization as a stimulus for the evolution of invasiveness in plants?" Euphytica 148(1-2): 35-46.

Gallagher, K. G., K. A. Schierenbeck, et al. (1997). "Hybridization and introgression in Carpobrotus spp. (Aizoaceae) in California .2. Allozyme evidence." American Journal of Botany 84(7): 905-911.

Grant, V. (1981). Plant speciation. New York, Columbia University Press.

Hammer, S. and S. Liede (1990). "Natural and artificial hybrids in mesembryanthemaceae." South African Journal of Botany 56(3): 356-362.

Heenan, P. B. and W. R. Sykes (2010). "Taxonomic notes on the New Zealand flora: xCarpophyma mutabilis and xCarpophyma pallida (Aizoaceae), new names for two wild intergeneric hybrids." New Zealand Journal of Botany 48(3-4): 225-230.

Heger, T. and L. Trepl (2003). "Predicting Biological Invasions." Biological Invasions 5(4): 313-321.

Jay, M., M. Morad, et al. (2003). "Biosecurity, a policy dilemma for New Zealand." Land Use Policy 20(2): 121-129. 
Levin, D. A., J. Francisco-Ortega, et al. (1996). "Hybridization and the Extinction of Rare Plant Species." Conservation Biology 10(1): 10-16.

Levine, J. M., M. Vilà, et al. (2003). "Mechanisms underlying the impacts of exotic plant invasions." Proceedings of the Royal Society of London Series B-Biological Sciences 270(1517): 775-781.

Lewontin, R. C. and L. C. Birch (1966). "Hybridization as a Source of Variation for Adaptation to New Environments." Evolution 20(3): 315-336.

Mack, Richard N. (2003). "Phylogenetic Constraint, Absent Life Forms, and Preadapted Alien Plants: A Prescription for Biological Invasions." International Journal of Plant Sciences 164(S3): S185-S196.

Mack, R. N., D. Simberloff, et al. (2000). "Biotic invasions: Causes, epidemiology, global consequences, and control." Ecological Applications 10(3): 689-710.

Maltez-Mouro, S., F. T. Maestre, et al. (2010). "Weak effects of the exotic invasive Carpobrotus edulis on the structure and composition of Portuguese sand-dune communities." Biological Invasions 12(7): 2117-2130.

Milne, R. I. and R. J. Abbott (2000). "Origin and evolution of invasive naturalized material of Rhododendron ponticum L. in the British Isles." Molecular Ecology 9(5): 541-556.

Moragues, E. and A. Traveset (2005). "Effect of Carpobrotus spp. on the pollination success of native plant species of the Balearic Islands." Biological Conservation 122(4): 611-619.

Nishitani, S., T. Takada, et al. (1999). "Optimal resource allocation to seeds and vegetative propagules under density-dependent regulation in Syneilesis palmata (Compositae)." Plant Ecology 141(1): 179-189.

Olden, J. D., N. L. Poff, et al. (2004). "Ecological and evolutionary consequences of biotic homogenization." Trends in Ecology \& Evolution 19(1): 18-24.

Parker, I. M., D. Simberloff, et al. (1999). "Impact: toward a framework for understanding the ecological effects of invaders." Biological Invasions 1(1): 3-19.

Price, E. A. C. and C. Marshall (1999). "Clonal Plants and Environmental Heterogeneity: An Introduction to the Proceedings." Plant Ecology 141(1/2): 3-7.

Raybould, A. F., A. J. Gray, et al. (1991). "The evolution of Spartina anglica C.E. Hubbard (Gramineae): origin and genetic variability." Biological Journal of the Linnean Society 43(2): 111-126.

Rhymer, J. M. and D. Simberloff (1996). "Extinction by hybridization and introgression." Annual Review of Ecology and Systematics 27: 83-109.

Richardson, D. M., N. Allsopp, et al. (2000). "Plant invasions - the role of mutualisms." Biological Reviews 75(1): 65-93.

Richardson, D. M. and P. Pyšek (2006). "Plant invasions: merging the concepts of species invasiveness and community invasibility." Progress in Physical Geography 30(3): 409-431.

Rieseberg, L. H. (1995). "The role of hybridization in evolution - old wine in new skins." American Journal of Botany 82(7): 944-953. 
Rieseberg, L. H., N. C. Ellstrand, et al. (1993). "What Can Molecular and Morphological Markers Tell Us About Plant Hybridization?" Critical Reviews in Plant Sciences 12(3): 213-241.

Sala, O. E., F. S. Chapin, et al. (2000). "Biodiversity - Global biodiversity scenarios for the year 2100." Science 287(5459): 1770-1774.

Sammul, M., K. Kull, et al. (2004). "A comparison of plant communities on the basis of their clonal growth patterns." Evolutionary Ecology 18(5-6): 443-467.

Schierenbeck, K. and N. Ellstrand (2009). "Hybridization and the evolution of invasiveness in plants and other organisms." Biological Invasions 11(5): 1093-1105.

Schierenbeck, K. A., V. V. Symonds, et al. (2005). "Genetic variation and phylogeographic analyses of two species of Carpobrotus and their hybrids in California." Molecular Ecology 14(2): 539-547.

Sheppard, A. W., R. H. Shaw, et al. (2006). "Top 20 environmental weeds for classical biological control in Europe: a review of opportunities, regulations and other barriers to adoption." Weed Research 46(2): 93-117.

Simberloff, D., I. M. Parker, et al. (2005). "Introduced species policy, management, and future research needs." Frontiers in Ecology and the Environment 3(1): 12-20.

Sintes, T., E. Moragues, et al. (2007). "Clonal growth dynamics of the invasive Carpobrotus affine acinaciformis in Mediterranean coastal systems: A non-linear model." Ecological Modelling 206(1-2): 110-118.

SPSS Inc. (2008). SPSS for Windows Release 16.0.2. Chicago, SPSS Inc.

Stuefer, J. F., H. DeKroon, et al. (1996). "Exploitation of environmental heterogeneity by spatial division of labour in a clonal plant." Functional Ecology 10(3): 328-334.

Suehs, C. M., L. Affre, et al. (2004). "Invasion dynamics of two alien Carpobrotus (Aizoaceae) taxa on a Mediterranean island: II. Reproductive strategies." Heredity 92(6): 550-556.

Thompson, J. D. (1991). "The bilogy of an invasive plant - what makes Spartina anglica so successful?" Bioscience 41(6): 393-401.

Thuiller, W., D. M. Richardson, et al. (2005). "Niche-based modelling as a tool for predicting the risk of alien plant invasions at a global scale." Global Change Biology 11(12): 2234-2250.

Traveset, A., G. Brundu, et al. (2008). "Consistent performance of invasive plant species within and among islands of the Mediterranean basin." Biological Invasions 10(6): 847-858.

Traveset, A., E. Moragues, et al. (2008). "Spreading of the invasive Carpobrotus aff. acinaciformis in Mediterranean ecosystems: The advantage of performing in different light environments." Applied Vegetation Science 11(1): 45-54.

Verlaque, R., L. Affre, et al. (2011). "Unexpected morphological and karyological changes in invasive Carpobrotus (Aizoaceae) in Provence (S-E France) compared to native South African species." Comptes Rendus Biologies 334(4): 311-319.

Vilà, M. and C. M. D'Antonio (1998). "Hybrid Vigour for Clonal Growth in Carpobrotus (Aizoaceae) in Coastal California." Ecological Applications 8(4): 1196-1205. 
Vilà, M., A.-S. D. Siamantziouras, et al. (2008). "Widespread resistance of Mediterranean island ecosystems to the establishment of three alien species." Diversity and Distributions 14(5): 839-851.

Vilà, M., M. Tessier, et al. (2006). "Local and regional assessments of the impacts of plant invaders on vegetation structure and soil properties of Mediterranean islands." Journal of Biogeography 33(5): 853-861.

Vilà, M., E. Weber, et al. (2000). "Conservation Implications of Invasion by Plant Hybridization." Biological Invasions 2(3): 207-217.

Vilà, M., E. Weber, et al. (1998). "Flowering and mating system in hybridizing Carpobrotus (Aizoaceae) in coastal California." Canadian Journal of Botany 76(7): 1165-1169.

Vitousek, P. M., C. M. D'Antonio, et al. (1997). "Introduced species: A significant component of human-caused global change." New Zealand Journal of Ecology 21(1): 1-16.

Walther, G. R., E. Post, et al. (2002). "Ecological responses to recent climate change." Nature 416(6879): 389-395.

Webb, C. J., W. R. Sykes, et al. (1988). Flora of New Zealand: Naturalised Pteridophytes, Gymnosperms, Dicotyledons. Christchurch, Department of Scientific and Industrial Research.

Weber, E. (2003). Invasive plant species of the world: a reference guide to environmental weeds. Wallingford, UK, CABI Publishing.

Williams, J. A. and C. J. West (2000). "Environmental weeds in Australia and New Zealand: issues and approaches to management." Austral Ecology 25(5): 425-444.

Williamson, M. (1996). Biological invasions. London, Chapman and Hall.

Wilson and Sykes (1999). "Is zonation on coastal sand dunes determined primarily by sand burial or by salt spray? A test in New Zealand dunes." Ecology Letters 2(4): 233-236.

Zedda, L., A. Cogoni, et al. (2010). "Impacts of alien plants and man-made disturbance on soilgrowing bryophyte and lichen diversity in coastal areas of Sardinia (Italy)." Plant Biosystems 144(3): 547-562. 


\section{Chapter four}

\section{Overall conclusions and recommendations}

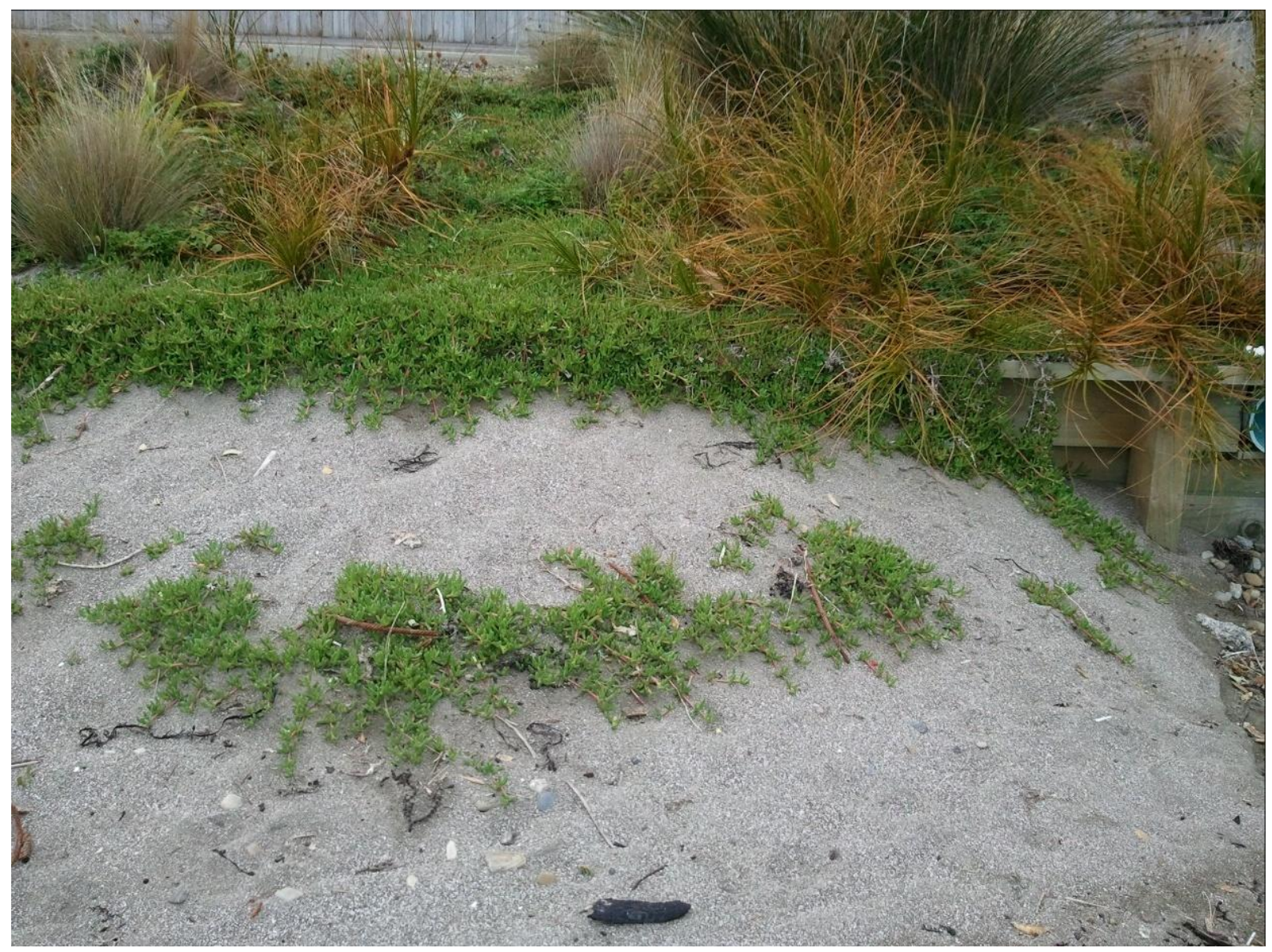

Fig. 4.1: XCarpohyma mutabilis (foreground) on the beach at Day's Bay, Wellington accumulating some sand. Photo taken by author in April 2012 


\subsection{Interactive effects of $C$. edulis on Spinifex sericeus and its role in sand dune restoration}

This was a neighbour removal experiment aimed at investigating the effects of $C$. edulis on survival and growth of Spinifex sericeus. Presence or absence of $C$. edulis did not have any effect on initial Spinifex seedling survival. However, seedling survival was significantly higher at the sub-plots nearer the high tide water mark than those at the top. Given that the formative period after planting was characterised by drought, the only confounding factor that could have been responsible for varied survivorship at the two subplots is soil moisture, attributable to inundation during high tides, strong wave splashes, and water draining from inland.

Spinifex seedling survival was consistently higher in the removal plots (iceplant removed) until the July storm (eight months after planting), although the difference was not statistically significant. In addition, seedlings in these plots produced significantly higher numbers of leaves than those in plots of the other treatments. This suggests that the previously extant iceplant may have improved soil micro-conditions to which the incoming seedlings responded positively.

The most important determinant of Spinifex seedling survival in this experiment was storm disturbance. Spinifex plants within iceplant stands survived storm disturbance better than those in the removal and bare plots because of the soil-binding nature of the extensive fibrous root system of $C$. edulis. Seedlings in the removal plots were the worst affected by the storm because of the steeper slope built by sand accretion activity of the previously extant iceplant. Furthermore, these plots were rendered less stable by the removal of the iceplant. Steep slopes are generally more prone to slumping and eventual formation of vertical scarps after storm undercutting events. Location of the seedlings (toward the top or bottom of the dune face) also mattered since storm disturbance removed plants closest to the sea.

Other environmental conditions that limit growth and survival of plants on coastal dunes are sand-blasting and salt sprays. Sandblasting brings about abrasive damage to plant leaves, reducing photosynthetic surface and predisposing plant to infections. Salt 
spray, on the other hand, has been observed to cause leaf necrosis beginning at the tips (Wilson and Sykes 1999). In this experiment, Spinifex seedlings in the removal and bare treatments had their leaves dying back from the tips, unlike those seedlings growing within the iceplant stands. This indicates that seedlings growing with iceplant neighbours were buffered from the harmful effects of sandblasting and salt sprays. Therefore, the expectation that facilitation would be the dominant effect of extant adult nurse plants on seedlings of other species at the harsher foredune zone (Padilla and Pugnaire 2006) seems plausible, at least in buffering against abrasive damage by sandblasting and necrosis due to salt spray.

Despite their better survival and less damage of leaf tips, Spinifex plants in the iceplant treatment (iceplant neighbour present) had significantly lower numbers of leaves and appeared more slender; confirming that presence of iceplant suppresses growth performance of native species (D'Antonio and Mahall 1991; D'Antonio, Odion et al. 1993). Salinity has been reported to cause internal plant toxicity (Wilson and Sykes 1999). In this study, soil salinity was higher under the canopy of $C$. edulis since salt particles trapped by leaves during salt sprays are then leached into the soil (Gormally and Donovan 2010). Accumulation of salts in leaves and eventual release into the soil after leaf senescence has been suggested as a mechanism by which Mesembryanthemum crystallinum (another member of Aizoaceae) contributes to desiccation and death of neighbouring plants (Conser and Connor 2009). Carpobrotus edulis has also been reported to have led to loss of floristic diversity at Berlangas, Portugal (Draper, Rossello-Graell et al. 2003). My inference from this is that $C$. edulis uses similar mechanisms to $M$. crystallinum to alter soil osmotic levels, to the detriment of neighbouring native plants. Comparison of the number of leaves produced by seedlings at the different sub-plots within a treatment showed that plants at the bottom of the iceplant plots had significantly higher numbers of leaves than their counterparts at the top of the dune, suggesting that competition from iceplant was less severe in the environmentally harsher section of the dune, and thus supporting the stress gradient hypothesis (Bertness and Callaway 1994; Brooker and Callaghan 1998).

Using dead debris of iceplant as a mulching material did not improve Spinifex survivorship. Presence of dead iceplant debris resulted in production of more leaves by 
plants at the top of the dune only in August. The fact that location of the plants did not have much effect on their performance means that the $2-4 \mathrm{~m}$ space between plants at the bottom and the top of the dune was not enough to produce a gradient to which plants respond differentially. This is confirmed by the lack of difference in soil moisture, soil organic matter and salinity between the two sampling locations separated by $5-8 \mathrm{~m}$.

It has been suggested that $C$. edulis has residual effects on the soil inhibiting reestablishment of native plant species even after its removal (Conser and Connor 2009). Spinifex seedlings in my removal plots (where iceplant had been present) produced significantly higher numbers of leaves than plants in the other treatments. While this improved response may be attributed to elimination of competition, plants in the removal plots actually performed better that those in bare plots where there was no preexisting iceplant. This suggests that $C$. edulis did not leave an allelopathic legacy, at least in the short-term but actually improved soil micro-conditions.

\subsection{Growth, substrate preference and mating systems of the various iceplant taxa}

The common garden experiment was set up to investigate growth performance of the three iceplant species in New Zealand and the intergeneric hybrid across three different substrates. The substrates in the experiment were made of one part potting mix and two parts sand or gravel, making them similar in initial fertility. However, because of differences in particle and interstitial pore size there would be variability among them in drainage and nutrient adsorption. It has been suggested that soil texture influences soil Carbon (C) and Nitrogen (N) accumulation as well as soil water dynamics (Hook and Burke 2000). Finetextured soils tend to have higher water holding capacity and labile $\mathrm{C}$ and $\mathrm{N}$ than coarsetextured ones (Austin, Yahdjian et al. 2004). Gravel, having bigger particle size and interstitial space, is more freely draining and adsorbs less nutrients. On the other hand, fine sand with smaller particle size will be better at moisture retention and nutrient adsorption, whereas coarse sand will occupy the intermediate position. The differences in water retention and nutrient adsorption ability of the substrates make it possible to infer 
tolerance of the taxa to moisture and nutrient deficits. The ratio of dry weight to fresh weight showed that Carpobrotus species were more succulent than the intergeneric hybrid, indicating that these exotics are more efficient at storing water (Rabas and Martin 2003) and may explain why substrate had little influence on growth rates of the two Carpobrotus species. It has further been found that water stress induces a weak Crassulacean Acid Metabolism (CAM) in Carpobrotus edulis (Earnshaw, Carver et al. 1987), but see (Rabas and Martin 2003).

According to the results obtained from the common garden experiment, only $C$. chilensis had some level of substrate preference, with plants growing in sand having significantly higher dry weight and producing more leaves than those in gravel. Despite this, they have been observed hanging down cliffs, e.g. at Taylor's Mistake near Christchurch, suggesting that the current distribution of the exotics is a product of human introduction rather than soil types. There was no difference in performance between the two Carpobrotus species, regardless of the substrate in the common garden experiment as well as in the field. The two exotics both had higher actual and estimated dry weights than the intergeneric hybrids and $D$. australe, with the hybrids in turn significantly outperforming $D$. australe.

The two varieties of $D$. australe, (green and red), did not differ in their performance in either of the substrate types, even though in nature the green one seems to predominate at rocky shores (K. Gould pers. comm.). Compared to the other taxa, D. australe allocated more biomass to its roots than shoot. The hybrid also invested more in the roots than the two Carpobrotus species. This implies that the hybrid and its native parent are better adapted morphologically to obtain water under desiccating conditions or in poor soils. Partitioning of more photosynthates to roots influences microbial biomass and hence, soil organic matter decomposition and nutrient recycling (Van Veen, Merckx et al. 1989). Therefore, $D$. australe contributes more to the "improvement" of soil micro-conditions which may not be advantageous to native sand-binders that normally prefer low nutrient environments. 
In terms of characters relating to vegetative growth (number of leaves, number of nodes, main axes length, and internode length), the hybrid on the whole performed significantly better than the other taxa, both in the field and in the common garden experiment. In the common garden experiment, $D$. australe had better vegetative growth than the exotic Carpobrotus but experienced the least growth in the field study, due to smothering by the neighbouring hybrid. The hybrid that is sexually sterile seems to have invested a lot in lateral branches as its only means of proliferation and self perpetuation. Vegetative reproduction has been found to be positively correlated with invasiveness (Kolar and Lodge 2001) but the scope of my study was not extensive enough to conclude whether the intergeneric hybrid will displace $D$. australe or not. My observation is that its stolons are thin and spread sparsely enough to allow it to intermingle with other plants, more so than the Carpobrotus species or D. australe.

Mating experiments in the present study have shown that flowers of Carpobrotus species are highly fertile to intrageneric and intergeneric pollen. However, $C$. edulis was not agamospermic and only slightly self-fertile, needing intervention of a pollinator since spontaneous self-fertilisation did not occur in bagged flowers that were not manipulated. Carpobrotus chilensis was slightly agamospermic and self-fertile.

\subsection{Recommendations for restoration of Carpobrotus dominated sand dunes}

- Along high energy eroding coasts, such as Kapiti, removal of the exotic iceplant prior to establishment of native sand-binder species is not advisable. Seedlings of native sand-binders will most likely be lost before they establish especially if the slope of the dune face is steep, unless measures to mitigate erosion are put in place. For future plantings to succeed, gently sloping (probably less than $28^{\circ}$ ), low disturbance sites should be selected. Although options like mechanical dune reshaping have been used with satisfactory results on steep slopes (Bergin, Miller et al. 2007), I would personally favour reducing density of existing iceplant and planting Spinifex 
in-between them. However, facilitation of Spinifex by Carpobrotus edulis in this study is not strong enough to warrant its retention as a nurse plant.

- If Spring is chosen as the planting season for native sand-binders, as is the case with my trials, planting should be done early in the season since the later months tend to be quite dry.

- Spinifex seedlings should be planted deep enough (at least $5 \mathrm{~cm}$ above the level of root trainer sleeve) to enhance root contact with water and guard against root exposure by erosion. Care should be taken to make planting holes perpendicular to the horizontal plane, not to the slope incline.

- Conducting trials with the intergeneric hybrid iceplant on bare foredunes before inplanting native sand-binders may help mitigate erosion and enhance survivorship of the native seedlings. Seedlings of some native sand-binders are costly and a nurse plant may be desirable. This hybrid, being sexually sterile and therefore dispersallimited, can be controlled by mechanical or chemical means if it proves undesirable. However more research needs to be conducted to establish its suitability.

- Even among the stands of invasive iceplant species, there were some invertebrates and reptiles. Dune reshaping, if deemed necessary, needs to include plans for some refugia for these animals.

- Human trampling was an issue at the Queen Elizabeth Park field site and therefore some form of fencing is desirable to enhance success. In urban settings where dunes lead onto the beach, adequate walkways should be provided. 


\subsection{Suggestions for future studies}

- Building on my trials, large scale longer-term restoration trials can be undertaken to further investigate the facilitative and competitive effects of the various iceplant taxa on Spinifex at sites that are less disturbed, in order to eliminate the confounding effects of storm and human disturbance.

- Field trials on suitability or otherwise of the intergeneric hybrid and Disphyma for sand dune restoration may be conducted at sites that are less disturbed.

- Molecular studies to identify the iceplant taxa currently found in NZ and further investigation of their mating systems would go a long way in providing insights into species identity and hybridisation of the iceplant taxa. Isozyme analysis of the two Carpobrotus species in California has been done (Gallagher, Schierenbeck et al. 1997) and was attempted in my study (see appendix 3). Morphological characters alone, of which flower colour is the most important, are not enough to assume identity of the iceplant morphotypes because of introgressive hybridisation. Analysis of chloroplast DNA (cpDNA) data for C. edulis, C. chilensis, and their hybrid morphotypes, has been done by Schierenbeck et al. (2005) and can be used as a basis for further studies.

- One factor contributing to invasiveness of $C$. edulis that has been investigated in the Mediterranean region is the enemy release hypothesis (release from soil pathogens) (Van Grunsven, Bos et al. 2009). This can be further built on in the context of New Zealand. During my study, I observed scale insects presumed to be Pulvinaria mesembryanthemi (Appendix 4) which have infested all iceplant taxa in New Zealand. It would be interesting to investigate how these natural enemies affect the various taxa and as a possible bio-control measure.

- Comparing biodiversity of sites invaded by the exotic iceplant species and uninvaded/restored sites would provide useful additional information on them. Patterns of co-occurrence may shed some light on intimate associations. Over the course of my study I have observed the presence of leaf-roller caterpillars in terminal buds of the exotic iceplant taxa, most of which hatched into moths while a few hatched into flies upon incubation (Appendix 4). There may be a guild of native or exotic arthropods that depend wholly or partially on these plants to complete their 
life cycles. Influence of $C$. edulis on soil biota has been studied by de la Pena et al. (2010) in Portugal and Spain but there is room to explore further in a New Zealand context.

- Studies of Disphyma have been few and far between, especially in recent years. (Chinnock 1971; 1972; 1976)studied species biology, but there is a need to develop on this and include autecological studies of the species. 


\section{REFERENCES}

Austin, A. T., L. Yahdjian, et al. (2004). "Water pulses and biogeochemical cycles in arid and semiarid ecosystems." Oecologia 141(2): 221-235.

Bergin, D., E. Miller, et al. (2007). Performance of indigenous sand-binders planted on a reshaped foredune at Oakura beach, New Plymouth. Coastal Dune Vegetation Network (Retrieved October 2011 from http://www.dunestrust.org.nz/OakuraReshapingTrial.pdf).

Bertness, M. D. and R. Callaway (1994). "Positive interactions in communities." Trends in Ecology \& Evolution 9(5): 191-193.

Brooker, R. W. and T. V. Callaghan (1998). "The balance between positive and negative plant interactions and its relationship to environmental gradients: a model." Oikos 81(1): 196-207.

Chinnock, R. J. (1971). "Studies in Disphyma - Genus Related to Mesembryanthemum- Part 1 a Revision of Disphyma australe." New Zealand Journal of Botany 9(2): 331-344.

Chinnock, R. J. (1972). "Natural Hybrids between Disphyma and Carpobrotus (Aizoaceae) in New Zealand." New Zealand Journal of Botany 10(4): 615-626.

Chinnock, R. J. (1976). "Studies in Disphyma - a genus related to Mesembryanthemum - Part 2 Infraspecific subdivision of Disphyma australe and notes on the Australian species of Disphyma." New Zealand Journal of Botany 14(1): 77-78.

Conser, C. and E. F. Connor (2009). "Assessing the residual effects of Carpobrotus edulis invasion, implications for restoration." Biological Invasions 11(2): 349-358.

D'Antonio, C. M. and B. E. Mahall (1991). "Root profiles and competition between the invasive, exotic perennial, Carpobrotus edulis, and two native shrub species in California coastal scrub." American Journal of Botany 78(7): 885-894.

D'Antonio, C. M., D. C. Odion, et al. (1993). "Invasion of maritime chaparral by the introduced succulent Carpobrotus edulis." Oecologia 95(1): 14-21.

Draper, D., A. Rossello-Graell, et al. (2003). "Application of GIS in plant conservation programmes in Portugal." Biological Conservation 113(3): 337-349. 
Earnshaw, M. J., K. A. Carver, et al. (1987). "Leaf anatomy, water relations and crassulacean acid metabolism in the chlorenchyma and colorless internal water-storage tissue of Carpobrotus edulis and Senecio? mandraliscae." Planta 170(3): 421-432.

Gallagher, K. G., K. A. Schierenbeck, et al. (1997). "Hybridization and introgression in Carpobrotus spp. (Aizoaceae) in California .2. Allozyme evidence." American Journal of Botany 84(7): 905-911.

Gormally, C. and L. Donovan (2010). "Responses of Uniola paniculata L. (Poaceae), an Essential Dune-Building Grass, to Complex Changing Environmental Gradients on the Coastal Dunes." Estuaries and Coasts 33(5): 1237-1246.

Hook, P. B. and I. C. Burke (2000). "Biogeochemistry in a Shortgrass Landscape: Control by Topography, Soil Texture, and Microclimate." Ecology 81(10): 2686-2703.

Kolar, C. S. and D. M. Lodge (2001). "Progress in invasion biology: predicting invaders." Trends in Ecology \& Evolution 16(4): 199-204.

Padilla, F. M. and F. I. Pugnaire (2006). "The role of nurse plants in the restoration of degraded environments." Frontiers in Ecology and the Environment 4(4): 196-202.

Rabas, A. R. and C. E. Martin (2003). "Movement of Water from Old to Young Leaves in Three Species of Succulents." Annals of Botany 92(4): 529-536.

Schierenbeck, K. A., V. V. Symonds, et al. (2005). "Genetic variation and phylogeographic analyses of two species of Carpobrotus and their hybrids in California." Molecular Ecology 14(2): 539-547.

Van Grunsven, R. H. A., F. Bos, et al. (2009). "Release from soil pathogens plays an important role in the success of invasive Carpobrotus in the Mediterranean." South African Journal of Botany 75(1): 172-175.

Van Veen, J., R. Merckx, et al. (1989). "Plant- and soil related controls of the flow of carbon from roots through the soil microbial biomass." Plant and Soil 115(2): 179-188.

Wilson and Sykes (1999). "Is zonation on coastal sand dunes determined primarily by sand burial or by salt spray? A test in New Zealand dunes." Ecology Letters 2(4): 233-236. 


\section{Appendices}

\section{Appendix 1: Geographical coordinates of the various sites}

This appendix gives the Geographic co-ordinates (WGS84 geodatum) of some of the sites that were visited during the course of this study. Locations of some of experimental plots at Queen Elizabeth Park are given in Table 1 while Table 2 shows the locations of the sample Carpobrotus plants whose flower phonologies were studied during the main flowering season of 2011 (September-December). In addition, the locations of populations from which cuttings for experimental growth in different substrates are given in Table 3.

Table 1. Locations of some of the experimental plots at Queen Elizabeth Park

\begin{tabular}{|c|c|c|}
\hline ID & Treatment & Geographical co-ordinates \\
\hline QEP_A1 & Iceplant intact & S40 57.466 E17458.069 \\
\hline QEP_A3 & Iceplant intact & S40 57.475 E17458.065 \\
\hline QEP_A7 & Iceplant intact & S40 57.519 E17458.044 \\
\hline QEP_B1 & Iceplant removed & S40 57.472 E17458.066 \\
\hline QEP_B3 & Iceplant removed & S40 57.478 E17458.063 \\
\hline QEP_B4 & Iceplant removed & S40 57.485 E17458.06 \\
\hline QEP_B6 & Iceplant removed & S40 57.519 E17458.045 \\
\hline QEP_B7 & Iceplant removed & S40 57.521 E17458.045 \\
\hline QEP_C3 & Bare & S40 57.492 E17458.058 \\
\hline QEP_C4 & Bare & S40 57.494 E17458.058 \\
\hline QEP_C5 & Bare & S40 57.504 E17458.052 \\
\hline QEP_C6 & Bare & S40 57.509 E17458.049 \\
\hline QEP_C7 & Bare & S40 57.517 E17458.047 \\
\hline SPRAY2 & Iceplant sprayed & S40 57.59 E17458.006 \\
\hline SPRAY3 & Iceplant sprayed & S40 57.601 E17458.001 \\
\hline
\end{tabular}


Table 2. Locations of the Carpobrotus plants at Eastbourne whose flower phenologies were monitored from September to December 2011.

\begin{tabular}{lll}
\hline ID & Taxon & Geographical co-ordinates \\
\hline EAS_CCPL1 & C. chilensis & S41 17.515 E174 53.605 \\
EAS_CCPL2 & C. chilensis & S41 17.502 E174 53.609 \\
EAS_CCPL3 & C. chilensis & S41 17.492 E174 53.618 \\
EAS_CCPL4 & C. chilensis & S41 $17.423 \mathrm{E} 17453.702$ \\
EAS_CCPL5 & C. chilensis & $\mathrm{S} 4117.467 \mathrm{E} 17453.638$ \\
EAS_CEPL1 & C. edulis & $\mathrm{S} 4117.48 \mathrm{E} 17453.63$ \\
EAS_CEPL2 & C. edulis & $\mathrm{S} 4117.408 \mathrm{E} 17453.701$ \\
EAS_CEPL3 & C. edulis & $\mathrm{S} 4117.397 \mathrm{E} 17453.736$ \\
EAS_CEPL4 & C. edulis & $\mathrm{S} 4117.377 \mathrm{E} 17453.763$ \\
EAS_CEPL5 & C. edulis & $\mathrm{S} 4117.392 \mathrm{E} 17453.731$ \\
\hline
\end{tabular}

Table 3. Sites from where iceplant cuttings of the various taxa were obtained for growth comparisons in different substrates (WGS84 geodatum) ( $g=$ Green, $r=$ Red)

\begin{tabular}{|c|c|c|c|}
\hline ID & Site & Taxa & Geographic co-ordinates \\
\hline EASTB01 & Eastbourne & C. edulis & S41 17.397 E174 53.735 \\
\hline EASTB02 & Eastbourne & C. chilensis & S41 17.514 E174 53.602 \\
\hline ISL01 & Island Bay & D. australe(g) & S41 20.934 E174 45.152 \\
\hline ISL02 & Island Bay & Hybrid & S41 20.882 E174 45.671 \\
\hline MOA1 & Moa Point & $\begin{array}{l}\text { D. australe(r), Hybrid, } \\
\text { C. edulis }\end{array}$ & S41 20.167 E174 48.474 \\
\hline PET01 & Petone & D. australe(g) & S41 13.547 E174 51.869 \\
\hline PUK01 & Pukerua Bay & C. chilensis & S41 $1.77 \quad$ E174 53.699 \\
\hline QEP01 & $\begin{array}{l}\text { Queen Elizabeth } \\
\text { Park }\end{array}$ & C. edulis & S40 $57.5 \quad$ E174 58.051 \\
\hline QEP02 & $\begin{array}{l}\text { Queen Elizabeth } \\
\text { Park }\end{array}$ & C. edulis & S40 57.664 E174 57.971 \\
\hline SEAT01 & Seatoun & D. australe(g) & S41 19.394 E174 50.184 \\
\hline SEAT02 & Seatoun & Hybrid & S41 19.606 E174 50.338 \\
\hline WOR01 & Worser Bay & $\begin{array}{l}\text { D. australe }(r) \text {, } \\
\text { C. edulis }\end{array}$ & S41 19.075 E174 49.73 \\
\hline WOR02 & Worser Bay & Hybrid & S41 19.061 E174 49.697 \\
\hline DAY01 & Day's Bay & Hybrid, D. australe(r) & S41 16.764 E174 54.375 \\
\hline
\end{tabular}




\section{Appendix 2: Initial biomass of sample cuttings}

In order to have an indicator of the initial biomass of the iceplant cuttings referred to in chapter two; I randomly selected ten cuttings of each taxon without regard to their source population and dried them in an oven for 48 hours at $70^{\circ} \mathrm{C}$. One-way ANOVA with dry weight as the dependent variable and taxon as the independent variable showed that there was significant variability in the initial biomass of the various taxa (Table 1). After running a Post-Hoc test of the data, it was found that cuttings $C$. edulis had a significantly higher initial biomass than all the other taxa. Carpobrotus chilensis cuttings also had a higher initial biomass than $D$. australe and the intergeneric hybrid. However, there was no difference in the initial biomass of the cuttings of $D$. australe and the hybrid (Table 2; Fig. 1).

Table 1. ANOVA table showing variability in initial biomass among the taxa

\begin{tabular}{lrrrrr}
\hline Source & $\begin{array}{c}\text { Type III Sum of } \\
\text { Squares }\end{array}$ & $\mathrm{df}$ & Mean Square & $\mathrm{F}$ & Sig. \\
\hline Taxon & 7.570 & 3 & 2.523 & 91.525 & $<.001$ \\
Error & .992 & 36 & .028 & & \\
Total & 22.910 & 40 & & & \\
& & & & & \\
\hline
\end{tabular}

Table 2. A Tukey HSD table comparing biomass of the cuttings of the various taxa

\begin{tabular}{llccc}
\hline (I) Taxon & (J) Taxon & Mean Difference (I-J) & Std. Error & Sig. \\
\hline C. chilensis & $\begin{array}{l}\text { D. australe } \\
\text { Hybrid }\end{array}$ & $.73^{*}$ & .074 & $<.001$ \\
& & $.58^{*}$ & .074 & $<.001$ \\
C. edulis & C. chilensis & $.34^{*}$ & .074 & $<.001$ \\
& D. australe & $1.07^{*}$ & .074 & $<.001$ \\
& Hybrid & $.93^{*}$ & .074 & $<.001$ \\
Hybrid & D. australe & .15 & .074 & .218 \\
& & & & \\
\hline
\end{tabular}




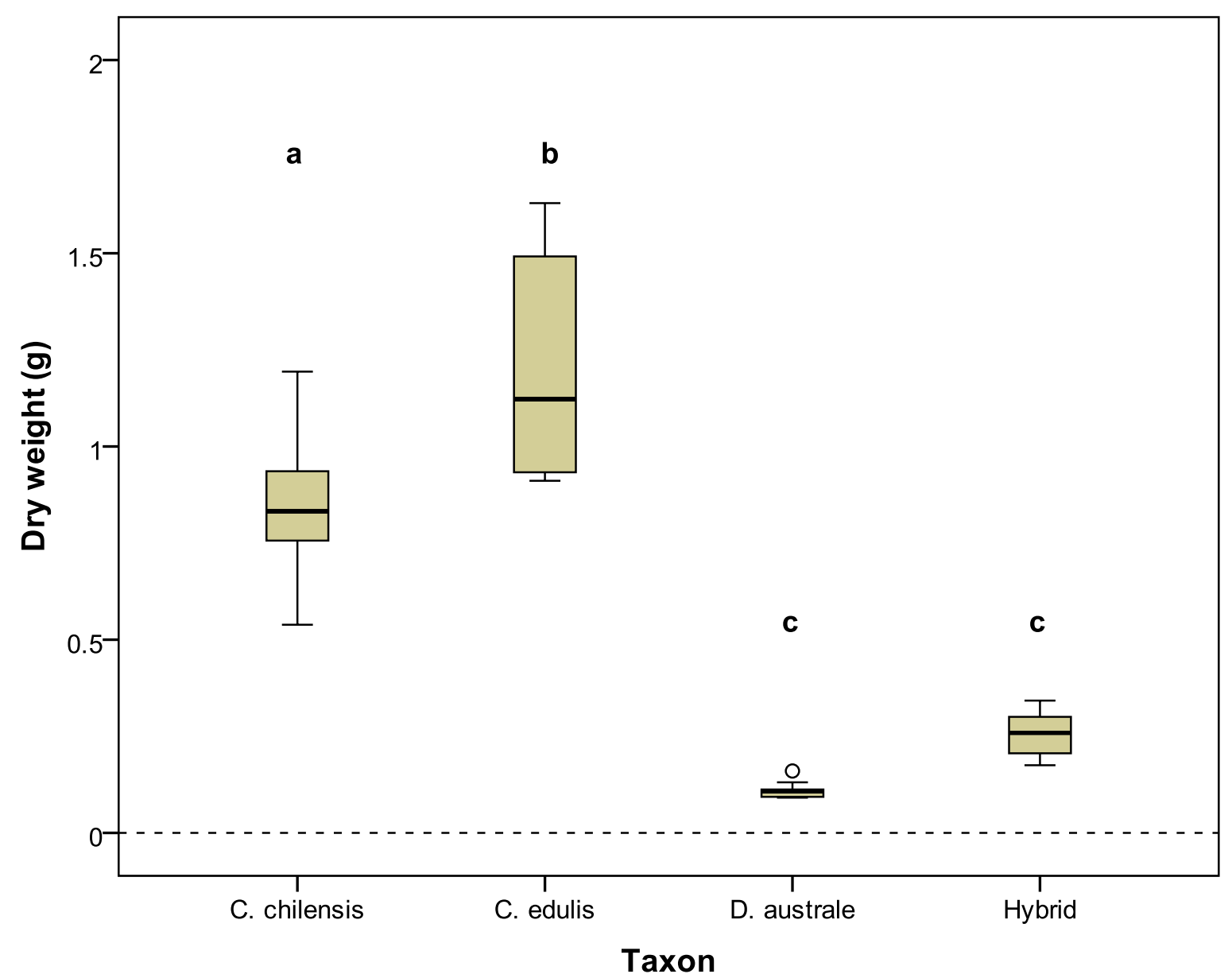

Fig. 1: Boxplots comparing the initial biomass of sample cuttings of the various taxa 


\section{Appendix 3: Allozyme Detection in Disphyma and Carpobrotus}

Lesley Milicich and Guyo Gufu

\section{Introduction}

In New Zealand the yellow-flowered Carpobrotus edulis and magenta-flowered $C$. chilensis co-occur at most sites. Carpobrotus chilensis appears to be hybridizing and backcrossing with C. edulis individuals (Vila \& D'Antonio 1998) according to morphometric (Albert et al. 1997) and isozyme analyses (Gallagher et al. 1997), although there are no presence records of the intrageneric hybrid in New Zealand (Heenan \& Sykes 2010). The widespread hybridisation and backcrossing events of these congeners and their general lack of morphometric differences, make it possible that Carpobrotus plants present in New Zealand may in fact be two colour morphs of a $C$. edulis and $C$. chilensis hybrid swarm. The exotic Carpobrotus species are also known to hybridise with the native horokaka, Disphyma australe (Chinnock 1972). We obtained samples from different populations of the various taxa and conducted some allozyme analysis to determine whether the exotic Carpobrotus found in Wellington region were pure species or introgressant hybrid swarms before attempting artificial cross pollination experiments. We also wanted to find out the exotic parent of the presumed intergeneric hybrid (Carpobrotus x Disphyma).

\section{Study taxa and sites}

Cuttings of the following taxa were collected from the Wellington region: Disphyma australe (Worser Bay and Titahi Bay), the putative hybrid Disphyma x Carpobrotus (Worser Bay, Seatoun, Island Bay and Titahi Bay), Carpobrotus yellow flowered (Worser Bay, QE2 Park, Waikanae Beach, Peka Peka Beach, Te Horo Beach, Otaki Beach, Hokio Beach, Foxton Beach and Himatangi Beach) and Carpobrotus red flowered (Seatoun, Plimmerton, Paraparaumu Beach Golf Course, Hokio Beach and Foxton Beach). The cuttings were grown on in a glasshouse prior to allozyme analysis. 


\section{Materials and methods}

Young leaf tips were ground in $75 \mathrm{mM}$ Tris/ $\mathrm{HCl}$ extraction buffer $\mathrm{pH} 7.5$, (Wendel and Weeden, 1989). The resulting crude protein extracts were absorbed on to $3 \mathrm{~mm} \times 15 \mathrm{~mm}$ paper wicks and loaded on to $12 \%$ starch gels for enzyme electrophoresis. The extraction and electrophoresis steps were performed on ice.

Samples representing each of the four taxa above were loaded on to 11 different gel/electrode buffer systems: Amine citrate, AC, pH 6.0; Tris citrate1,2 \& 3, TC 1,2 \&3 pH 6.7, 7.0 and 8.0 respectively; Phosphate, $\mathrm{PH}, \mathrm{pH}$ 6.7; Ridgeway, RW, $\mathrm{pH}$ 8.5; Histidine citrate, $\mathrm{HC}$, $\mathrm{pH}$ 5.7; Citrate/histidine, $\mathrm{C} / \mathrm{H}, \mathrm{pH}$ 7.0; Lithium borate tris citrate, $\mathrm{LB} / \mathrm{TC}, \mathrm{pH} 8.3$; Tris borate EDTA, TBE, pH 8.6 and Tris borate histidine citrate, TBHE, pH 8.6. References: AC, TC1 and RW, Allendorf et al., 1977; TC3, PH and TC2, Selander et al, 1971;TBE, LB/TC, HC and C/H, Wendel and Weeden, 1989; TBHE Suehs et al 2004.

Among 17 assayed enzyme systems, eight regularly showed scorable results: acid phosphatase (ACP; E.C. 3.1.3.2), adenylate kinase (AK; E.C/2.7.4.3), glucose phosphate isomerase (GPI; E.C. 5.3.1.9), isocitric dehydrogenase (ICD; E.C.1.1.1.42), malate dehydrogenase (MDH; E.C. 1.1.1.37), 6 phosphogluconate dehydrogenase (PGD; E.C. 1.1.1.44), phosphoglucomutase (PGM; E.C. 5.4.2.2 and shikimate dehydrogenase (SKD; E.C. 1.1.1.25).

The combinations which gave clearest activity were selected from these eleven gel/electrode buffer systems x eight stains (Table 1).

Table 1. The combinations of buffer systems giving optimal staining activity.

\section{Gel/electrode buffer system}

$\mathrm{C} / \mathrm{H} \mathrm{pH}=7.0$

$\mathrm{TC} 2 \mathrm{pH}=8.0$

TBHE $\mathrm{pH}=8.6$

\section{Optimal staining}

$A C P, I C D, P G M \& S K D$.

$\mathrm{MDH} \& \mathrm{GPI}$.

AK \& PGD. 
Samples of young leaf material from one plant from each of the following taxa/ locations (Table 2.) were applied to each of the three gels above.

Table 2. Order of the taxa for optimal comparison.

\section{Sample lane}

DYE

1

2

3

4

5

6

DYE

7

8

9

10

11

12

13

14

15

16

17

18

19

20

DYE

\section{Plant and location}

Disphyma australe Worser Bay

Disphyma australe Titahi Bay

Disphyma australe Titahi Bay (long leaved)

Putative hybrid Disphyma $\times$ Carpobrotus Seatoun

Putative hybrid Disphyma $\times$ Carpobrotus WorserBay

Putative hybrid Disphyma $\times$ Carpobrotus Island Bay

Carpobrotus yellow-flowered Worser Bay/Seatoun

Carpobrotus yellow-flowered QE2 Park

Carpobrotus yellow-flowered Waikanae Beach

Carpobrotus yellow-flowered Peka Peka Beach

Carpobrotus yellow-flowered Otaki Beach

Carpobrotus yellow-flowered Hokio Beach

Carpobrotus yellow-flowered Foxton Beach

Carpobrotus yellow-flowered Himitangi Beach

Carpobrotus sp. Te Horo Beach

Carpobrotus red-flowered Seatoun

Carpobrotus red-flowered Plimmerton

Carpobrotus red-flowered Paraparaumu Beach Golf Club

Carpobrotus red-flowered Hokio Beach

Carpobrotus red-flowered Foxton Beach 
The dye, red food colouring, was applied to track the movement of the buffer front as well as to make identification of individual samples easier. One of each of the eight stains was performed on a slice of the gel indicated as giving optimum activity above.

\section{Results}

Differences were detected among the taxa Disphyma australe, the putative hybrid Disphyma $\times$ Carpobrotus and Carpobrotus. While variable alleles were found in the genus Carpobrotus, no consistent differences were found between the yellow-flowered and the red-flowered forms of the plant (Fig 1a-1e).

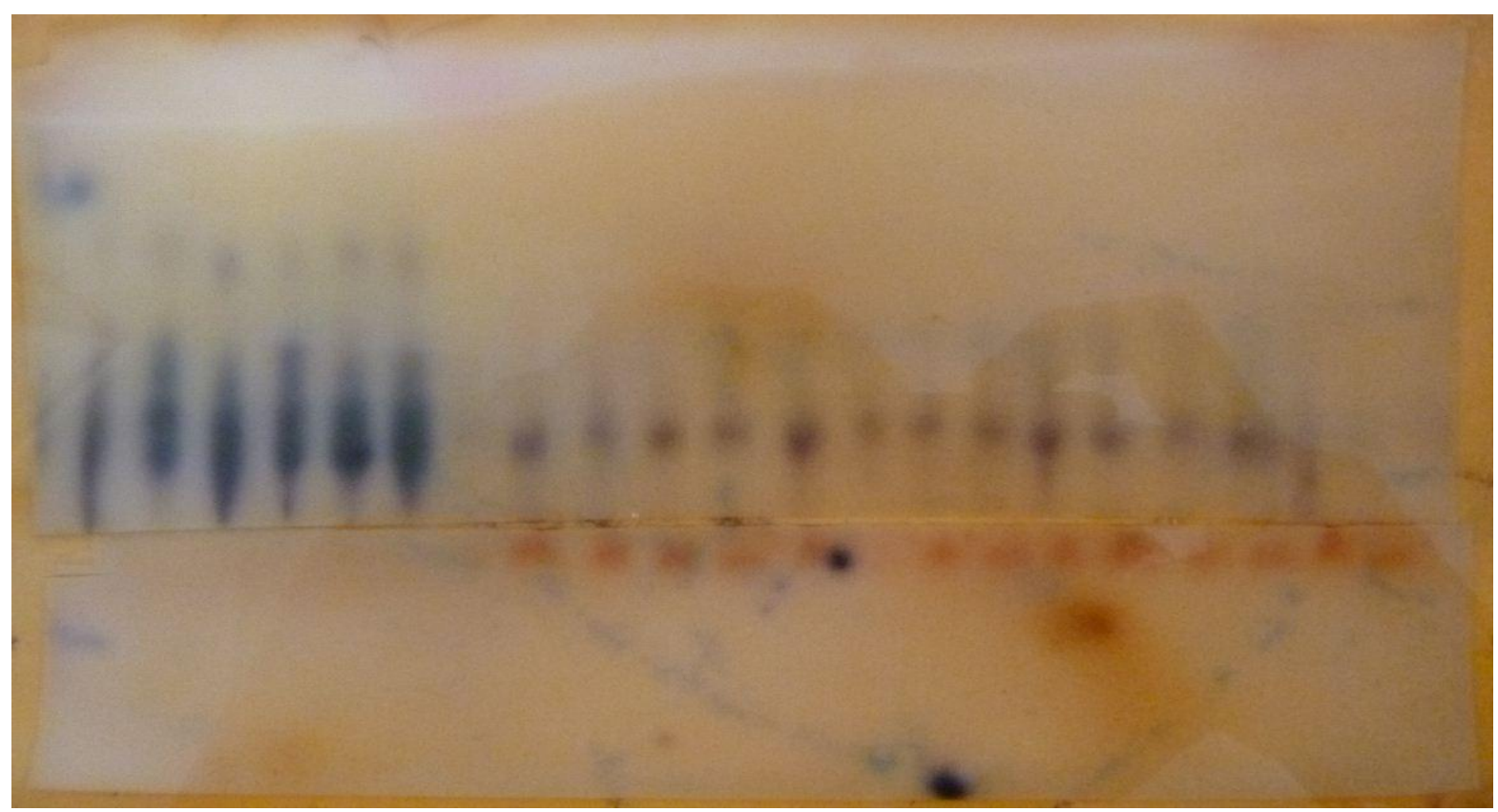

Fig. 1a: ACP bands on $\mathrm{CH}$ gel/buffer electrode system 


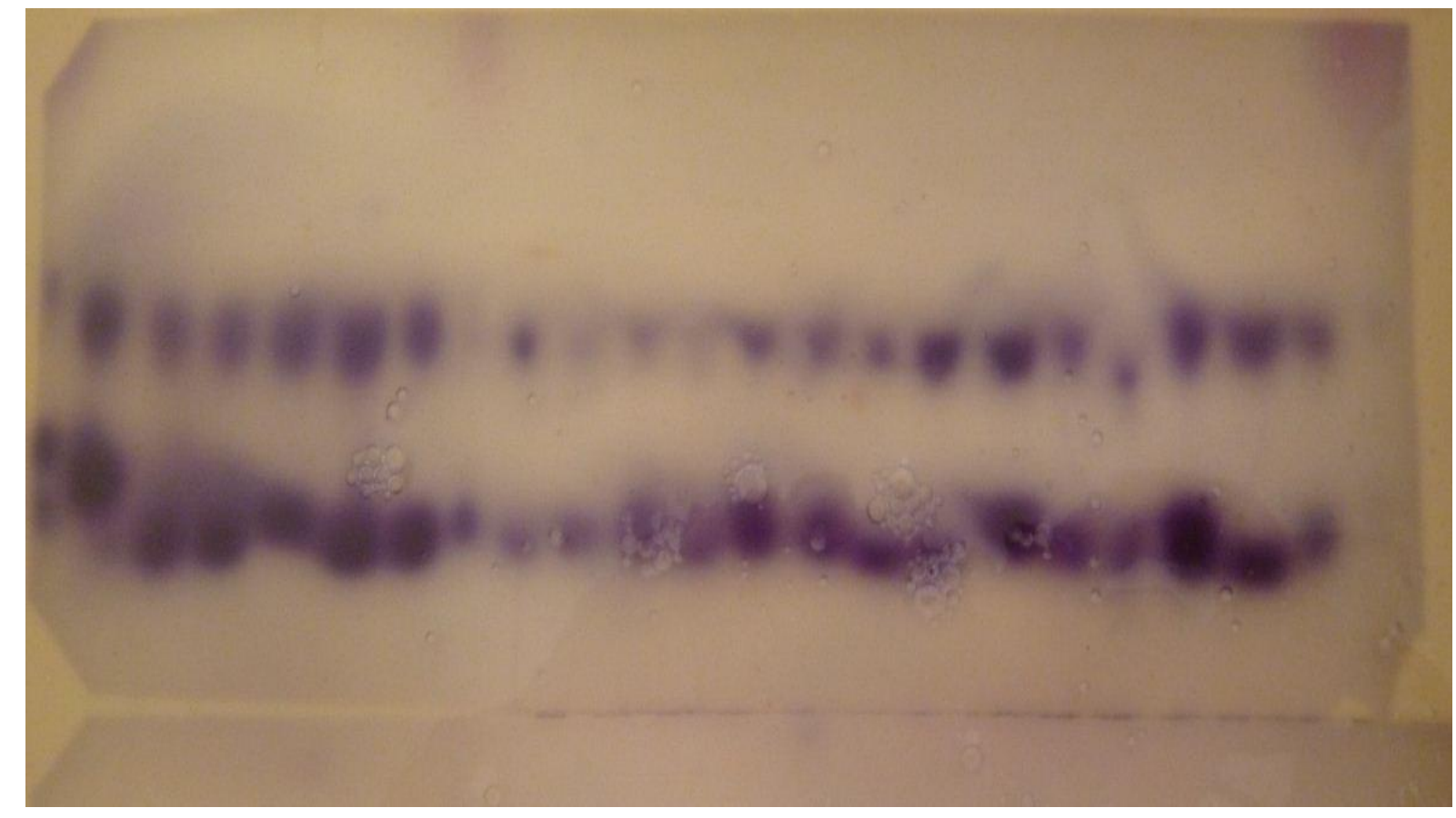

Fig. 1b: GPI bands on TC2 gel/buffer electrode system

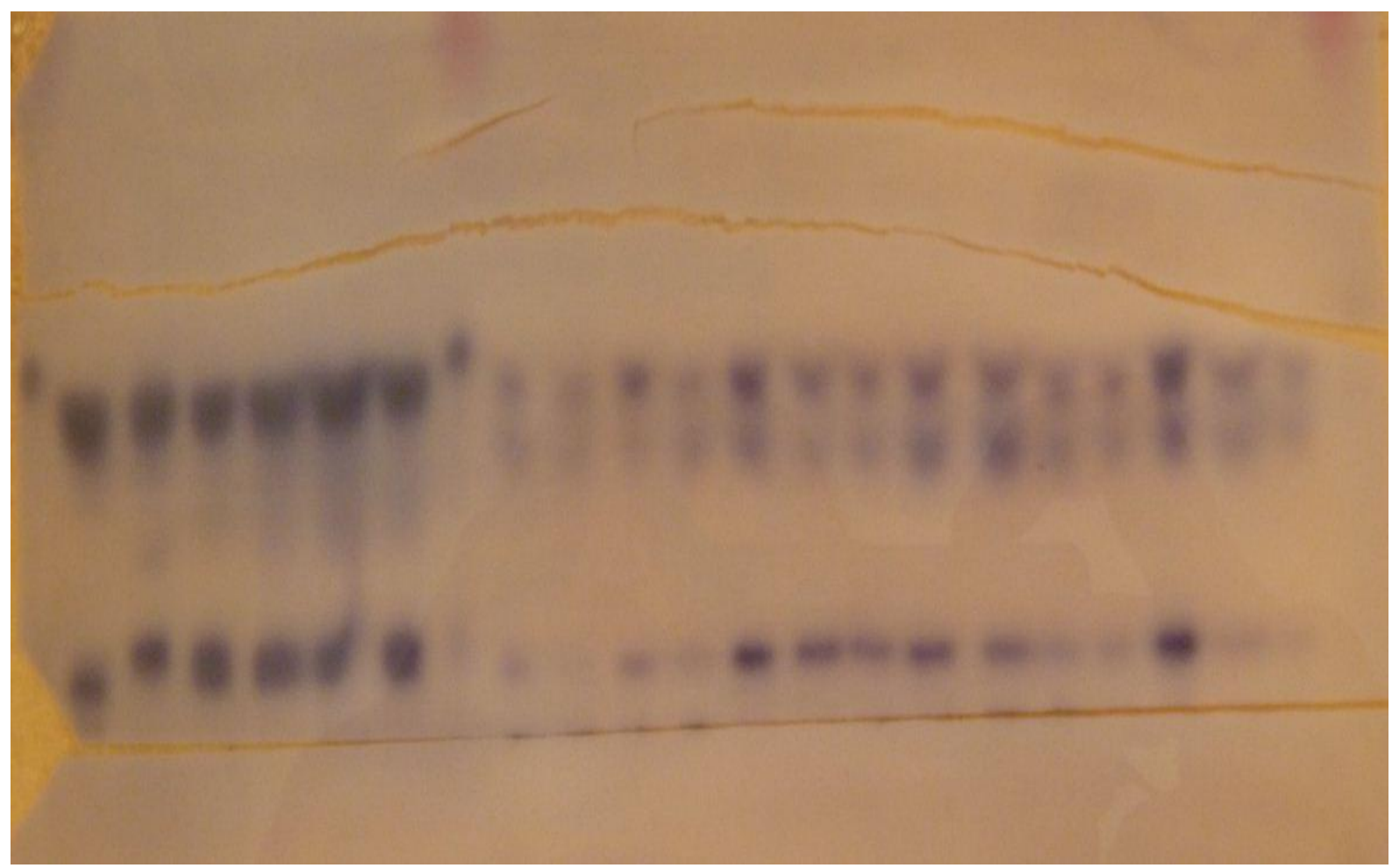

Fig. 1c: MDH bands on TC2 gel/buffer electrode system 
Fig. 1d: PGD bands on TBHE gel/buffer electrode system

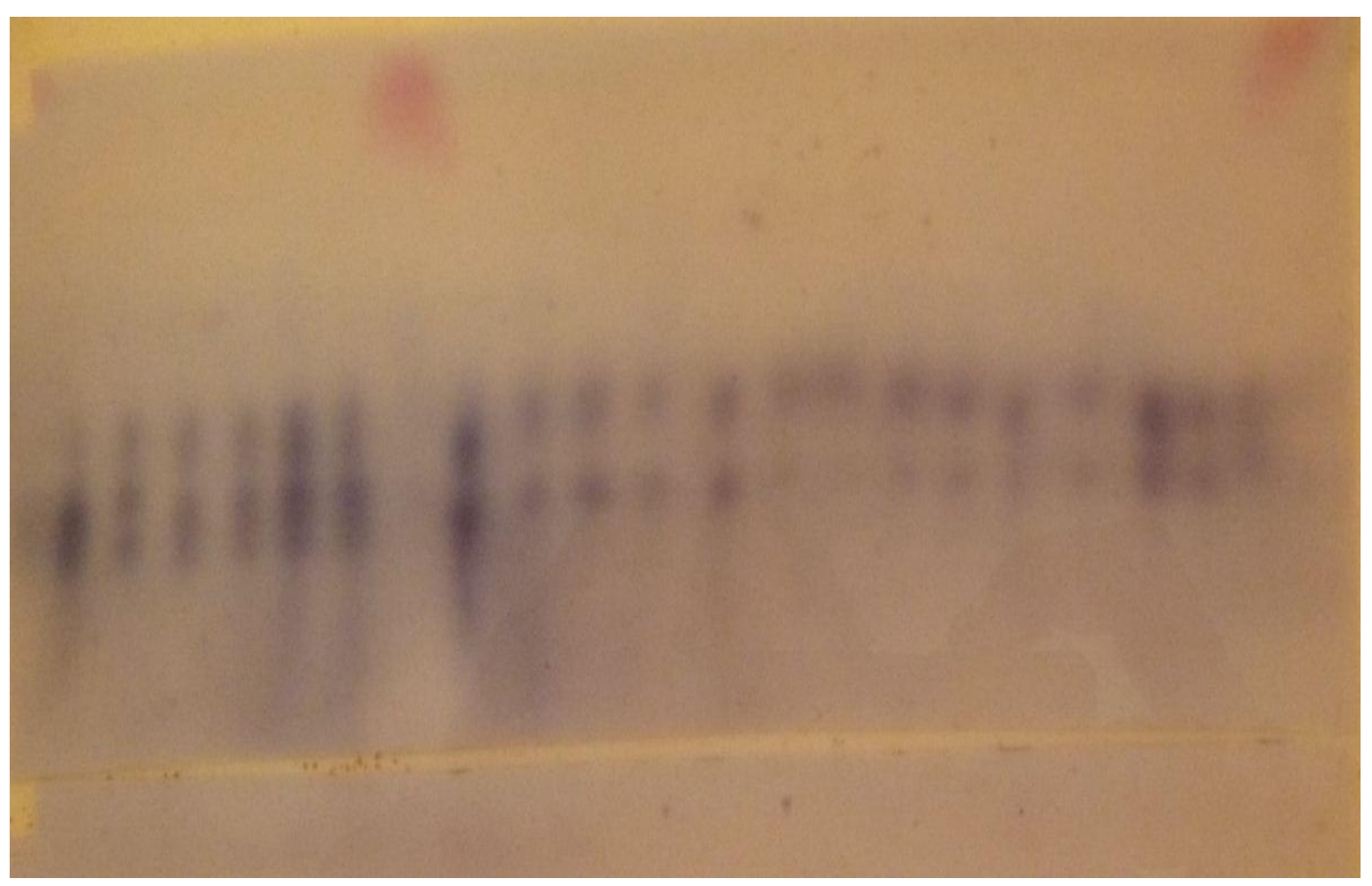

Fig. 1e: PGM bands on $\mathrm{CH}$ gel/buffer electrode system 


\section{Discussion and Conclusion}

The two different colour morphs of Carpobrotus did not display any consistent differences in allozyme bands; hence the parent of the putative hybrid Disphyma $x$ Carpobrotus could not be determined by allozyme analysis. The low variation within and between Carpobrotus taxa is contrary to the results of Gallagher et al., (1997). It is possible that the taxa introduced into NZ was a hybrid of $C$. edulis and $C$. chilensis which has retained variation for flower colour, but no detectable variation in allozyme bands. Further work with more sensitive genetic methods is required to investigate this hypothesis more fully.

\section{References}

Albert, M. E., C. M. D'Antonio, et al. (1997). Hybridization and introgression in Carpobrotus spp. (Aizoaceae) in California .1. Morphological evidence. American Journal of Botany 84(7): 896-904.

Alleddorf, F.W.; Mitchell, N.; Ryan, N.; Stahl, G. 1977: Isozyme loci in brown trout (Salmo trutta L.): detection and interpretation from population data. .Hereditas 86: 179-190.

Chinnock, R. J. (1972). Natural Hybrids between Disphyma and Carpobrotus (Aizoaceae) in New Zealand. New Zealand Journal of Botany 10(4): 615-626.

Gallagher, K. G., K. A. Schierenbeck, et al. (1997). Hybridization and introgression in Carpobrotus spp. (Aizoaceae) in California .2. Allozyme evidence. American Journal of Botany 84(7): 905-911.

Heenan, P. B. and W. R. Sykes (2010). Taxonomic notes on the New Zealand flora: xCarpophyma mutabilis and xCarpophyma pallida (Aizoaceae), new names for two wild intergeneric hybrids. New Zealand Journal of Botany 48(3-4): 225-230. 
Selander, R.K.; Smith, M.H.; Yang S.Y.; Johnson, W.E.; Gentry J.B. 1971: Biochemical polymorphisms and systematics in the genus Peromyscus. I Variation in the old field mouse, Peromyscus polionotus. Studies in genetics, University Texas publication 7103. Pp. 49-90.

Suehs, C.M.; Affre, L.; Médail, F. 2004: Invasion dynamics of two alien Carpobrotus (Aizoaceae) taxa on a Mediterranean island:1. Genetic diversity and introgression. Heredity 92: 31.40.

Vilà, M. and C. M. D'Antonio (1998). Hybrid Vigour for Clonal Growth in Carpobrotus (Aizoaceae) in Coastal California. Ecological Applications 8(4): 1196-1205.

Wendel, J.F.; Weeden, N.F. 1989: Visualisation and interpretation of plant isozymes. In: Soltis, D.E.; Soltis, P.S. ed. Isozymes in plant biology. Disciodes Press, Portland, Oregon. 


\section{Appendix 4: Iceplant - Insect interactions}

The terminal bud of the iceplant taxa initially appears as a single blade that bisects to form two leaves or sepals as it matures. Some caterpillars were observed between the terminal leaves of stolons of the exotic Carpobrotus at Eastbourne. It is seems that some lepidopteran lays its eggs before the bisection of the terminal bud such that the caterpillars are found in a tunnel between the two leaves that are held together with silk. When the terminal bud develops into a flower the caterpillar burrows a tunnel into the receptacle thereby destroying part or whole of the flower. The caterpillars were more abundant on $C$. chilensis plants than on $C$. edulis. They were also more abundant on plants at the backdune than those at the foredune. Samples of these caterpillars were collected with leaves of the plants where they occur and later incubated in test tubes with General Purpose Diet in the laboratory and the resultant insects preserved for identification. In general, most caterpillars hatched into moths while a few hatched into flies or wasps (Table 1; Fig. 1).

Table1: Summary results of the caterpillar incubation

\begin{tabular}{lccccccc}
\hline $\begin{array}{l}\text { Plant and } \\
\text { part }\end{array}$ & $\begin{array}{l}\text { No. of } \\
\text { caterpillars }\end{array}$ & $\begin{array}{l}\text { No. of } \\
\text { pupae }\end{array}$ & $\begin{array}{l}\text { No. of } \\
\text { moths }\end{array}$ & $\begin{array}{l}\text { No. of } \\
\text { flies }\end{array}$ & $\begin{array}{l}\text { No. of } \\
\text { 'wasps' }\end{array}$ & $\begin{array}{l}\text { Failed } \\
\text { pupae }\end{array}$ & $\begin{array}{l}\text { Failed } \\
\text { to } \\
\text { pupate }\end{array}$ \\
\hline $\begin{array}{l}\text { C. chilensis } \\
\text { leaves }\end{array}$ & 15 & 12 & 8 & 2 & 1 & 1 & 3 \\
$\begin{array}{l}\text { C. chilensis } \\
\text { flowers }\end{array}$ & 5 & 5 & 3 & 0 & 0 & 2 & 0 \\
$\begin{array}{l}\text { C. edulis } \\
\text { leaves } \\
\begin{array}{l}\text { C. edulis } \\
\text { flowers }\end{array}\end{array}$ & 10 & 6 & 6 & 0 & 0 & 0 & 4 \\
\hline
\end{tabular}




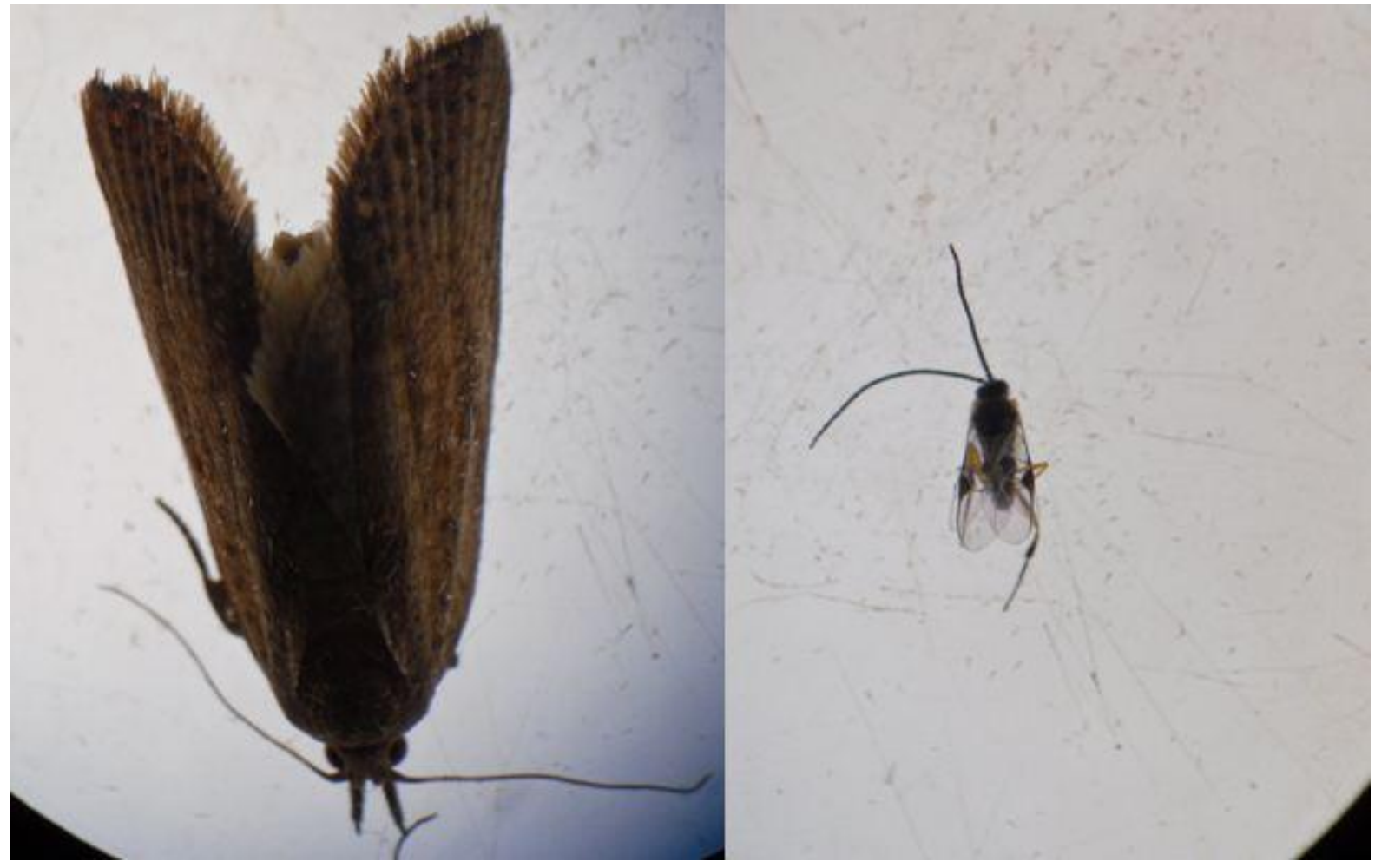

Fig. 1: A moth (left) and a wasp (right) that emerged from the incubated caterpillars

In addition, scale insects were observed to have infested some plants of all the iceplant taxa in the glasshouse and in the field (Fig. 2). At moa point where C. edulis, $D$. australe and their hybrid co-occur, the scale insects were found only on $D$. australe plants. 


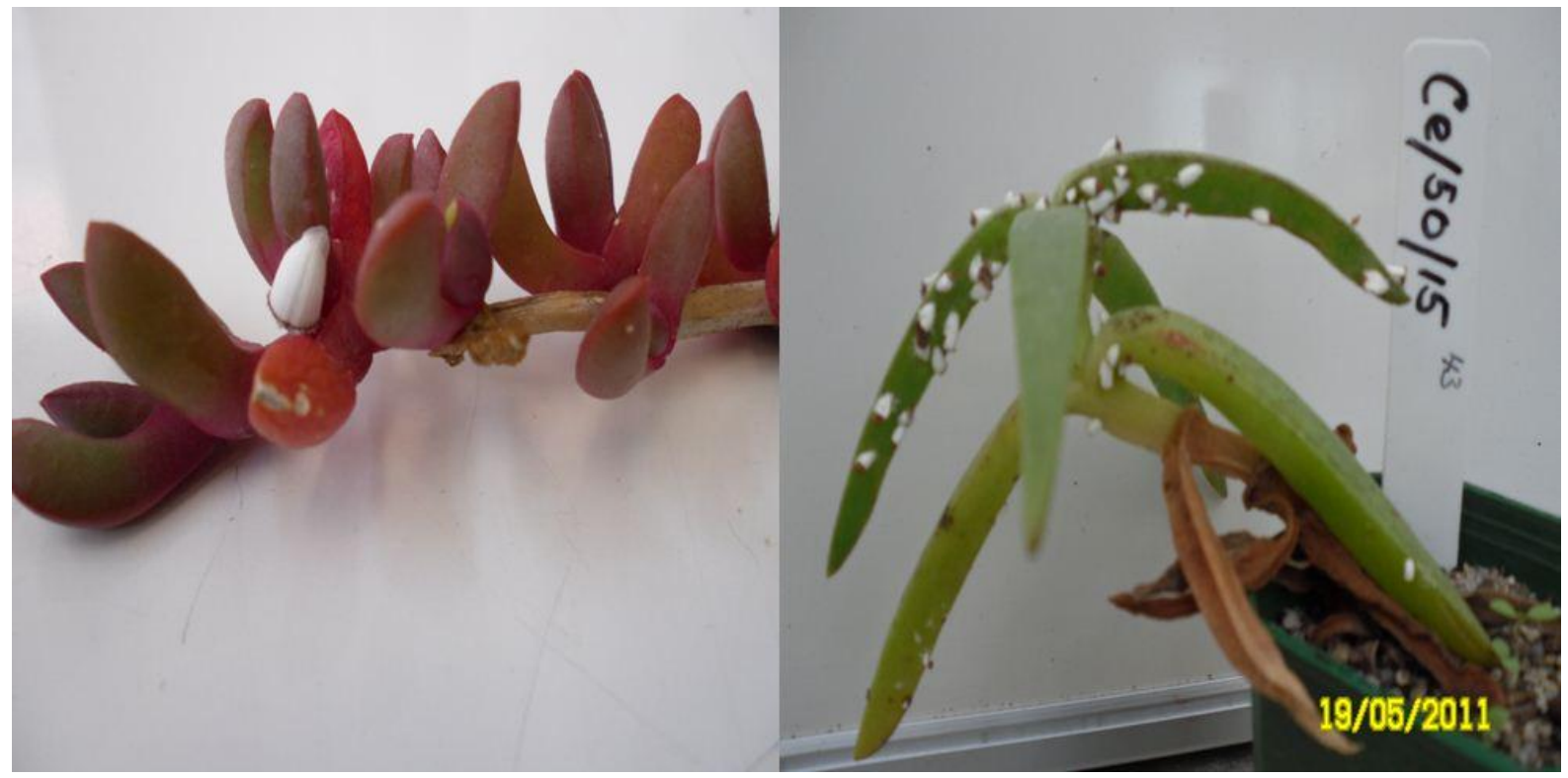

Fig. 2: Disphyma australe plant from the field and C. edulis plant in the glasshouse infested by scale insect (Pulvinaria mesembryanthemi). 